\title{
Development and evaluation of glass fiber-reinforced composite/ wood railroad crossties
}

Krit Laosiriphong

West Virginia University

Follow this and additional works at: https://researchrepository.wvu.edu/etd

\section{Recommended Citation}

Laosiriphong, Krit, "Development and evaluation of glass fiber-reinforced composite/wood railroad crossties" (2000). Graduate Theses, Dissertations, and Problem Reports. 1080.

https://researchrepository.wvu.edu/etd/1080

This Thesis is protected by copyright and/or related rights. It has been brought to you by the The Research Repository @ WVU with permission from the rights-holder(s). You are free to use this Thesis in any way that is permitted by the copyright and related rights legislation that applies to your use. For other uses you must obtain permission from the rights-holder(s) directly, unless additional rights are indicated by a Creative Commons license in the record and/ or on the work itself. This Thesis has been accepted for inclusion in WVU Graduate Theses, Dissertations, and Problem Reports collection by an authorized administrator of The Research Repository @ WVU. For more information, please contact researchrepository@mail.wvu.edu. 


\title{
DEVELOPMENT AND EVALUATION OF GLASS FIBER REINFORCED COMPOSITE/WOOD RAILROAD CROSSTIES
}

\author{
Krit Laosiriphong \\ Thesis submitted to the \\ College of Engineering and Mineral Resources \\ at West Virginia University \\ Master of Science \\ in \\ Civil and Environmental Engineering
}

Hota GangaRao, Ph.D., Chair

Udaya Halabe, Ph.D.

P.V. Vijay, Ph.D.

Department of Civil and Environmental Engineering

Morgantown, West Virginia

2000

Keyword: Composite, Crossties, Glass Fiber

Copyright 2000 Krit Laosiriphong 


\author{
ABSTRACT \\ DEVELOPMENT AND EVALUATION OF GLASS FIBER REINFORCED \\ COMPOSITE/WOOD RAILROAD CROSSTIES
}

Krit Laosiriphong

Railroad crossties are strengthened by wrapping glass fiber reinforced composites (GFRC). In addition, durability of crossties has been found to have enhanced by reinforcing them with GFRC wraps. In order to reduce the cost, GFRC wraps are not used to wrap the entire length of a crosstie, but only in the region that holds steel plates. The objective of this research is to select compatible adhesive between creosote treated wood and glass fabric, and study the performance of wrapped wooden crossties.

Five primer/resin combinations (Resorcinol Formaldehyde group) were screened for strength and durability of treated wood crossties. To evaluate stiffness and durability of wrapped samples under natural environmental conditions (simulated by six cycles aging), half scale wooden crossties ( 3 in. $x 4$ in. $x 42$ in.) were wrapped with glass fabric at midspan over a length of $20 \mathrm{in}$. before subjecting them to three point bending test. These tests were conducted on half scale samples, before and after accelerated aging conditions.

To study the performance of GFRC full scale crossties, fatigue testing was carried out on full scale non-wrapped and GFRC wrapped specimens. Full scale crossties were wrapped over the rail-seat zones and then embedded in ballast under flexural fatigueThe experimental deflections and bending moment correlated well with the analytical values using the bending theory of beams on elastic foundation. After evaluating the performance of GFRC wrapped crossties in the laboratory, the GFRC full scale crossties were manufactured and installed in the field. Preliminary field results of full scale GFRC wrapped crossties are reported herein. 


\section{ACKNOWLEDGEMENTS}

I am greatly indebted to my advisor, Dr. Hota Gangarao, and other committee members for their invaluable guidance throughout this research. I would like to express special thanks to Dr. Hemanth Thippeswamy for his suggestions and encouragement. I would also like to thank to my committee members, Dr. Udaya Halabe and Dr. P.V. Vijay for reviewing the thesis and providing constructive comments.

I thank Paul Frum, Dana Humberson, Dave Turner and John Philbrick for their assistance in the experimental work. I would also like to thank Sharon Santos and Sharon Chadderton for their administrative help. I sincerely thank Vimala Shekar for her support. I would also like to thank the Federal Railroad Administration for providing the financial support for this project, Project No.CFC-99-276, through the Constructed Facilities Center, WVU.

Finally, I would like to express my gratitude to my father, mother, brother and friends for their support and encouragement during the course of my graduate work at West Virginia University. 


\section{TABLE OF CONTENTS}

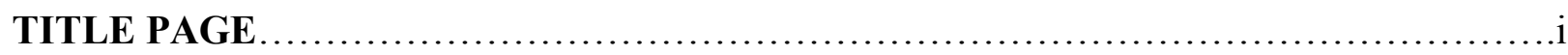

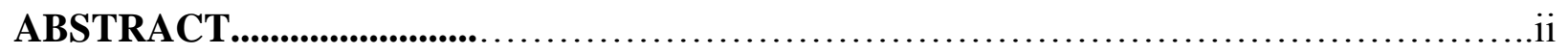

ACKNOWLEDGEMENTS.........................................................

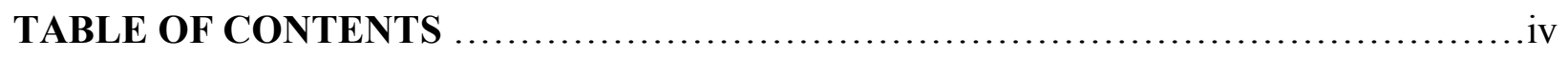

\section{CHAPTER 1 : INTRODUCTION}

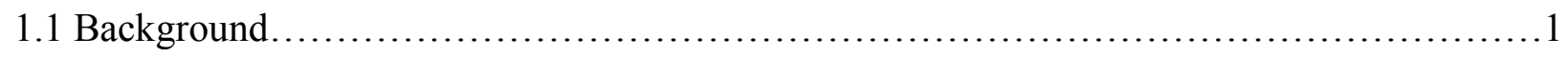

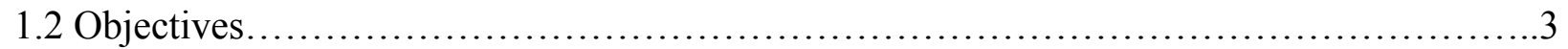

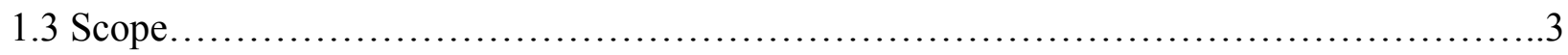

\section{CHAPTER 2 : LITERATURE REVIEW}

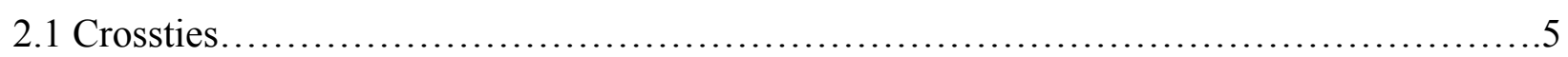

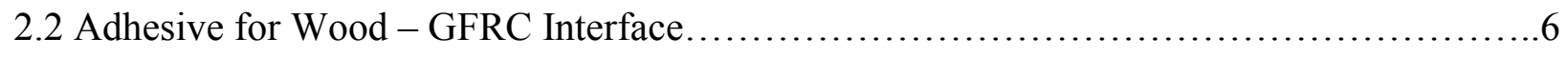

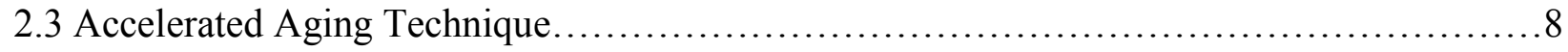

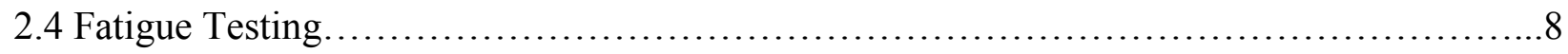

\section{CHAPTER 3 : TESTING AND EVALUATION OF WOOD-GFRC ADHESIVE}

\section{INTERFACE}

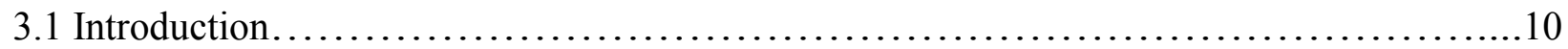

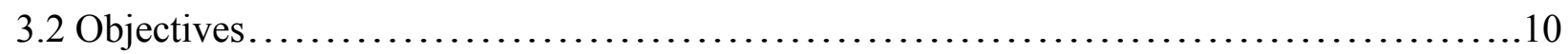

3.3 Scope................................................................

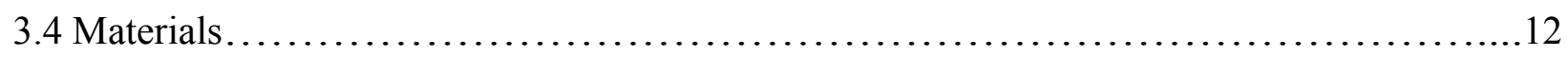

3.5 Primer/Resin Combination.............................................. 14

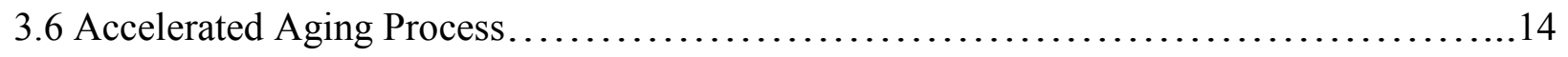


3.8 Conclusions................................................................. 17

\section{CHAPTER 4 :TESTING AND EVALUATION OF HALF-SCALE CROSSTIE UNDER}

\section{ACCELERATED AGING}

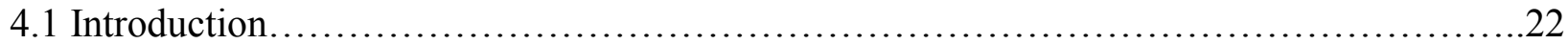

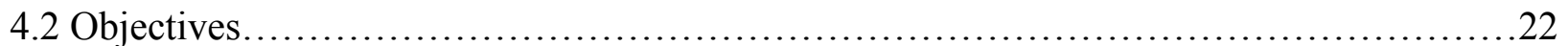

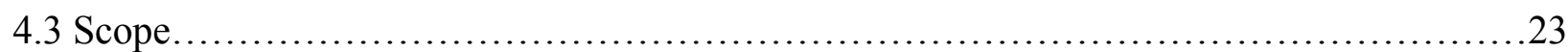

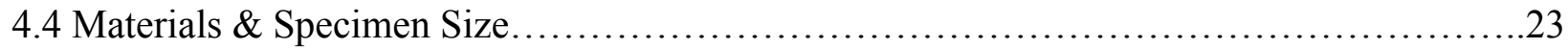

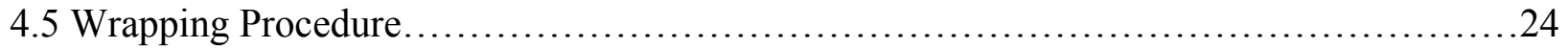

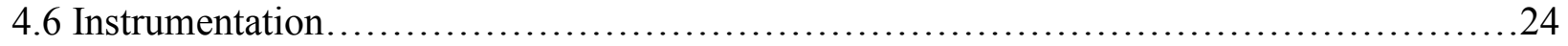

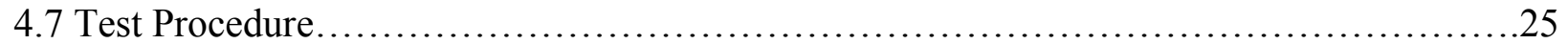

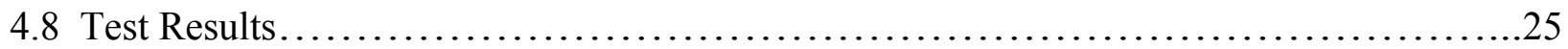

4.9 Comparison of Flexural Rigidity and Shear Modulus

between Non-Wrap and Wrap Cases................................................. 30

4.10 Comparison of Flexural Rigidity between Non-Wrap and Non-Wrap+Aging Cases.........30

4.11 Comparison of Flexural Rigidity between Wrap and Wrap+Aging Cases.................31

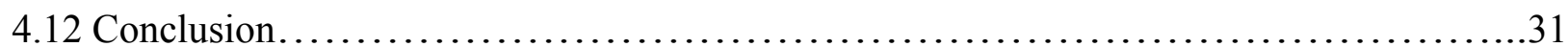

CHAPTER 5 : TESTING AND EVALUATION OF FULL - SCALE NON-WRAPPED

AND WRAPPED CROSSTIE UNDER FATIGUE LOADING

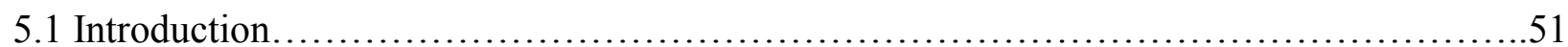

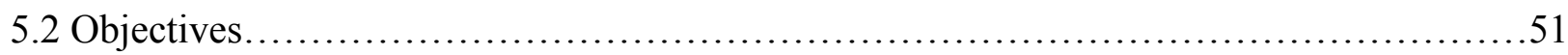

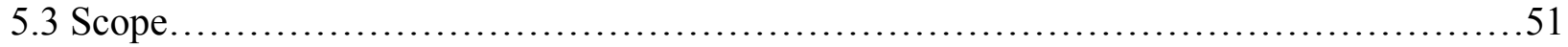




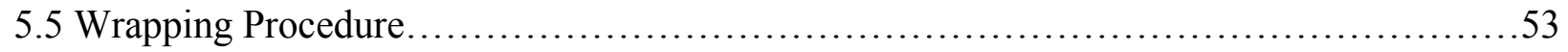

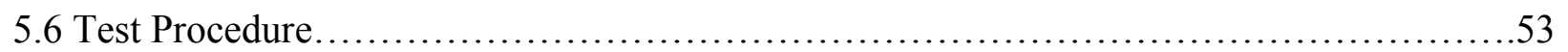

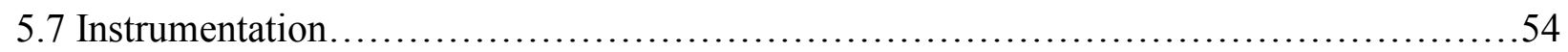

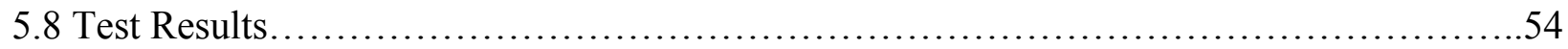

5.8.1 Performance of Wrapped Crosstie Versus Non-Wrapped Crosstie...................55

5.8.2 Performance of One Layer Wrap Versus Two Layers Wrap.......................56

5.8.3 Performance of Two Layers of 30-60, 0-90 Degrees Oriented Fabric Versus Two layers of 0-90, 0-90 Degrees Oriented Fabric......................................56

5.8.4 Performance of Wrapped Crosstie Under 5-35 kips Fatigue Load Range Versus

3-53 kips Fatigue Load Range.............................................57

5.8.5 Compositeness (Integrity) Between the Wrap and Crosstie.......................58

5.8.6 Theoretical Evaluation (Finite Beam on Elastic Foundation)......................58

5.8.6.1 Comparison between experimental deflection and theoretical deflection using finite beam on elastic foundation theory...........................59

5.8.6.2 Comparison between experimental bending moment and theoretical bending moment using finite beam on elastic foundation theory $\ldots \ldots \ldots \ldots \ldots \ldots 60$

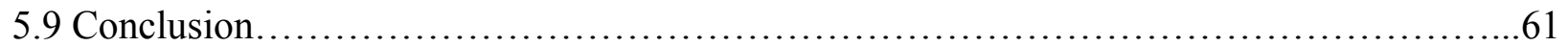

\section{CHAPTER 6 INSTALLATION AND MONITORING OF FULL SCALE CROSS TIE IN}

\section{THE FIELD}

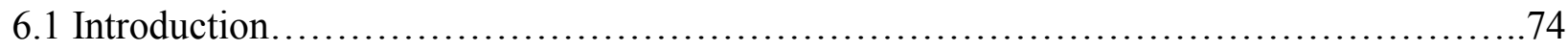

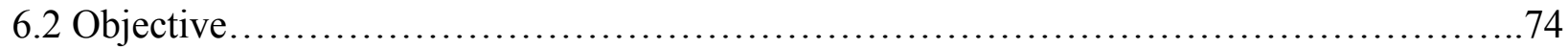

6.3 Installation of Crossties............................................................ 74 
6.3.1 Materials.............................................................. 74

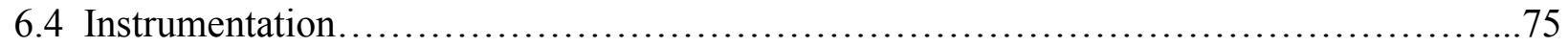

6.4.1 Calibration Test For Strain on Thin Metal Strip.................................. 75

6.5 Monitor Procedures.............................................................. 77

6.5.1 Deflection and Strain Measurement.............................................77

6.5.2 Lateral Movement Measurement..............................................79

6.5.3 Gage Change Measurement.............................................. 79

6.5.4 Spike Pulling Force Measurement............................................ 80

6.5.5 Moisture Content Measurement................................................ 81

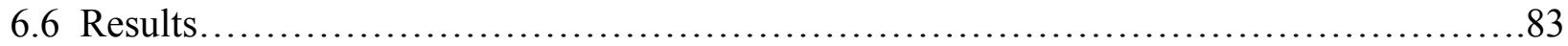

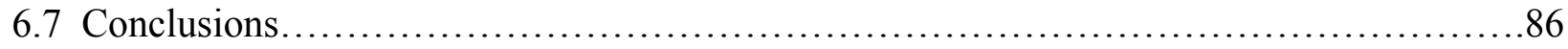

\section{CHAPTER 7 CONCLUSIONS AND RECOMMENDATIONS}

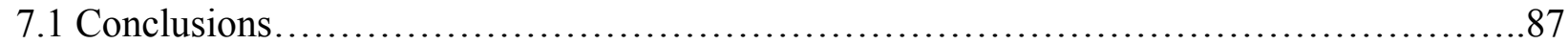

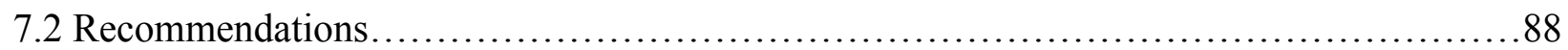

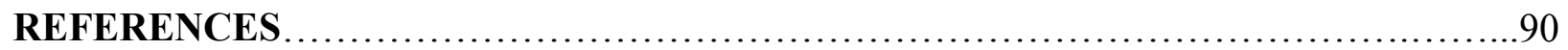

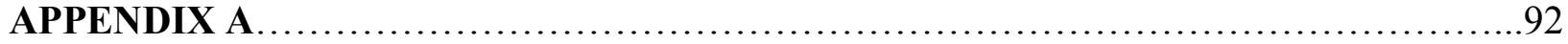

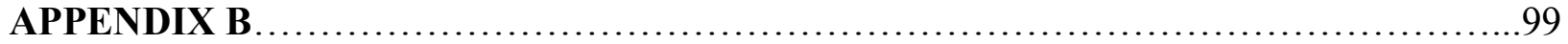

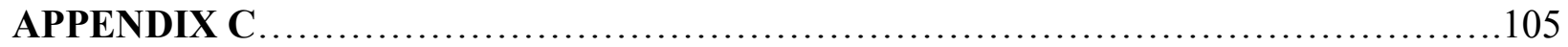




\section{Chapter 1}

\section{Introduction}

\subsection{Background}

Railroads were built to economically mass transport commodity products with rapid movement. Mostly, wood crossties have been in service on the United States railroad system because of abundance of timber, light weight, ease of installation and excellent damping/shock absorbing capability. A typical wood railroad crosstie used in the United States is 7in. $\mathrm{x}$ 8in. to 7in. $\mathrm{x}$ 9in. in cross section and 8 to $9 \mathrm{ft}$. in length placed transversely to the traffic flow. The tie is placed under the rails. Steel tie plates are placed between the ties and the rails in order to reduce stress concentration on wood (Refer to Figure 1.1). Spikes are driven into the tie through holes in the plate in order to secure both the rails and the ties. The functions of a crosstie are to securely hold two rails to correct gage and to distribute the axle loads to ballast.

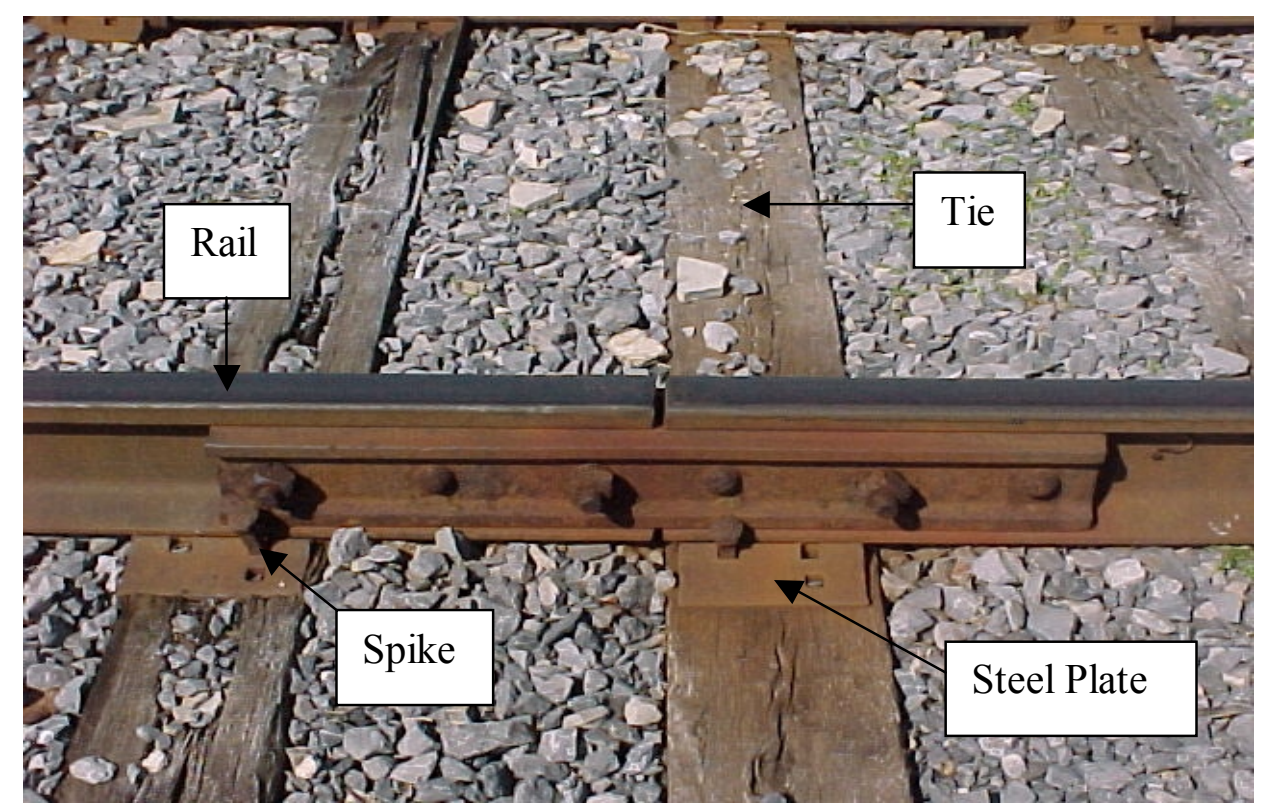

Figure 1.1 Railroad Crosstie 
Other types of crossties being used in the railroad system are made of prestressed concrete and steel crosstie (Hay, 1982). The concrete and steel crossties are extensively used in some areas where timber is scarce. The disadvantages of concrete crossties are corrosion of fastenings, concrete cracking, inadequate flexibility leading to uneven load distribution, and lack of adequate damping capability.

In the past, untreated wood crossties were placed in track. The life of untreated wood crossties varied from 3 to 12 years, depending on wood type and weather conditions. Today, mostly treated wood crossties are being used in the United States railroad system. The average service life span of treated wood crossties varies from 25-30 years on trunk lines. There were nearly 930 million ties in service in the United States. Approximately $15-18$ millions ties (1.5 to $2 \%$ ) of all crossties should be renewed annually.

To increase stiffness and durability of cross ties, glass fiber reinforced composites (GFRC) are wrapped on crossties. In order to reduce the cost, GFRC wraps are used only in a crosstie region that holds steel plates instead of the entire length. The GFRC wrapping resists splitting of wood crossties and plate cutting or digging on wood. The GFRC crossties also have better damping capability, less moisture content and higher load capacity compared to traditional crossties (non-wrap crosstie).

Adhesive, used to bond glass fabric to wood, is a significant factor to enhance strength and durability of GFRC-wood crossties. Each adhesive has its inherent performance advantages and limitations with GFRC and wood. Shear strength based on ASTM D905 of shear block specimen was utilized to choose the compatible combination of adhesive and wood specimen. The adhesive bond strength may deteriorate over a period of time under service due to aging, acidic or alkaline exposure, or even under excessive fatigue induced stresses; thus leading to; 
partial or total delamination. Therefore, shear strength under long-term service conditions should be evaluated as a factor for choosing the best adhesive. In order to reduce evaluation time, the accelerated aging technique (Chow et.al., 1987) has been utilized to simulate aging effects.

\subsection{Objectives}

1. Select a commercially available adhesive that can provide strong and durable bond between wood and GFRC.

2. Produce half-scale GFRC-wood crosstie using the adhesive selected and study the crosstie performance under static load testing after accelerated aging.

3. Manufacture full-scale GFRC-wood crossties and study their performance under fatigue (sinusoidal) loading.

4. Install full-scale GFRC-wood crossties in the field and monitor their performance in terms of their field durability.

\subsection{Scope}

A study of published literature has been reported in Chapter 2, which emphasizes the development of GFRC system and adhesive. To evaluate compatibility between adhesive and treated wood, the test procedure and test set-up are described in Chapter 3.

Flexural rigidity and shear modulus data of half scale wrapped crossties are presented in Chapter 4. In addition, performance of the specimens under accelerated aging cycles is presented in the same chapter. 
The full scale wrapped crosstie responses on simulated elastic foundation subjected to fatigue (sinusoidal) loading are described in Chapter 5. Comparisons of performance of wrapped and non-wrapped crossties are presented in the same chapter.

Field installation procedure, monitoring and evaluation of field data of wrapped crossties are described in Chapter 6. Spike pulling force, moisture content, lateral movement, gage change, deflection and strain measurement are presented in the same chapter, in addition to tie response evaluations with time.

Finally, Chapter 7 presents the conclusions and recommendations for future study. Appendix A presents standard test method for strength properties of adhesive bonds in shear by compression loading (ASTM D 905). Appendix B presents standard test method for direct moisture content measurement of wood (ASTM D 4442-92). Appendix C presents the experimental data for chapter 4 . 


\section{Chapter 2}

\section{Literature Review}

\subsection{Crossties}

Early analysis of crosstie action under load assumed a uniform distribution of ballast pressures across the length and width of the crosstie. Experiments, by Talbot (1920) in the United States, showed this to be an erroneous concept. The distribution of pressures is anything but uniform. When in freshly tamped ballast, a loaded tie most nearly represents a beam with the supporting reactions concentrated under the points of application of the load, the rails, and with equal end lengths overhanging the supports. The shape assumed by the crosstie under these conditions and the distribution of pressures along the tie can be seen in Figure 2.1. Since the ballast is composed of non-cohesive particles, the transmission of pressures in directions other than vertical directions imparted by the tie must result from friction between the particle, and vertical pressures at the center of the crosstie must be greater than those transmitted by its edges [Hay, 1982 ].

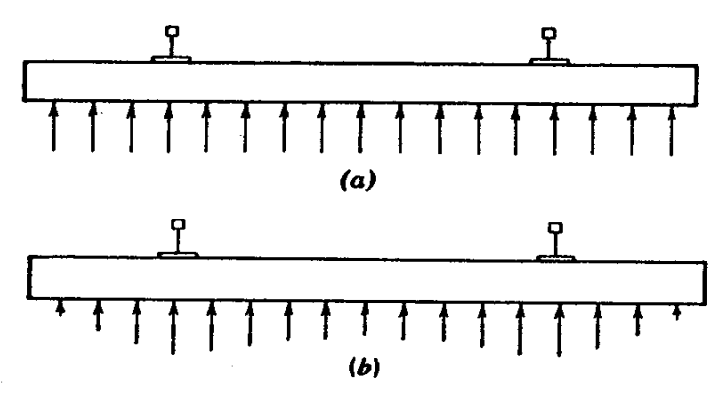

Figure 2.1 Distribution of ballast pressures under a crosstie : (a) theoretical uniform distribution ;

(b) practical distribution in newly tamped track. (Talbot 1920) 
The stiffness and flexibility of ballast are not constant but vary from point to point along the tie. Eventually the repeated applications of pressure under the rails result in a greater depression there than at the center. The crosstie under load assumes the position of the dotted line as shown in Figure 2.2a. The maximum bending moment will occur at the midpoint, and the tie may even suffer rupture at that point owing to the upward pressure of the ballast.

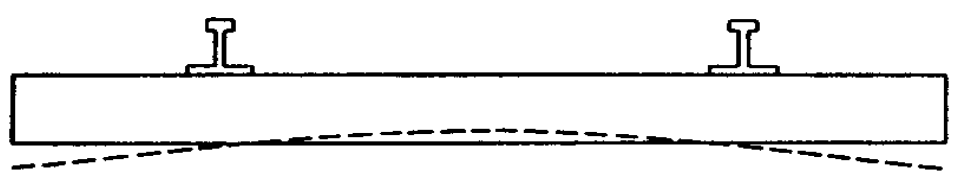

(a)

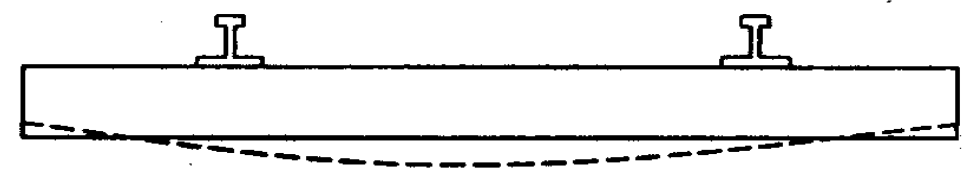

b)

Figure 2.2 Crosstie deflections.

This is center-bound track, a condition all too familiar to maintenance officers. The opposite condition, that of a newly tamped crosstie, shown in Figure $2.2 \mathrm{~b}$, may be called end-bound track.

\subsection{Adhesive for Wood-GFRC Interface}

Adhesives that are excellent for bonding certain wood species may not be as well suited for other materials. As an example, alkaline phenolics have been the mainstay in production of exterior-type softwood plywood, but their high-tempurature-curing requirements keep them from being practical for laminated timbers. Such timbers would explode from steam formation in the 
interior if heated to the temperature that is required to cure phenolic-type adhesives [Selbe, 1975].

Rowlands, et. al., (1986) used ten adhesives (three epoxy resins, two resorcinol formaldehydes, two phenol resorcinol formaldehydes, two isocyanates, and one phenolformaldehyde) to bond numerous reinforcements (uni- and cross-woven glass, Kevlar, and graphite fibers). Rowlands, et. al., evaluated shear stress and tensile strength as per ASTM D 905 and ASTM 1344-72, respectively. To evaluate the durability of various glass-adhesive systems, ASTM D 2559 was used as the accelerated aging standard for specimens. The results have shown that the epoxies (e.g., manufactured by Dow and Ciba) exhibited good performance with glass, aramid and graphite fibers. Neither isocyanates nor the phenol-formaldehyde performed well in the test (Rowlands, et. al., 1986).

Anegunta (2000) wrapped CCA (chromated copper arsenate) treated southern pine dowels of diameter 0.5 in. with E-glass fabric (0-45 degree). The length of samples was 7.5 in.. HMR (Hydroxy Methylated Resorcinol) was used as a primer, and epoxy (TYFO-S) was used as an adhesive. Samples were subjected to five different conditions (6 cycle accelerated aging, freeze thaw cycles in acidic solution, alkaline solution and in $3 \%$ salt water). Three point bending tests were used to evaluate flexural rigidity of test samples in different conditions. The results have shown that composite wrapping of wood with HMR/epoxy/glass fibers increases the flexural rigidity of wood by 2.62 times under unaged conditions and by 1.77 times under six cycle aging. The wrapped samples were damaged the most by freeze-thaw cycling in acidic solution. 


\subsection{Accelerated Aging Technique}

Quality and failure of wood crossties have always been judged based on actual performance. The service life of treated wood crossties in the United States is typically 20-30 years, thereby it takes at least 20-30 years to obtain the results. Chow (et. al.,1987) conducted a test to develop suitable short-term test methods and to establish correlations between short-term test results and long-term in-service performance of wood cross ties. Chow's results have shown that the six-cycle accelerated aging process could be equivalent to more than 20 years of natural aging. Each accelerated aging cycle consisted of vacuum soaking, pressure soaking, freezing and oven drying. The hardness and compression properties perpendicular to grain are significantly affected by the six-cycle aging process and natural weathering.

\subsection{Fatigue Testing}

Chang (1993) studied stress laminated decks made of northern red oaks. The objective was to study fatigue life and fatigue behavior of stress laminated decks under different conditions such as prestress level, butt joint arragement, and maximum applied cyclic stress. The energy analysis was used to evaluate stress-laminated beams under mechanical fatigue loading.

Talakanti (1997) wrapped quarter-scale specimens (2.5 in.x2.5in.x36in.) using filament winding process. A total of six wrapped and non-wrapped wood crossties of $30 \mathrm{in}$. length were tested. The load was applied at the midspan of simply supported specimen in upward and downward direction. The test was designed to apply stress reversals on the specimens. The results of this test have shown that wrapped specimens have lower rate of stiffness degradation 
compared to non-wrapped specimen. Both the wrapped and non-wrapped specimens have shown gradual reduction in stiffness when subjected to mechanical fatigue loading.

Fatigue tests of GFRC wood ties using filament winding (2.5in.x2.5in.x36in.) were conducted by Talakanti (1997). The fatigue tests were similar to a three point bending test except that the load moved in upward and downward direction at midspan resulting in compressive and tensile strain of around $\pm 3250 \times 10^{-6} \mathrm{in} /$ in on the surface of samples for 2.7 million cycles. The static tests were conducted at every 100,000 cycles. Strain on wood and wrap surfaces were measured. If there is $100 \%$ compositeness between wood and wrap, the strain on wood and wrap surfaces are expected to vary linearly when samples are subjected to static testing. The results show that the strain on wrap surface was slightly higher than strain on wood due to the fact that the wrap surface was farther from neutral axis than the wood surface. $100 \%$ compositeness between wood and wrap was found up to 2.5 millions. After 2.5 million cycles, the strain on wood surface became non-linear while the strain on wrap surface remained linear. This shows that the beam samples lost their compositeness between wood and wrap. This loss of compositeness or degradation occurred after $85 \%$ of mechanical fatigue life. Therefore, it is concluded that the GFRC-wood adhesive interface was intact during $85 \%$ of the fatigue life at strain range of $\pm 3250 \times 10^{-6} \mathrm{in} / \mathrm{in}$. 


\section{Chapter 3}

\section{Testing and Evaluation of Treated Wood-GFRC Adhesive Interface}

\subsection{Introduction}

The primary function of an adhesive is to provide strength, at least equal to the substrate. In addition, durability of adhesive bond between an adherend and adherent must be satisfactory during the service life of a structure. Bond strength and durability requirements between a particular adhesive and substrate are very important in a given application. In GFRCwood crossties, the primary requirement for the adhesive bond is to transfer shear forces between the adherend and adherent with failure in the wood substrate and not in the glue line. In addition, the adhesive bond has to survive the harsh service conditions of a crosstie. Therefore, in this study, different adhesives from resorcinol formaldehyde and epoxy groups were selected, and were evaluated on the basis of bond strength and durability. Interlaminar shear strength values were established for creosote treated wood-GFRC samples under unaged and aged (with applying accelerated aging condition) conditions.

\subsection{Objectives}

The objectives of this component of the research are to:

1. Select commercially available adhesives that are compatible with treated wood and glass fabric; and

2. Establish and compare the shear strength of treated wood-GFRC adhesive bond under unaged and aged conditions, utilizing different adhesives. 


\subsection{Scope}

Methodology: The experimental program consisted of determining the shear strength of adhesively bonded wood composites, and evaluating the bond durability using accelerated aging procedure similar to that suggested by Chow, et. al., 1987. These tests were performed on shear block specimens prepared as per the ASTM D-905. The two blocks of wood were bonded together to form a shear block specimen (Figure 3.1). Also, a glass fabric layer between the two wooden blocks forming a wood-composite sandwiched shear block specimen was prepared as per ASTM 905.

Sample Preparation: The wooden blocks for making the test specimens were cut from used treated Red Oak crossties, the dimensions of these blocks were 0.75 in. $x 2$ in. $x 12$ in. The wooden blocks were sanded and then air sprayed to remove dust particles. These wood blocks were first coated with a layer of adhesive called a primer and were allowed to cure for 24 hours at room temperature under a pressure of 250 psi. The pressure was applied by inserting the sample between two steel plates and applying 6 kips of load on steel plate. The 6 kip load was transferred to the test sample uniformly and then the bolts were tightened around steel plate to retain the load. After bolts were tightened, the $6 \mathrm{kip}$ load was released. The sample was allowed to cure for 24 hours and then bolts were loosened. It should be noted that, curing of primer could be achieved in few hours if higher temperatures are used. A single layer of glass fabric of 2 in. $x$ 12 in. soaked in the adhesive (resin) was then sandwiched between these wooden blocks. Soaking of the fabric was completed to saturate the fabric thoroughly with resin. The sandwich was then allowed to cure under 250 psi pressure. Application of pressure leads to better penetration of resin into wood and consequently better bond, and squeezing out of excess resin. The curing period varied for different adhesives as per the manufacturer's recommendation. 
After curing, the 12 in. long sandwich was cut to obtain 5 shear block specimens of dimensions 0.75 in. $x 2$ in. $x 1.75$ in. as shown in the Figure 3.1 .

Testing for Shear Strength: The shear strength tests were performed as per the guidelines given in the ASTM D-905 specifications. Careful testing of the samples for shear strength was very important because applied load should create pure shear on the adhesive; i.e., no bending. For this purpose, a shearing tool (Figure 3.2) was designed to hold the specimen tightly in place so that the load acting on the specimen would only result in pure shear at the bond-line. During testing, care was taken to align the specimen properly in the shearing tool. This shearing tool was then placed in Baldwin machine as shown in Figure 3.3 and load was applied. The failure load was noted. The shear strength at failure of wood-composite bond-line was then calculated based on bonded area between the wood blocks and the fiber layer. The number of samples tested was 136 samples (Table 3.1). The average failure strength in shear was used to compare the performance of each adhesive.

\subsection{Materials}

Resorcinol Formaldehyde (RF) and Phenol-Resorcinol Formaldehyde (PRF): In general, resorcinol formaldehyde and Phenol-Resorcinol Formaldehyde adhesives have high resistance to severe weathering, humidity, boiling water, temperature, biodeterioration and strong affinity towards wood (as per the manufacturer, Indspec Chemicals). Therefore, RF based adhesives (G1131) and PRF (G1149), manufactured by Indspec Chemicals, were used in this experiment. These adhesives have a working life of 30 minutes at room temperature. To obtain the full strength, this adhesive should be cured for six days at room temperature. RF and PRF are 
used in many applications such as plywood and timber structures for exterior use, ship and marine construction, and wooden structural assemblies such as roofs, bridges and frameworks.

Phenol Formaldehyde (Acid Catalysed) : Phenol formaldehyde is a group of synthetic thermosetting resin. Physical form of phenol formaldehyde is high viscosity resin and liquid acid-catalyst. Phenol Formaldehyde have resistant to weather, boiling water and biodeteriation. Resistance to elevated temperatures is good but inferior to that of heat curing phenolic and resorcinol resins. Excess acidity of phenol formaldehyde, due to poor control over acid-catalyst content, often leads to wood damage on exposure to warm humid air. Phenol Formaldehyde is used in some applications such as woodwork assemblies where service temperatures do not excess $40{ }^{\circ} \mathrm{C}$, furniture construction. Trade name of phenol formaldehyde manufactured by Indspec Chemicals is G1260.

Epoxy: Epoxy is the most widely used resin to bond composites to substrates made of conventional materials. The reason for their extensive use is their superior processing versatility compared to other adhesives. In addition, curing reaction for epoxy resins does not involve release of water like other adhesives, which helps in low shrinkage and minimization of void formation during curing (Subramanian, 1981). This leads to low residual stresses and better bond strength. Epoxy was chosen in our study to evaluate its relative performance.

Glass Fiber: The glass fiber used in the study was compatible with phenolics in the sense that fiber sizing provides better bonding compatibility with phenolic based resins than other resins. 


\subsection{Primer/Resin Combination}

The following five primer/resin combinations were used in the study:

1. G1131A + G1131B (Primer) and G1149A + G1149B (Resin)

2. G1260 (Primer) and G1149A + G1149B (Resin)

3. G1131A + G1131B (Primer) and G1149A + G1149B (Resin)

4. G1260 (Primer) and Epoxy (Resin) and

5. G1149-A (Primer) and G1131A + G1131B (Resin)

It should be noted that a phenolic compatible glass fabric was used for primer/resin combinations 2 through 5, and a phenolic incompatible glass fabric was used for primer/resin combination 1.

Table 3.1 Adhesive used in adhesive screening

\begin{tabular}{|l|c|c|}
\hline \multicolumn{1}{|c|}{ Adhesive } & Trade Name & Manufacturer \\
\hline Resorcinol Formaldehyde (RF) & G-1131 & Borden Chemicals \\
\hline Phenol Resorcinol Formaldehyde (PRF) & G-1149 & Borden Chemicals \\
\hline Phenol Formaldehyde & G-1260 & Borden Chemicals \\
\hline Epoxy & TYFO-S & Borden Chemicals \\
\hline
\end{tabular}

\subsection{Accelerated Aging Process}

The accelerated aging process (Chow, et. al., 1987) is generally used to simulate the field conditions and to establish the durability of bond between adhesive and substrate. Since the average service life of a crosstie spans over 25 years (Bescher, 1987), the only avenue to determine the durability of the adhesive bond is to use an accelerated technique that can simulate 
20-25 years of service life of a crosstie. Therefore, a procedure developed on the basis of ASTM standard 1101 and also a study done by Chow et.al., 1987, were used in this study.

In the accelerated aging process, the wood-composite bond-line was subjected to severe swelling and shrinkage to account for long-term effects. The swelling and shrinkage effects were introduced to the adhesive bond for a total of six times (six cycles). Each cycle consisted of the following process:

Table 3.2 Accelerated Aging Procedure Steps

\begin{tabular}{|c|l|}
\hline Step 1 & $\begin{array}{l}\text { Soaking of samples in water at a vacuum of } 25 \text { in. Hg at room temperature } \\
\text { for } 30 \text { minutes; }\end{array}$ \\
\hline Step 2 & Soaking of samples in water at a pressure of $100-110$ psi. for 30 minutes; \\
\hline Step 3 & Freezing at a temperature of $15^{\circ} \mathrm{F}$ for 2 hours; and \\
\hline Step 4 & Oven drying at a temperature of about $150^{\circ} \mathrm{F}$ for 8 hours. \\
\hline
\end{tabular}

During each cycle of aging, the samples were first placed in a container and submerged in water. The container was then placed in a cylinder connected to a vacuum pump and an air compressor. The samples were then removed from the container and were placed in a freezer which was maintained at a temperature of $15^{\circ} \mathrm{F}$. After two hours of freezing, the samples were then placed in an oven to dry them at a temperature of about $150{ }^{\circ} \mathrm{F}$. This procedure was repeated six times to complete the aging process.

The significance of using vacuum soaking and pressure soaking is that the expansion of wood composite under moisture exposure must be very minimal compared to that of wood. Therefore, a combination of vacuum and pressure soaking results in differential expansion of 
wood and composite subjecting their bond-line to severe shrinkage and swelling. This is used to simulate the varying field environmental conditions.

The freezing helps in simulating winter conditions that a crosstie may experience in its operating environment. This is followed by oven drying which causes the bond-line to be subjected to severe stresses.

The oven drying helps in simulating summer heat. The hot conditions coupled with freezing can effectively simulate varying temperatures of a crosstie field environment.

\subsection{Test Results}

To judge the compatibility of adhesive with treated wood sample, failure modes have to be inspected by visual judgment in addition to shear strength. The failure of an adhesive bond can be classified as either cohesive or adhesive. Cohesive failure occurs in the adherend, whereas adhesive failure occurs in the bond line (Caster, 1981). The desired mode of failure for an adhesive bond is the cohesive failure. In this test, the cohesive failure was measured in percentage of wood failure after the samples failed. The bond performance is considered to be better with higher percent of wood failure. AITC requires a minimum of $80 \%$ failure in wood and minimum shear strength of 1075 psi under unaged condition and retain $50 \%$ of 1075 psi shear strength after samples are subjected to accelerated aging. ASTM D-1101 requires that the samples must be intact after subjected to accelerated aging.

Unaged and aged shear strength values obtained from the shear block testing, for different combinations of primer and resins (section 3.5), were compared to evaluate the bond performance and durability. The shear strength values obtained under dry and aged conditions using different primer/resin combinations are presented in Table 3.3. The results are also graphically represented in Figure 3.4. 
Under unaged conditions, a primer/resin combination of G1149A/G1131A+ G1131B has shown the highest shear strength with a value of 2041 psi and $82 \%$ wood failure which meets the requirement of AITC. Under aged conditions, primer/resin combination of G1149A (Phenolic)/G1131A+1131B(RF) has shown the highest shear strength with a value of 614 psi and $40 \%$ wood failure. A resin part has higher effect in shear strength of shear block compared to a primer part since the amount of resin used in shear block test was higher than the amount of primer. The primer/resin combination of G1149 (phenolic)/G1131A $+\mathrm{G} 1131 \mathrm{~B}$ (resorcinol formaldehyde) provided the highest shear strength compared to the rest because resorcinol formaldehyde has more $\mathrm{OH}$ per benzene ring so it has a better potential for hydrogen bonding. Also, more sites are available on the resorcinol formaldehyde for better cross linking; hence we expect it to perform better as a resin than phenolic (see Table 3.3).

Samples bonded by a primer/resin combination of G1260/Epoxy were separated from each other after subjected to accelerated aging.

\subsection{Conclusions}

- For bonding the creosote treated wood substrates, primer/adhesive combination is recommended instead of the use of adhesive alone.

- All the primer/resin combinations except G1260/Epoxy survived the severe stresses applied by accelerated aging process.

- Based on the shear strength values observed, the best combination, which provided maximum bond both under unaged and aged conditions, is the primer/resin combination of G1149A/G1131A+G1131B.

- The primer/resin combination of $\mathrm{G} 1149 \mathrm{~A} / \mathrm{G} 1131 \mathrm{~A}+\mathrm{G} 1131 \mathrm{~B}$ is recommended for wrapping full-scale used crossties. 
- The percentage of wood failure and shear strength of aged samples decreased after the test samples were subjected to accelerated aging cycle. It means that the adhesive bond is affected by accelerated aging cycle.

- Based on the test data, the resin used for primer should have low viscosity to allow its penetration into wood with ease. 
Table 3.3 Shear Strength Values

\begin{tabular}{|c|c|c|c|c|c|c|}
\hline \multirow{2}{*}{$\begin{array}{l}\text { Combination } \\
\text { type }\end{array}$} & \multirow{2}{*}{ Primer } & \multirow{2}{*}{ Resin } & \multicolumn{2}{|c|}{$\begin{array}{c}\text { No of Samples } \\
\text { Tested }\end{array}$} & \multirow{2}{*}{$\begin{array}{l}\text { Unaged Shear } \\
\text { Strength (psi) }\end{array}$} & \multirow{2}{*}{$\begin{array}{l}\text { Aged Shear } \\
\text { Strength (psi) }\end{array}$} \\
\hline & & & Unaged & Aged & & \\
\hline 1 & $\begin{array}{c}\mathrm{G} 1131 \mathrm{~A}+ \\
\mathrm{G} 1131 \mathrm{~B}\end{array}$ & $\begin{array}{c}\text { G1149A + } \\
\text { G1149B }\end{array}$ & 6 & 6 & $\begin{array}{l}1,675 \\
(50 \%)\end{array}$ & $\begin{array}{c}575 \\
(20 \%)\end{array}$ \\
\hline 2 & G1260 & $\begin{array}{c}\text { G1149A + } \\
\text { G1149B }\end{array}$ & 15 & 15 & 985 & 530 \\
\hline 3 & $\begin{array}{c}\mathrm{G} 1131 \mathrm{~A}+ \\
\mathrm{G} 1131 \mathrm{~B}\end{array}$ & $\begin{array}{c}\text { G1149A + } \\
\text { G1149B }\end{array}$ & 15 & 15 & $\begin{array}{l}1,325 \\
(30 \%)\end{array}$ & $\begin{array}{c}566 \\
(15 \%)\end{array}$ \\
\hline 4 & G1260 & Epoxy & 15 & 15 & See Note3 & See Note 3 \\
\hline 5 & G1149A & $\begin{array}{c}\text { G1131A + } \\
\text { G1131B }\end{array}$ & 17 & 17 & $\begin{array}{l}2,041 \\
(82 \%)\end{array}$ & $\begin{array}{c}614 \\
(40 \%)\end{array}$ \\
\hline
\end{tabular}

Note: 1. A phenolic compatible glass fabric is used for combination type 2 through 5.

2. A phenolic incompatible glass fabric is used for combination type 1 .

3. The samples were separated after aging procedure for combination type. Hence, no shear strength test was conducted.

4. The percent number in parenthesis is $\%$ of wood failure.

5. \% wood failure in combination type 4 is incomplete.

6. All above adhesive are manufactured by Indspec Chemicals 


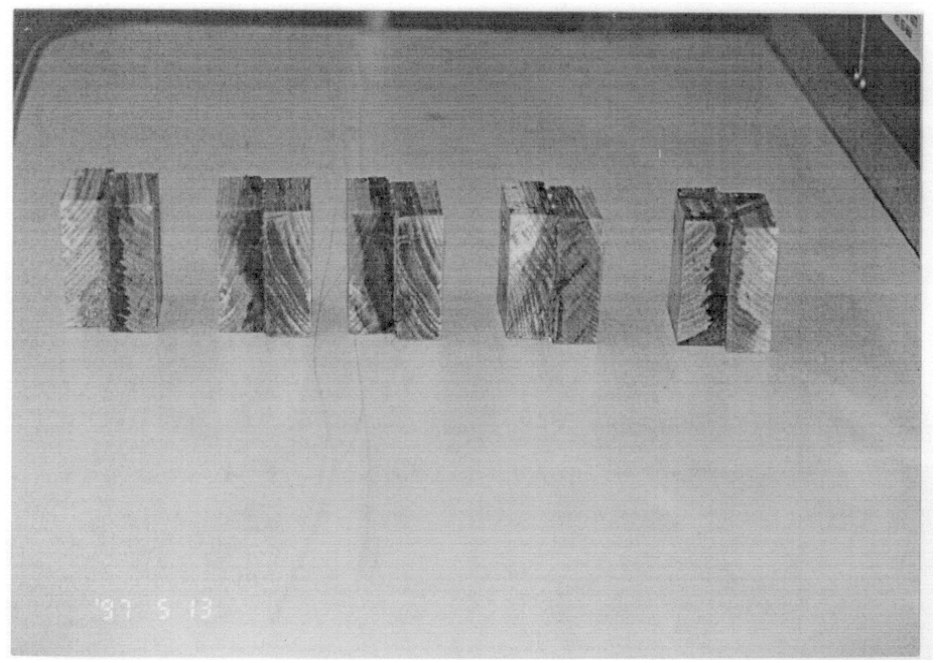

Figure 3.1 Shear Block Specimen

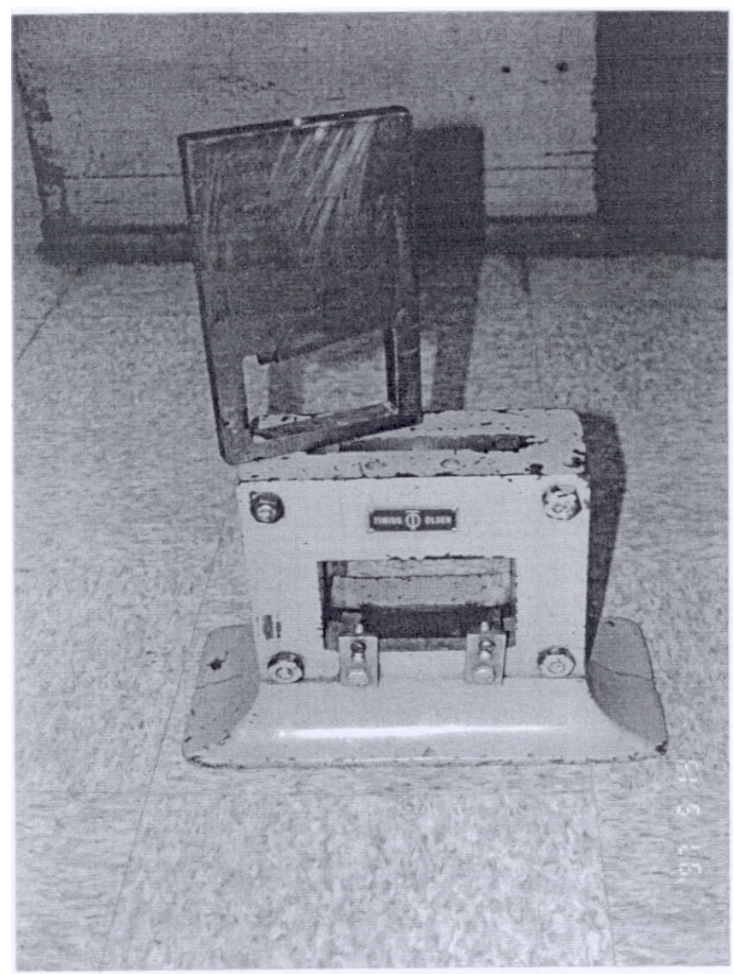

Figure 3.2 Shearing Tool 


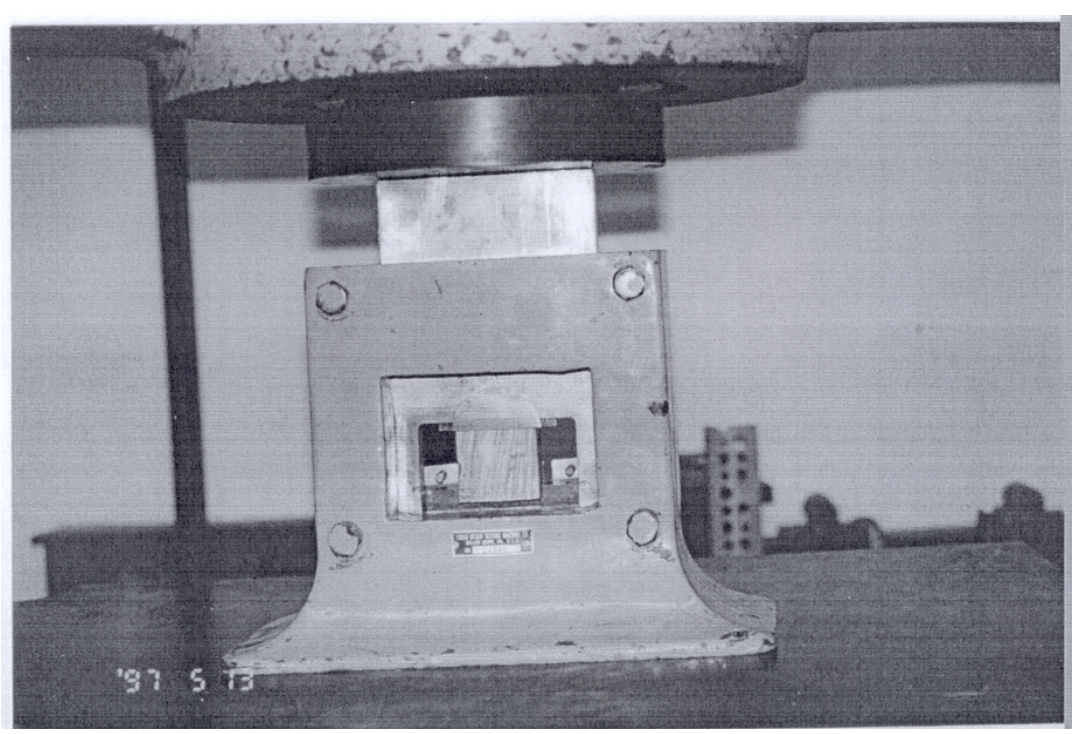

Figure 3.3 Baldwin Machine Test Set -up

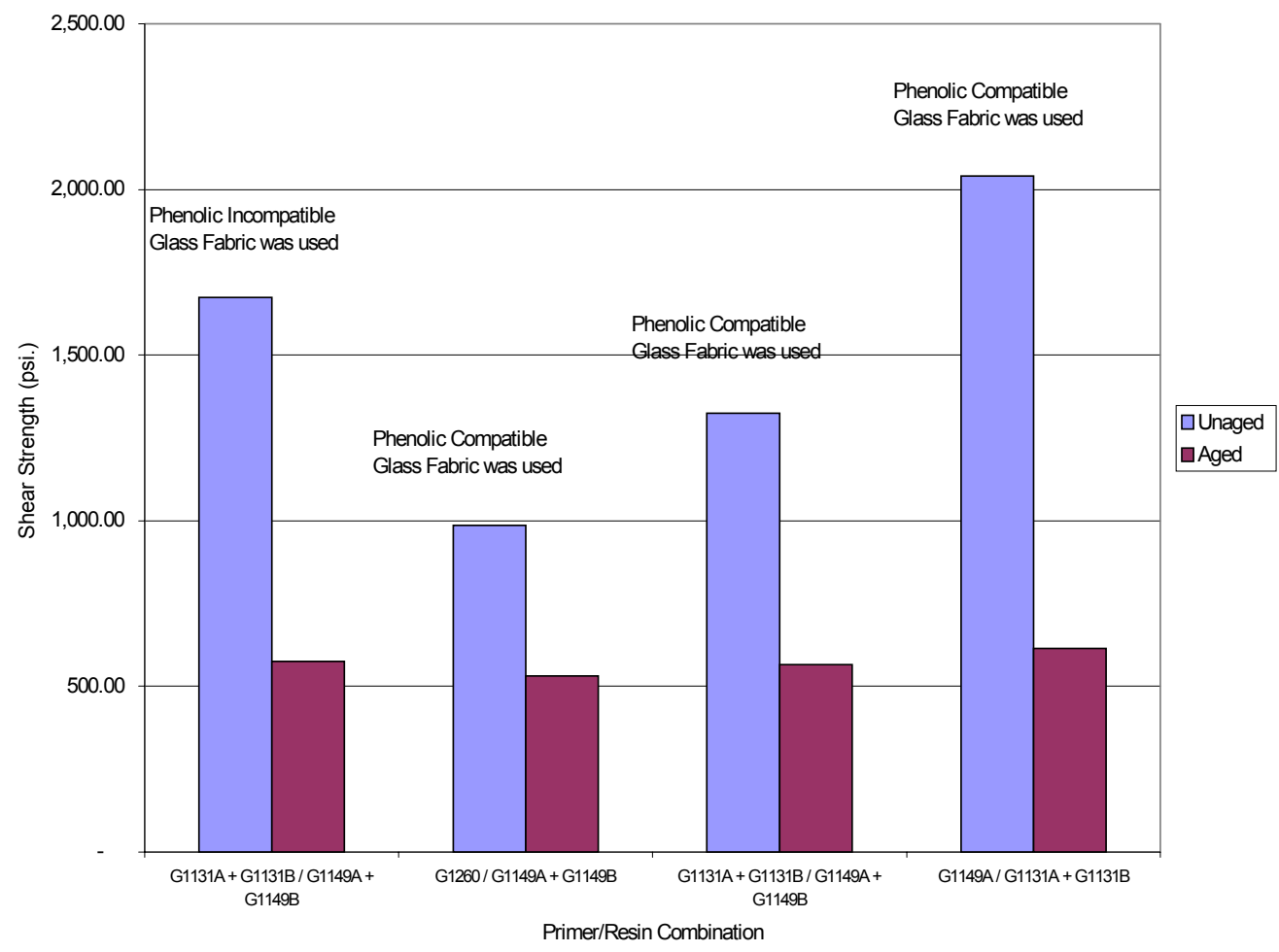

Figure 3.4 Unaged and Aged shear Strength of Treated Wood-GFRC Specimens 


\section{Chapter 4}

\section{Testing and Evaluation of Half-Scale Crosstie Under Accelerated Aging}

\subsection{Introduction}

In-service crossties have to survive harsh environmental conditions, including cyclic variations in temperature and moisture. In a GFRC-wood crosstie, where wood is bonded to GFRC fiber wrap with an adhesive, variations in temperature and moisture can lead to swelling mismatch between the glass wrap and wood tie. This mismatch can result in high stresses at the bond line, possibly resulting in bond failure. An accelerated aging technique (Chow,et.at., 1987) as stated in chapter 3 was used to simulate aging on coupon level samples and to evaluate the bond strength of different adhesives. It was established that the bond resistance offered by a resin/primer combination (resorcinol formaldehyde with lower viscosity) could be adequate to overcome stresses induced by environmental and mechanical loads. The objective was to extend the aging study, beyond the coupon level, to evaluate half-scale GFRC-wooden crosstie bond resistance under harsh conditions, i.e. cyclic environmental conditions.

\subsection{Objectives}

The objective herein was to determine the improvement of flexural rigidity of half-scale crosstie with wrap and their effects of aging on stiffness. 


\subsection{Scope}

Three point bending tests were conducted on five half-scale (3in. x 4in. x 42in.) wood crosstie samples in this study. Span length of these test samples was 38 in. Each specimen was tested under static load applied at midspan up to 7 kips to establish stiffness of the non-wrapped specimen. After the first static tests were completed, three of five specimens were wrapped with GFRC composite at midspan over 20 in length. After 6 days of curing, the same three wrapped specimens were tested again under the same conditions of the first static test. After that, the three wrapped specimens and two non-wrapped specimens were subjected to accelerated aging technique (Chow, et. al., 1987) as stated in chapter 3 before testing. Deflection and strains on wood, and strains on glass wrap were measured in each test.

\subsection{Materials \& Specimen Size}

Half Scale Crosstie: Red oak was used in these tests. The dimensions of each specimen were 3 in $x 4$ in $x 42$ in. Clear wood was selected as test specimens.

GFRC System: E-glass fabric with phenolic compatible sizing was used in these tests. Orientation of E-glass fabric was 0-45 degree. The specimens were wrapped in two layers of fabric.

Adhesive System: Resorcinol Formaldehyde (G1131A) was used as primer instead of Phenol Resorcinol Formaldehyde (G1149A) since G1149A was not available at that time and the general purposes of G1149A are nearly similar to that of G1131A. A combination of G1131-A and G1131-B was used as resin. 


\subsection{Wrapping Procedure}

The crosstie surfaces were cleaned using air pressure, and then four edges were rounded at midspan over 20 in length to properly facilitate the wrapping. The four faces of the crosstie at midspan over 20 in length were sanded using electric sander. After surface preparation, primer (G1131-A) was applied using a paintbrush. A layer of wax paper was used over the primer, and a 110 psi pressure was applied in a retort vessel for 24 hours.

After the primer was cured for 24 hours under pressure at room temperature, the crosstie with primed surface was wrapped with GFRC at midspan over a length of 20 in. The glass fabric was cut to the required dimensions using scissors. The lead end of the glass fabric ran through a resin bath and was stapled on to the crosstie. The crosstie was rotated to wrap the glass fabric around it. Uniform tension was applied to the glass fabric using banding machine by rotating the crosstie in order to eliminate gap and air between each layer of fabric. After the glass fabric was wrapped, the far end of the glass fabric was stapled on to the crosstie. The half scale crosstie was then cured for 6 days at room temperature.

\subsection{Instrumentation}

Dial gages and electrical resistance strain gages were used to measure deflection and strains, respectively. In case of non-wrapped crosstie, strain gages were mounted on test specimens on tension side at midspan. Deflection was measured at midspan of each specimen, for varying load levels. In case of wrapped crossties, an additional gage was mounted on glass fabric on tension side at midspan. Deflection was measured at midspan of each specimen for varying load levels. 


\subsection{Test Procedure}

Three point bending tests were conducted on five red oak half scale crossties: non-wrap, wrap and wrap+aging.

The non-wrapped half scale crossties were placed on two concrete base supports with 38 in. span length. All specimens were tested under static loads up to 7 kips. Midspan deflections and strains were measured at 0.25 kip increments.

The three of five non-wrapped half scale crossties were reinforced by wrapping with Eglass phenolic compatible fabric. All three wrapped specimens were tested under static loads up to 7 kips at midspan, while midspan deflections, strain on wood and strain on glass fabric were measured at $0.25 \mathrm{kip}$ increments.

The three wrapped and two non-wrapped half scale crossties were subjected to six-cycle aging conditions and testing them to 7 kip midspan static loads at 0.25 kip increments. The results were compared with those of similar tests conducted on the same specimen prior to wrapping and aging. Finally, these specimens were tested to failure.

\subsection{Test Results}

Strain and deflection data of each specimen are presented in Table C.4.1, Table C.4.2 and Table C.4..3 as shown in Appendix C. Stiffness of half scale crosstie was evaluated using deflection and strain data measured during static testing. The values of EI (Flexural Rigidity) and shear modulus were calculated from the experimental data.

\subsubsection{Flexural Rigidity of non-wrapped crosstie Specimen \# 1}

1. Elastic Modulus of non-wrapped specimen ( $E_{\text {non-wrap }}$ from Figure 4.1 


$$
\mathrm{E}_{\text {non-wrap }}=2.54 \times 10^{6} \mathrm{psi} \text {. }
$$

2. Shear Modulus of non-wrapped specimen $\left(G_{\text {non-wrap }}\right)$ from Figure 4.2

$$
\mathrm{G}_{\text {non-wrap }}=67,859 \text { psi. }
$$

3. Moment of Inertia

$$
I_{\text {non-wrap }}=\frac{b h^{3}}{12}=\frac{(4)\left(3^{3}\right)}{12}=9 \mathrm{in}^{4}
$$

4. Flexural rigidity of non-wrapped half scale crosstie (EI)

$$
\mathrm{EI}_{\text {non-wrap }}=\left(2.54 \times 10^{6}\right)(9)=22.86 \times 10^{6} \text { lbs.-in. }{ }^{2}
$$

\subsubsection{Flexural Rigidity of Wrapped Crosstie Specimen\# 1}

1. Elastic Modulus of wrapped specimen ( $\left.E_{w r a p}\right)$

$$
\begin{aligned}
& \mathrm{E}_{\text {wrap }}=2.75 \times 10^{6} \text { psi. (From Figure 4.3) } \\
& \mathrm{E}_{\text {wrap + aging }}=1.83 \times 10^{6} \text { psi. (From Figure 4.13) }
\end{aligned}
$$

2. Shear Modulus of wrapped specimen $\left(\mathrm{G}_{\mathrm{wrap}}\right)$ from Figure 4.4

$$
\mathrm{G}_{\mathrm{wrap}}=79,163 \text { psi. }
$$

3. Moment of Inertia

$$
I_{\text {wrap }}=I_{\text {transformed }}=12 \mathrm{in}^{4} \text { (Refer to note in Table C.4.6) }
$$

4. Flexural Rigidity of wrapped half scale crosstie (EI)

$$
\begin{aligned}
& \mathrm{EI}_{\text {wrap }}=\left(2.75 \times 10^{6}\right)(12)=32.97 \times 10^{6} \text { lbs.-in. }{ }^{2} \\
& \mathrm{EI}_{\text {wrap }+ \text { aging }}=\left(1.83 \times 10^{6}\right)(12)=21.96 \times 10^{6} \text { lbs.-in. }^{2}
\end{aligned}
$$

\subsubsection{Flexural Rigidity of non-wrapped crosstie Specimen \# 2}

1. Elastic Modulus of non-wrapped specimen ( $\left.E_{\text {non-wrap }}\right)$ from Figure 4.5

$$
\mathrm{E}_{\text {non-wrap }}=1.97 \times 10^{6} \text { psi. }
$$


2. Shear Modulus of non-wrapped specimen $\left(G_{\text {non-wrap }}\right)$ from Figure 4.6

$$
\mathrm{G}_{\text {non-wrap }}=76,912 \text { psi. }
$$

3. Moment of Inertia

$$
I_{n o n-w r a p}=\frac{b h^{3}}{12}=\frac{(4)\left(3^{3}\right)}{12}=9 \mathrm{in}^{4}
$$

4. Flexural Rigidity of non-wrapped half scale (EI)

$$
\mathrm{EI}_{\text {non-wrap }}=\left(1.97 \times 10^{6}\right)(9)=17.73 \times 10^{6} \text { lbs.-in. }{ }^{2}
$$

\subsubsection{Flexural Rigidity of Wrapped Crosstie Specimen \# 2}

1. Elastic Modulus of wrapped specimen ( $\left.E_{w r a p}\right)$

$$
\begin{aligned}
& E_{\text {wrap }}=1.55 \times 10^{6} \text { psi. (From Figure 4.7) } \\
& E_{\text {wrap + aging }}=1.39 \times 10^{6} \text { psi. (From Figure 4.14) }
\end{aligned}
$$

2. Shear Modulus of wrapped specimen $\left(G_{\text {wrap }}\right)$ from Figure 4.8

$$
\mathrm{G}_{\mathrm{wrap}}=83,619 \text { psi. }
$$

3. Moment of Inertia

$$
\mathrm{I}_{\mathrm{wrap}}=\mathrm{I}_{\text {transformed }}=12.86 \mathrm{in}^{4} \text { ( Refer to note below Table C.4.10 ) }
$$

4. Flexural Rigidity of wrapped half scale (EI)

$$
\begin{aligned}
& \mathrm{EI}_{\text {wrap }}=\left(1.55 \times 10^{6}\right)(12.86)=19.93 \times 10^{6} \text { lbs.-in. }{ }^{2} \\
& \mathrm{EI}_{\mathrm{wrap}}+\text { aging } \\
& =\left(1.39 \times 10^{6}\right)(12.86)=17.88 \times 10^{6} \text { lbs.-in. }{ }^{2}
\end{aligned}
$$

\subsubsection{Flexural Rigidity of non-wrapped crosstie Specimen \# 3}

1. Elastic Modulus of non-wrapped specimen ( $E_{\text {non-wrap }}$ ) from Figure 4.9

$$
\mathrm{E}_{\text {non-wrap }}=2.04 \times 10^{6} \mathrm{psi} \text {. }
$$

2. Shear Modulus of non-wrapped specimen $\left(\mathrm{G}_{\text {non-wrap }}\right)$ from Figure 4.10 


$$
\mathrm{G}_{\text {non-wrap }}=43,177 \text { psi. }
$$

3. Moment of Inertia

$$
I_{\text {non-wrap }}=\frac{b h^{3}}{12}=\frac{(4)\left(3^{3}\right)}{12}=9 \mathrm{in}^{4}
$$

4. Flexural Rigidity of non-wrapped half scale (EI)

$$
\mathrm{EI}_{\text {non-wrap }}=\left(2.04 \times 10^{6}\right)(9)=18.36 \times 10^{6}{\text { lbs. }- \text { in. }^{2}}^{2}
$$

\subsubsection{Flexural Rigidity of Wrapped Crosstie Specimen \# 3}

1. Elastic Modulus of wrapped specimen ( $\left.E_{w r a p}\right)$

$$
\begin{aligned}
& \mathrm{E}_{\mathrm{wrap}}=1.68 \times 10^{6} \text { psi. (From Figure 4.11) } \\
& \mathrm{E}_{\mathrm{wrap}+\text { aging }}=1.35 \times 10^{6} \text { psi. (From Figure } 4.15 \text { ) }
\end{aligned}
$$

2. Shear Modulus of wrapped specimen $\left(G_{\text {wrap }}\right)$ from Figure 4.12

$$
\mathrm{G}_{\mathrm{wrap}}=50,891 \text { psi. }
$$

3. Moment of Inertia

$$
I_{\text {wrap }}=I_{\text {transformed }}=12.72 \text { in }^{4} \text { ( Refer to note below Table C.4.14 ) }
$$

4. Flexural Rigidity of wrapped half scale (EI)

$$
\begin{aligned}
& \mathrm{EI}_{\mathrm{wrap}}=\left(1.68 \times 10^{6}\right)(12.72)=21.37 \times 10^{6} \text { lbs.-in. }{ }^{2} \\
& \mathrm{EI}_{\text {wrap }+ \text { aging }}=\left(1.35 \times 10^{6}\right)(12.72)=17 . \times 10^{6} \mathrm{lbs} .- \text { in }{ }^{2}
\end{aligned}
$$

\subsubsection{Flexural Rigidity of Non-Wrapped Crosstie Specimen \# 4}

1. Elastic Modulus of non-wrapped specimen ( $E_{\text {non-wrap }}$ )

$$
\begin{aligned}
& \left.E_{\text {non-wrap }}=2.04 \times 10^{6} \text { psi. (From Figure } 4.16\right) \\
& E_{\text {non-wrap }+ \text { aging }}=1.69 \times 10^{6} \text { psi. (From Figure } 4.17 \text { ) }
\end{aligned}
$$

2. Moment of Inertia 


$$
I_{n o n-w r a p}=\frac{b h^{3}}{12}=\frac{(4)\left(3^{3}\right)}{12}=9 \mathrm{in}^{4}
$$

4. Flexural Rigidity of wrapped half scale (EI)

$$
\begin{aligned}
& \mathrm{EI}_{\text {non-wrap }}=\left(2.04 \times 10^{6}\right)(9)=18.36 \times 10^{6} \text { lbs.-in. }{ }^{2} \\
& \mathrm{EI}_{\text {non-wrap+ aging }}=\left(1.69 \times 10^{6}\right)(9)=15.21 . \times 10^{6} \mathrm{lbs} . \text {-in. }^{2}
\end{aligned}
$$

\subsubsection{Flexural Rigidity of Non-Wrapped Crosstie Specimen \# 5}

1. Elastic Modulus of non-wrapped specimen ( $\left.E_{\text {non-wrap }}\right)$

$$
\begin{aligned}
& E_{\text {non-wrap }}=1.75 \times 10^{6} \text { psi. (From Figure } 4.17 \text { ) } \\
& E_{\text {non-wrap }+ \text { aging }}=1.46 \times 10^{6} \text { psi. (From Figure 4.18) }
\end{aligned}
$$

2. Moment of Inertia

$$
I_{n o n-w r a p}=\frac{b h^{3}}{12}=\frac{(4)\left(3^{3}\right)}{12}=9 \mathrm{in}^{4}
$$

4. Flexural Rigidity of wrapped half scale (EI)

$$
\begin{aligned}
& \mathrm{EI}_{\text {non-wrap }}=\left(1.75 \times 10^{6}\right)(9)=15.75 \times 10^{6} \text { lbs.-in. }{ }^{2} \\
& \mathrm{EI}_{\text {non-wrap+ aging }}=\left(1.46 \times 10^{6}\right)(9)=13.14 \times 10^{6} \text { lbs.-in. }{ }^{2}
\end{aligned}
$$

Table 4.1 Summary of Flexural Rigidity of Half-Scale Crossties

\begin{tabular}{|c|c|c|c|c|}
\hline \multirow{2}{*}{ Specimen No. } & \multicolumn{4}{|c|}{ Flexural Rigidity ( EI, lbs.-in. ${ }^{2}$ ) } \\
\cline { 2 - 5 } & Non-Wrap & $\begin{array}{c}\text { Non-Wrap }+ \\
\text { Aging }\end{array}$ & Wrap & $\begin{array}{c}\text { Wrap }+ \\
\text { Aging }\end{array}$ \\
\hline$\# 1$ & $22.86 \times 10^{6}$ & N/A & $32.97 \times 10^{6}$ & $21.96 \times 10^{6}$ \\
\hline$\# 2$ & $17.73 \times 10^{6}$ & N/A & $19.93 \times 10^{6}$ & $17.88 \times 10^{6}$ \\
\hline$\# 3$ & $18.36 \times 10^{6}$ & N/A & $21.37 \times 10^{6}$ & $17.68 \times 10^{6}$ \\
\hline$\# 4$ & $18.36 \times 10^{6}$ & $15.21 \times 10^{6}$ & N/A & N/A \\
\hline$\# 5$ & $15.75 \times 10^{6}$ & $13.14 \times 10^{6}$ & N/A & N/A \\
\hline
\end{tabular}


Table 4.2 Summary Table of Shear Modulus of Half-Scale Crossties

\begin{tabular}{|c|c|c|}
\hline \multirow{2}{*}{ Specimen No. } & \multicolumn{2}{|c|}{ Shear Modulus ( G, psi ) } \\
\cline { 2 - 3 } & Non-Wrap & Wrap \\
\hline$\# 1$ & 67,859 & 79,163 \\
\hline$\# 2$ & 76,912 & 83,619 \\
\hline$\# 3$ & 43,177 & 50,891 \\
\hline
\end{tabular}

\subsection{Comparison of Flexural Rigidity and Shear Modulus between Non-Wrap and Wrap}

\section{Cases}

In terms of flexural rigidity, the values of EI (Table 4.1) were used to evaluate bending resistance increase of half-scale crosstie after wrapping. The flexural rigidity (EI) of wrapped specimens \# 1, 2, and 3 is more than that of non-wrapped specimens \# 1, 2, and 3 by about 44,13, and 17 percent, respectively. Therefore, we can conclude that bending resistance has increased after reinforcing a tie with GFRC wrap.

In term of shear stiffness, shear modulus ( $G$ ) was computed to evaluate increases in shear resistance of half-scale crossties. Shear modulus (Table 4.2) of wrapped specimens \# 1, 2 , and 3 is more than that of non-wrapped specimens \# 1,2, and 3 by about 17,9, and 18 percent, respectively.

\subsection{Comparison of Flexural Rigidity between Non-Wrap and Non-Wrap + Aging Cases}

The flexural rigidity (EI) (Table 4.1) of both non-wrapped half scale crossties \#4 and \#5 after subjected to accelerated aging were reduced by 17 percent in relation to non-wrapped halfscale crossties before aging. 


\subsection{Comparison of Flexural Rigidity between Wrap and Wrap+Aging Cases}

The flexural rigidity (EI) (Table 4.1) of wrapped half-scale crossties after accelerated aging was reduced by $33,10,17$ percent, respectively, in relation to wrapped half-scale cross ties before accelerated aging. Accepting that the accelerated aging process of Chow as a means to determine the survivability of crossties, the results indicate that flexural rigidity of wrapped specimens after accelerated aging is nearly similar to that of non-wrapped specimens. Therefore, it is reasonable to extrapolate that the wrapped crossties will have a minimum service life of about 20 years.

\subsection{Conclusion}

- GFRC system can improve the stiffness and durability of half-scale cross ties in a range of $13 \%-44 \%$ in flexural rigidity and $9 \%-18 \%$ in shear modulus.

- The flexural rigidity (EI) of half scale wrapped specimens was reduced in the range of $10 \%$ to $30 \%$ after accelerated aging while noting that half scale non-wrapped specimen EI reduces around 17-20 percent after accelerated aging.

- Based on the results in section 4.10 and 4.11 , a strength reduction of 17 percent is noted in both non-wrapped and wrapped half scale crossties with aging; hence it is reasonable to conclude that bond degradation is very limited due to the laboratory based aging process.

To cost effectively use the GFRC system with full-scale crossties, we need to reduce the area of wrapping over full-scale cross ties. The area of GFRC wrapping should be the area that is subjected to high stresses induced under axle loads. Testing and evaluation of test results of wrapped wooden crossties are described in the next chapter. 


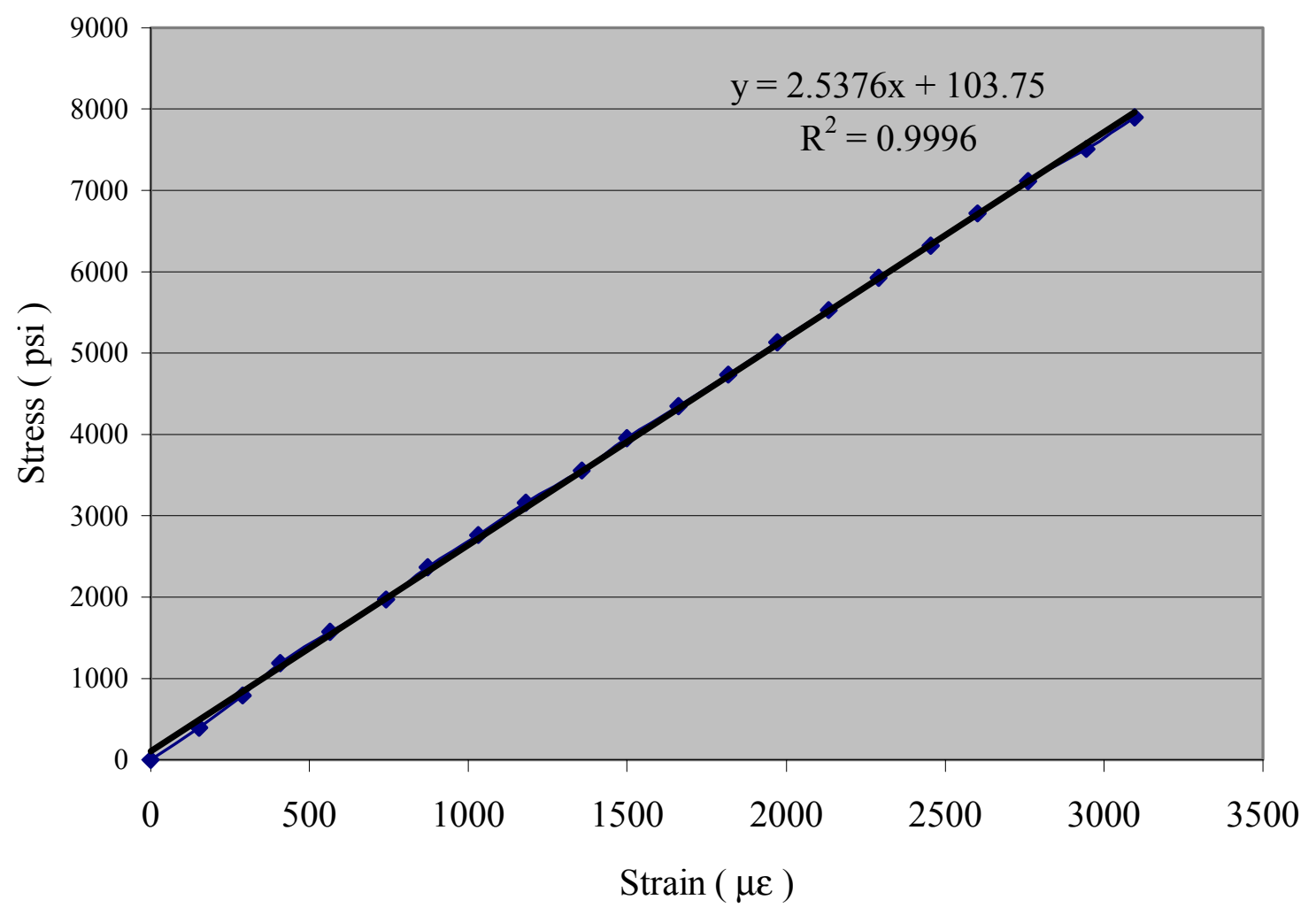

Figure 4.1 Stress VS Strain of Non-Wrapped Specimen\# 1

Note 1. Data are referred to Table C.4.4

2. $\mathrm{E}_{\text {non-wrap }}=2.54 \times 10^{6} \mathrm{psi}$. (The slope of above chart ) 


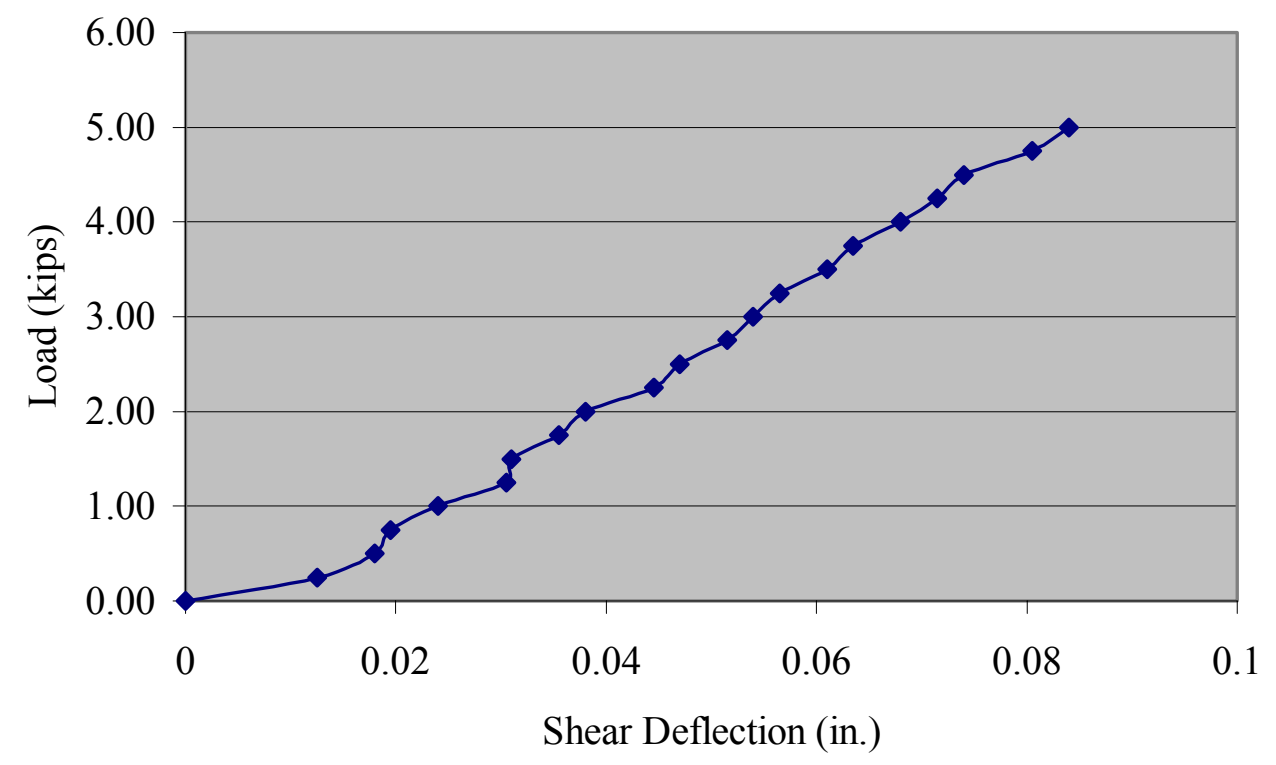

Figure 4.2 Load and Shear Deflection of Non-Wrapped Specimen\# 1

Note 1. Data are referred to Table C.4.5

2. The load range considered in this computation is 2.5 kips to 4 kips.

3.Slope of above chart $=\frac{\text { Load }}{\text { ShearDeflection }}=\frac{P}{\delta_{s}}=71.43 \mathrm{kips} / \mathrm{in}=71,430 \mathrm{lb} / \mathrm{in}$

4. Shear Deflection Formula of Simple Beam subjected to point load at midspan

$$
\delta_{s}=\frac{1.2 P L}{4 A_{e} G} \quad, \text { therefore } \mathrm{G}=\frac{1.2 P L}{4 A_{e} \delta_{s}}
$$

5. $\mathrm{G}_{\text {non-wrap }}=67,859$ psi. ( $\mathrm{L}=38$ in., $\mathrm{A}_{\mathrm{e}}=12$ in. $\left.{ }^{2}, \frac{P}{\delta_{s}}=71,430 \mathrm{lb} / \mathrm{in}.\right)$ 


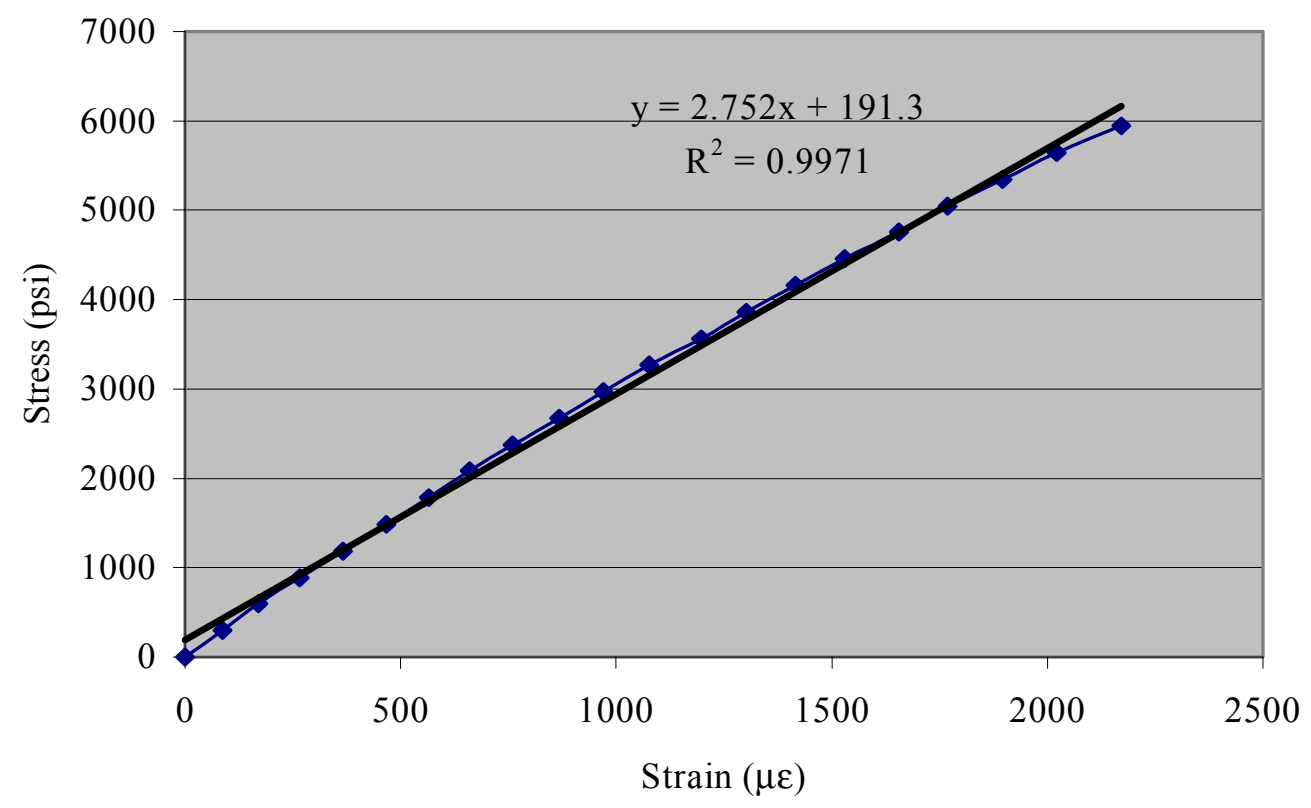

Figure 4.3 Stress VS Strain of Wrapped Specimen \# 1

Note 1. Data are referred to Table C.4.6

2. $E_{\text {wrap }}=2.75 \times 10^{6} \mathrm{psi}$ (The slope from above chart) 


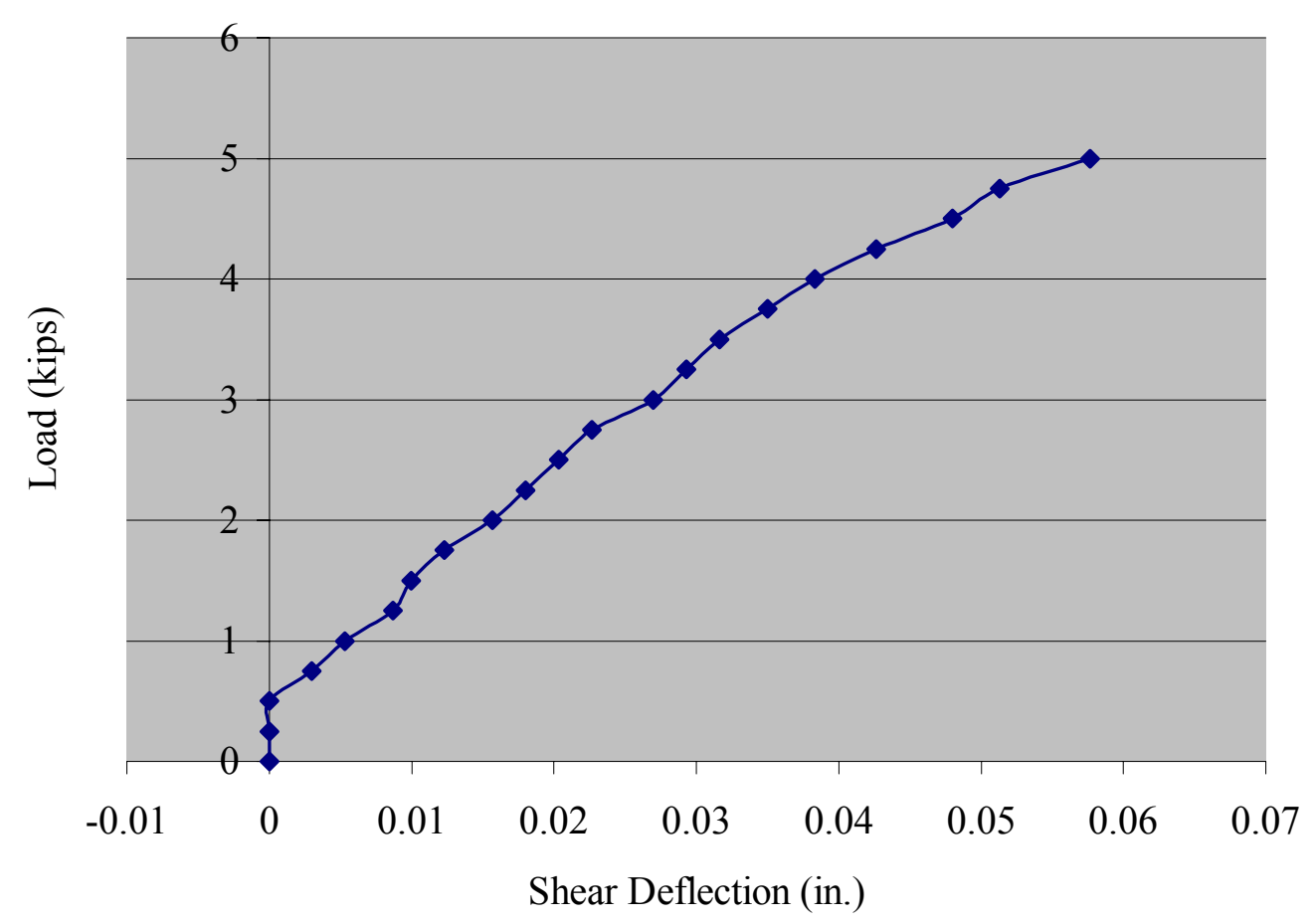

Figure 4.4 Load VS Shear Deflection of Wrapped Specimen \# 1

Note 1.Data are referred to Table C.4.7

2. The load range considered in this computation is 2.5 kips to 4 kips.

3.Slope of above chart $=\frac{\text { Load }}{\text { ShearDeflection }}=\frac{P}{\delta_{s}}=83.33 \mathrm{kips} / \mathrm{in}=83,330 \mathrm{lb} / \mathrm{in}$

4. Shear Deflection Formula of Simple Beam subjected to point load at midspan

$$
\delta_{s}=\frac{1.2 P L}{4 A_{e} G} \quad, \text { therefore } \mathrm{G}=\frac{1.2 P L}{4 A_{e} \delta_{s}}
$$

5. $\mathrm{G}_{\text {wrap }}=79,163$ psi. ( $\mathrm{L}=38$ in., $\mathrm{A}_{\mathrm{e}}=12$ in. $\left.^{2}, \frac{P}{\delta_{s}}=83,330 \mathrm{lb} / \mathrm{in}.\right)$ 


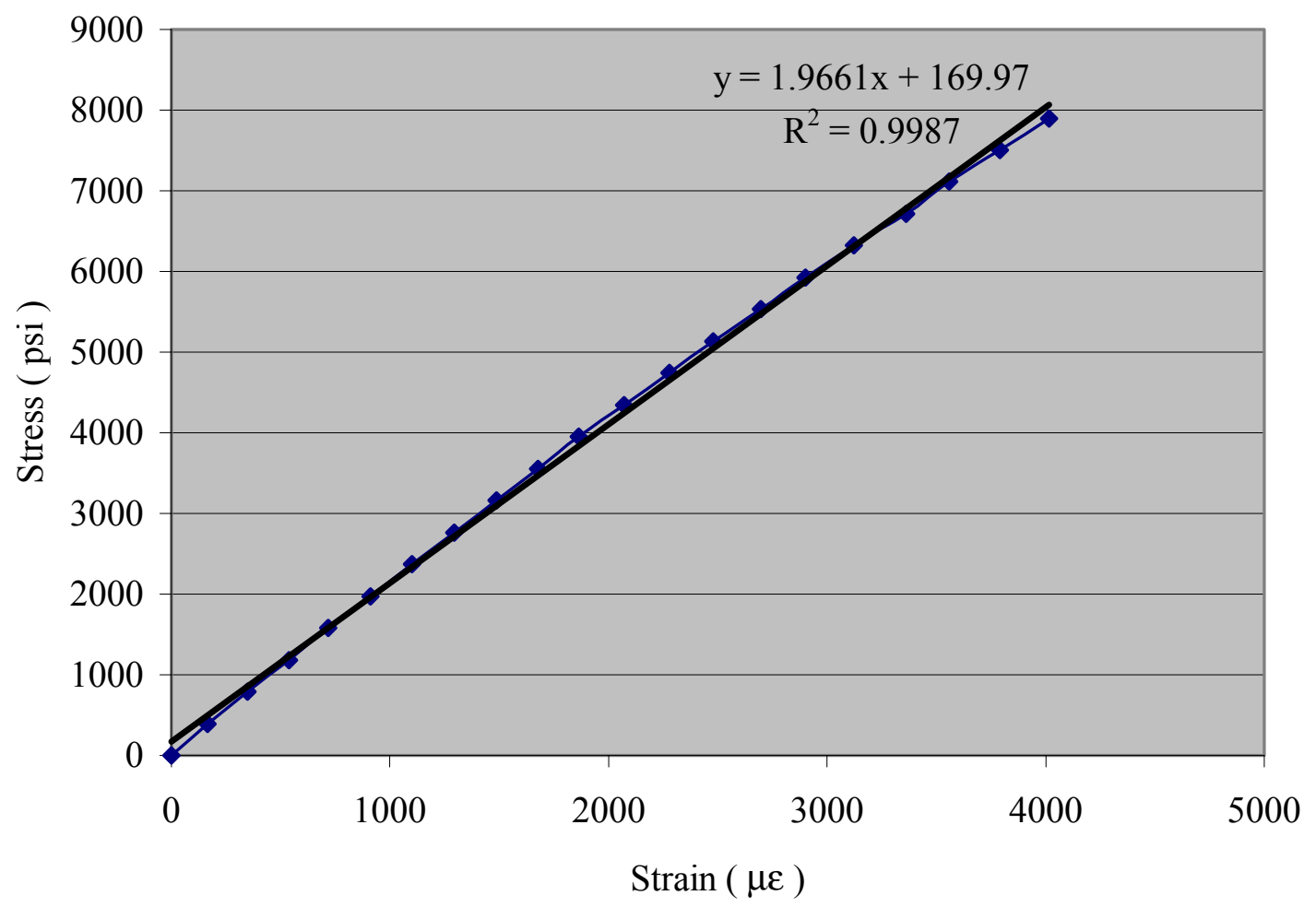

Figure 4.5 Stress VS Strain of Non-Wrapped Specimen \# 2

Note 1. Data are referred to Table C.4.8

2. $E_{\text {non-wrap }}=1.97 \times 10^{6}$ psi. (The slope of above chart ) 


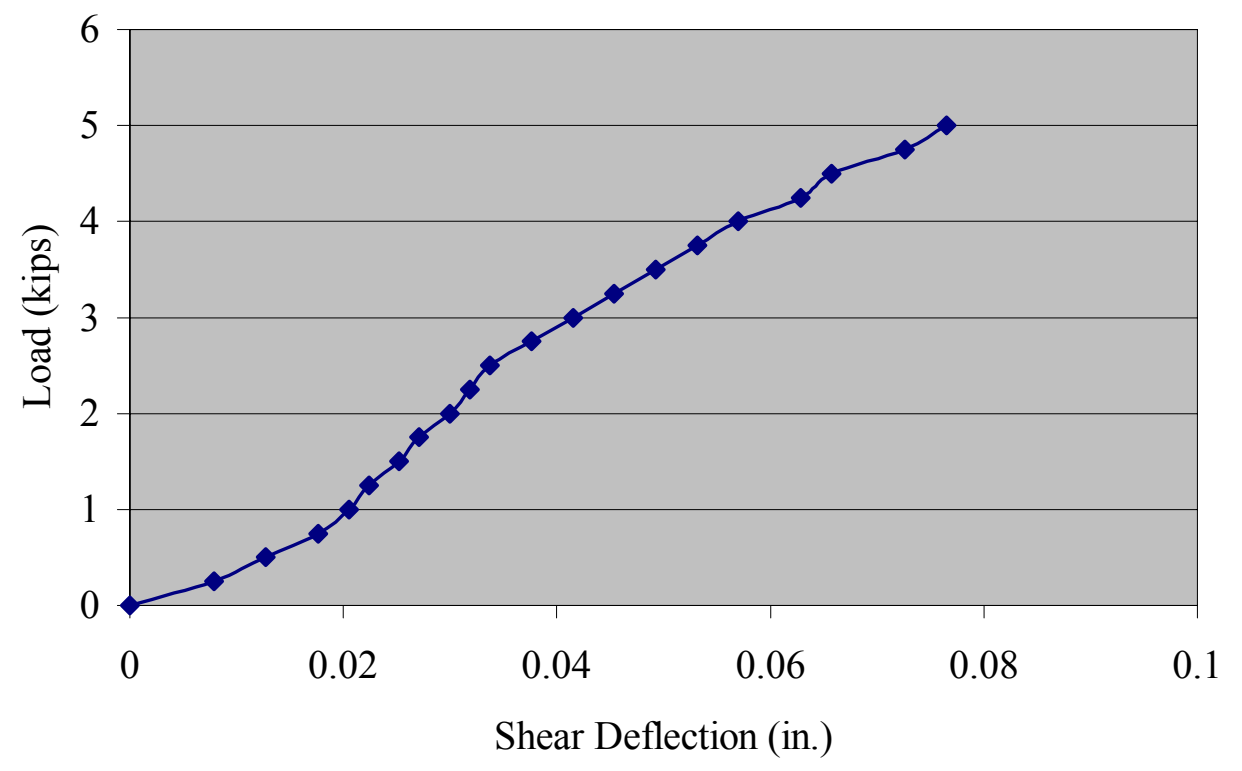

Figure 4.6 Load VS Shear Deflection of Non-Wrapped Specimen \# 2

Note 1. Data are referred to Table C.4.9

2. The load range considered in this computation is 1 kips to 4 kips.

3.Slope of above chart $=\frac{\text { Load }}{\text { ShearDeflection }}=\frac{P}{\delta_{s}}=80.96 \mathrm{kips} / \mathrm{in}=80,960 \mathrm{lb} / \mathrm{in}$

4. Shear Deflection Formula of Simple Beam subjected to point load at midspan

$$
\delta_{s}=\frac{1.2 P L}{4 A_{e} G} \quad, \text { therefore } \mathrm{G}=\frac{1.2 P L}{4 A_{e} \delta_{s}}
$$

5. $\mathrm{G}_{\text {non-wrap }}=76,912$ psi. ( $\mathrm{L}=38$ in., $\mathrm{A}_{\mathrm{e}}=12$ in. $^{2}, \frac{P}{\delta_{s}}=80,960 \mathrm{lb} /$ in. $)$ 


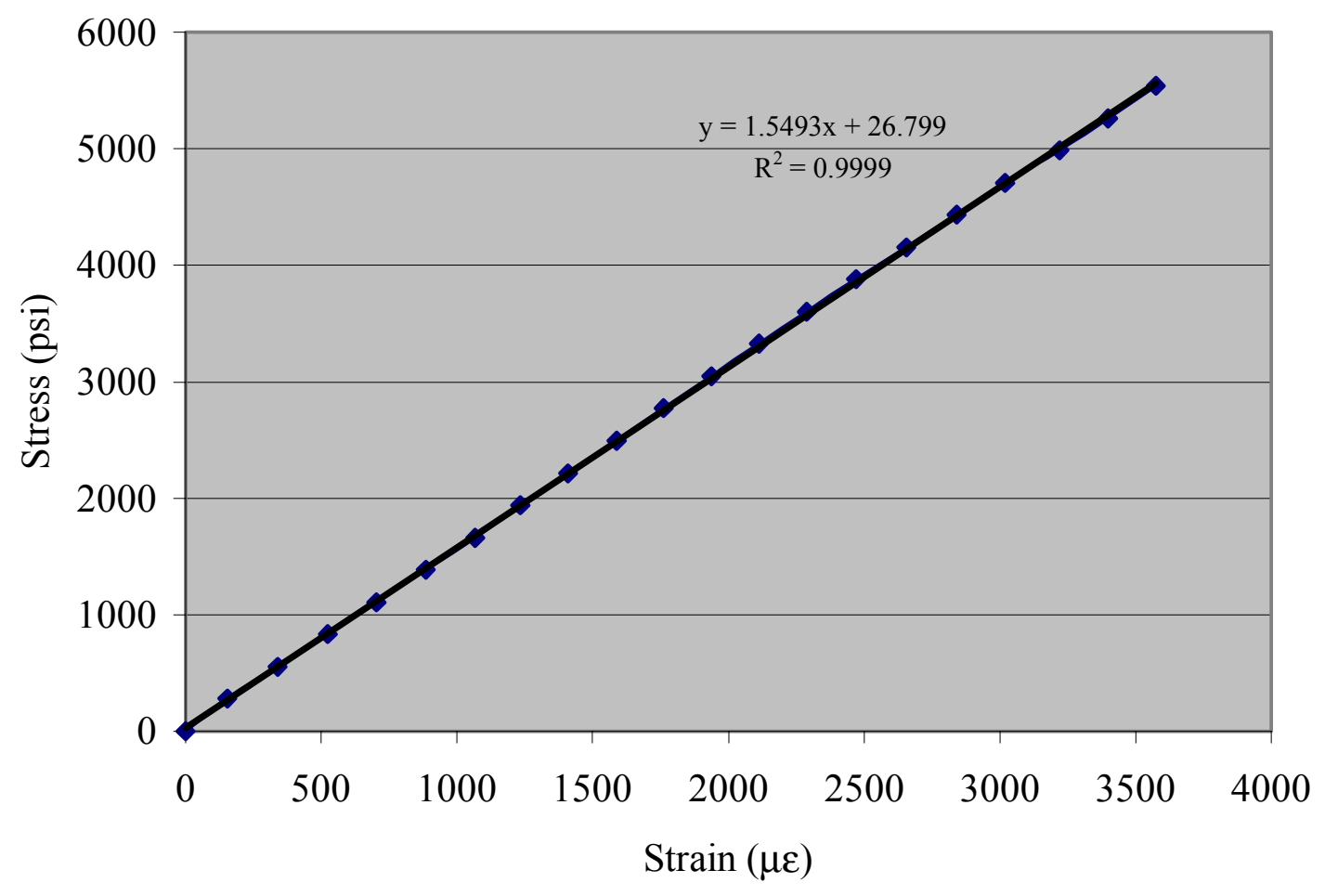

Figure 4.7 Stress VS Strain of Wrapped Specimen \# 2

Note 1. Data are referred to Table C.4.10

2. $\mathrm{E}_{\text {wrap }}=1.55 \times 10^{6} \mathrm{psi}$ (The slope from above chart) 


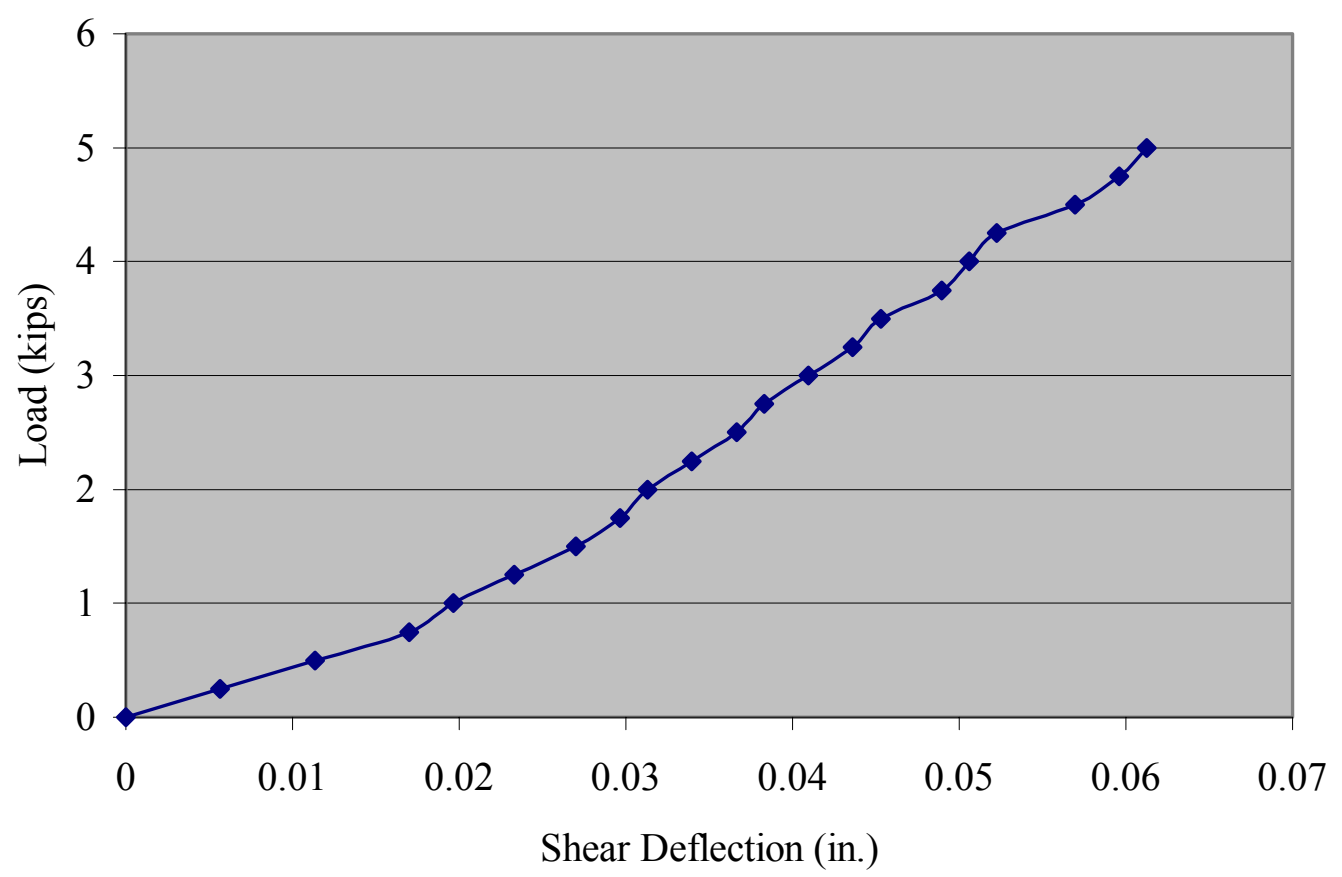

Figure 4.8 Load VS Shear Deflection of Wrapped Specimen \#2

Note 1.Data are referred to Table C.4.11

2.The load range considered in this computation is 1 kips to 4 kips.

2.Slope of above chart $=\frac{\text { Load }}{\text { ShearDeflection }}=\frac{P}{\delta_{s}}=88.02 \mathrm{kips} / \mathrm{in}=88,020 \mathrm{lb} / \mathrm{in}$

3. Shear Deflection Formula of Simple Beam subjected to point load at midspan

$$
\delta_{s}=\frac{1.2 P L}{4 A_{e} G} \quad, \text { therefore } \mathrm{G}=\frac{1.2 P L}{4 A_{e} \delta_{s}}
$$

4. $\mathrm{G}_{\text {wrap }}=83,619$ psi. ( $\mathrm{L}=38$ in., $\mathrm{A}_{\mathrm{e}}=12$ in. $\left.^{2}, \frac{P}{\delta_{s}}=88,020 \mathrm{lb} / \mathrm{in}.\right)$ 


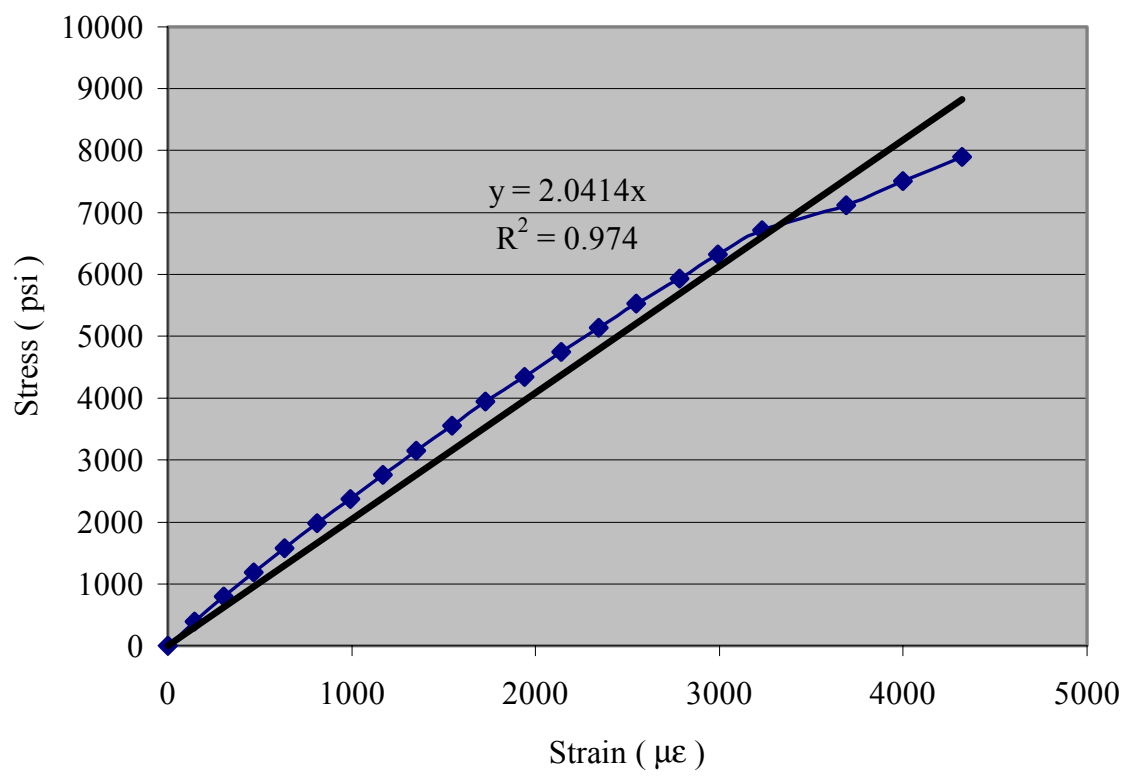

Figure 4.9 Stress VS Strain of Non-Wrapped Specimen\# 3

Note 1. Data are referred to Table C.4.12

2. $\mathrm{E}_{\text {non-wrap }}=2.04 \times 10^{6} \mathrm{psi}$. (The slope of above chart ) 


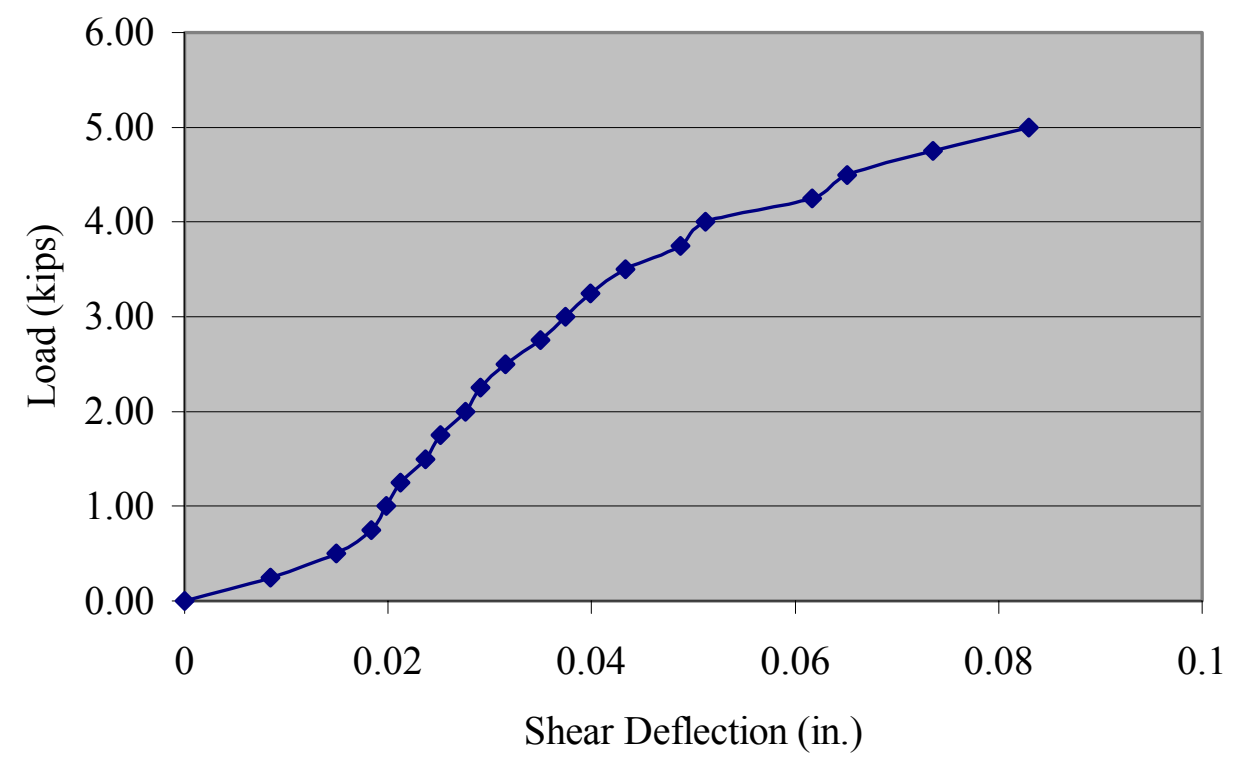

Figure 4.10 Load and Shear Deflection of Non-Wrapped Specimen\# 3

Note 1. Data are referred to Table C.4.13

2. The load range considered in this computation is 2.5 kips to 4 kips.

3.Slope of above chart $=\frac{\text { Load }}{\text { ShearDeflection }}=\frac{P}{\delta_{s}}=45.45 \mathrm{kips} / \mathrm{in}=45,450 \mathrm{lb} / \mathrm{in}$

4. Shear Deflection Formula of Simple Beam subjected to point load at midspan

$$
\delta_{s}=\frac{1.2 P L}{4 A_{e} G} \quad, \text { therefore } \mathrm{G}=\frac{1.2 P L}{4 A_{e} \delta_{s}}
$$

5. $\mathrm{G}_{\text {non-wrap }}=43,177$ psi. ( $\mathrm{L}=38$ in., $\mathrm{A}_{\mathrm{e}}=12$ in. $\left.{ }^{2}, \frac{P}{\delta_{s}}=45,450 \mathrm{lb} / \mathrm{in}.\right)$ 


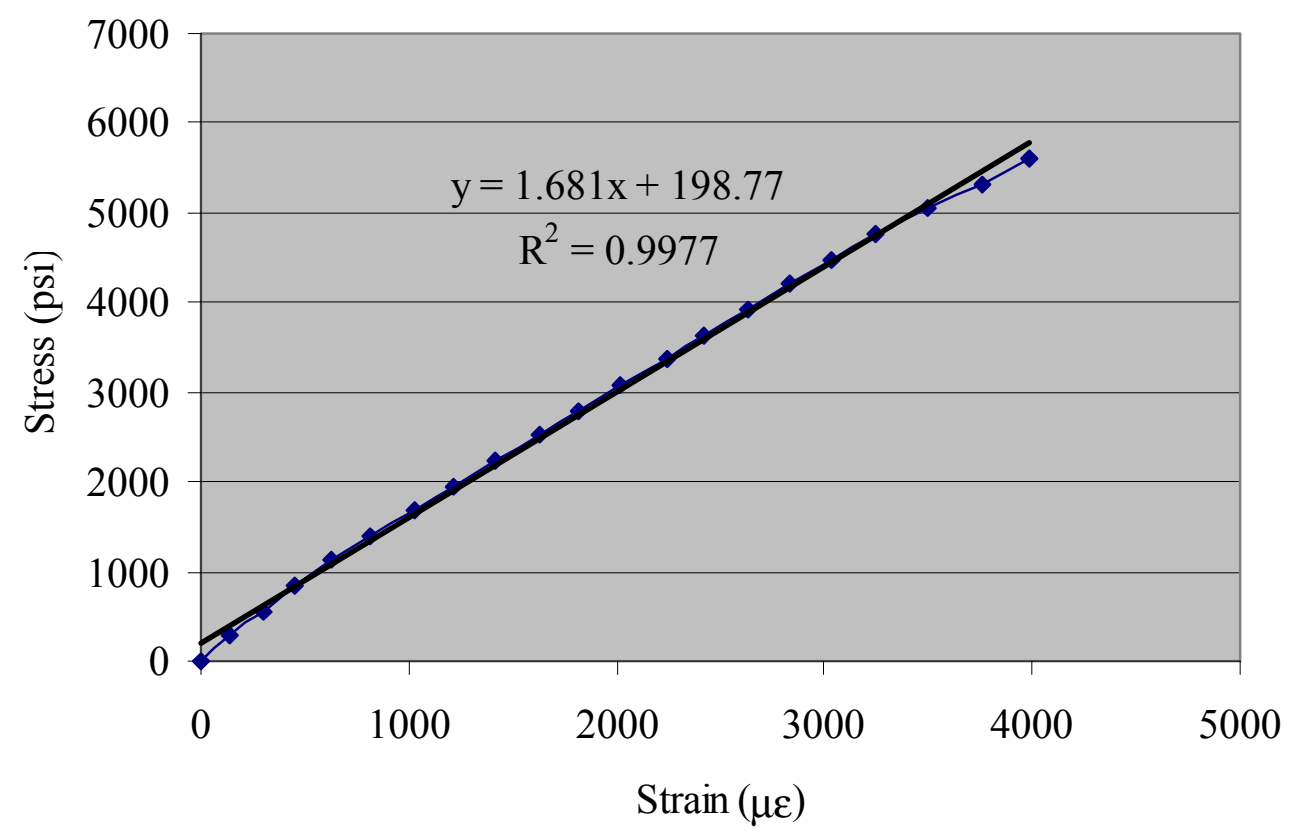

Figure 4.11 Stress VS Strain of Wrapped Specimen \# 3

Note 1. Data are referred to Table C.4.14

2. $\mathrm{E}_{\mathrm{wrap}}=1.68 \times 10^{6} \mathrm{psi}$ (The slope from above chart) 


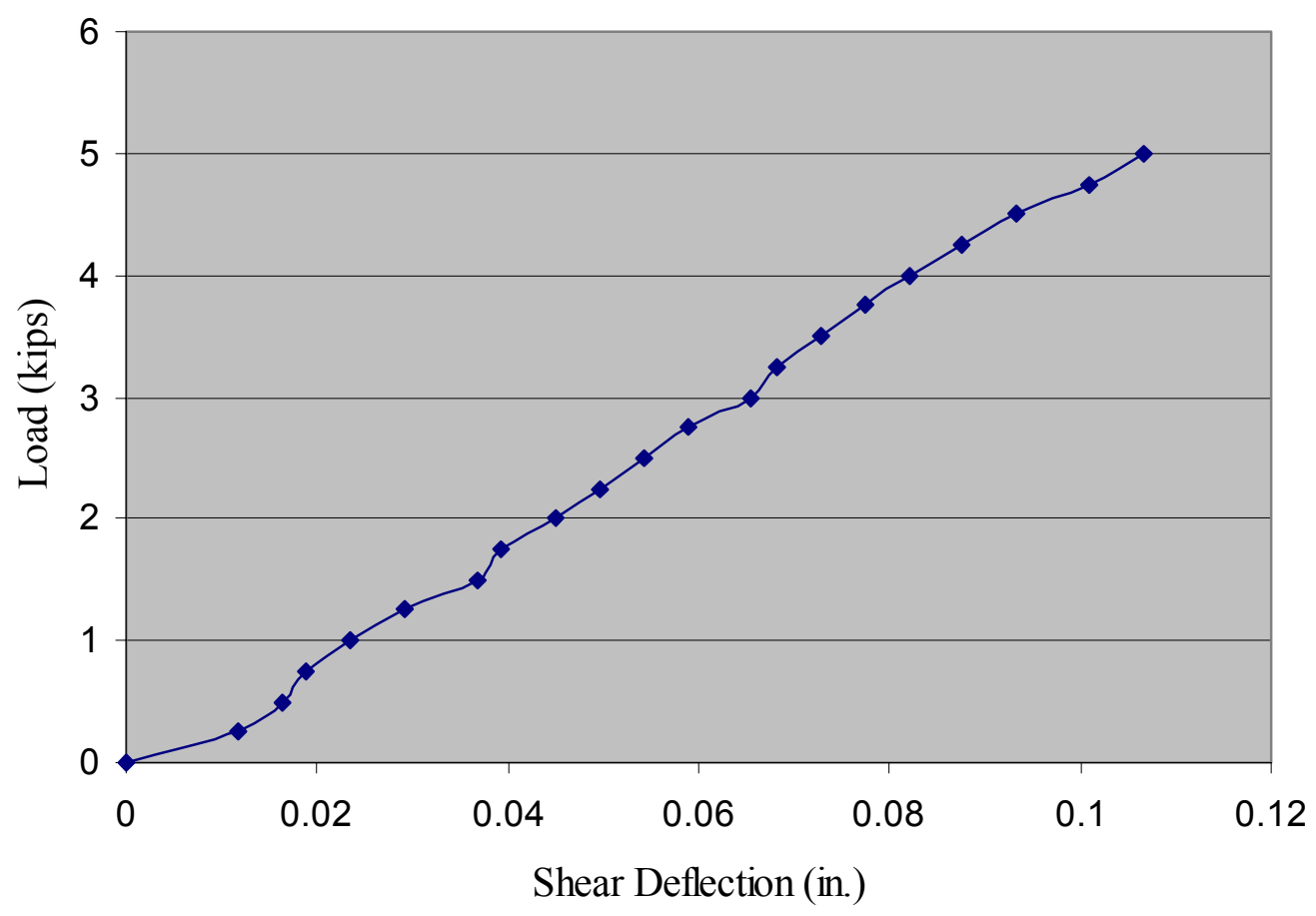

Figure 4.12 Load VS Shear Deflection of Wrapped Specimen \# 3

Note 1.Data are referred to Table C.4.15

2. The load range considered in this computation is 2.5 kips to 4 kips.

3.Slope of above chart $=\frac{\text { Load }}{\text { ShearDeflection }}=\frac{P}{\delta_{s}}=53.57 \mathrm{kips} / \mathrm{in}=53,570 \mathrm{lb} / \mathrm{in}$

4. Shear Deflection Formula of Simple Beam subjected to point load at midspan

$$
\delta_{s}=\frac{1.2 P L}{4 A_{e} G} \quad, \text { therefore } \mathrm{G}=\frac{1.2 P L}{4 A_{e} \delta_{s}}
$$

5. $\mathrm{G}_{\text {wrap }}=50,891$ psi. ( $\mathrm{L}=38$ in., $\mathrm{A}_{\mathrm{e}}=12$ in. $\left.^{2}, \frac{P}{\delta_{s}}=53,570 \mathrm{lb} / \mathrm{in}.\right)$ 


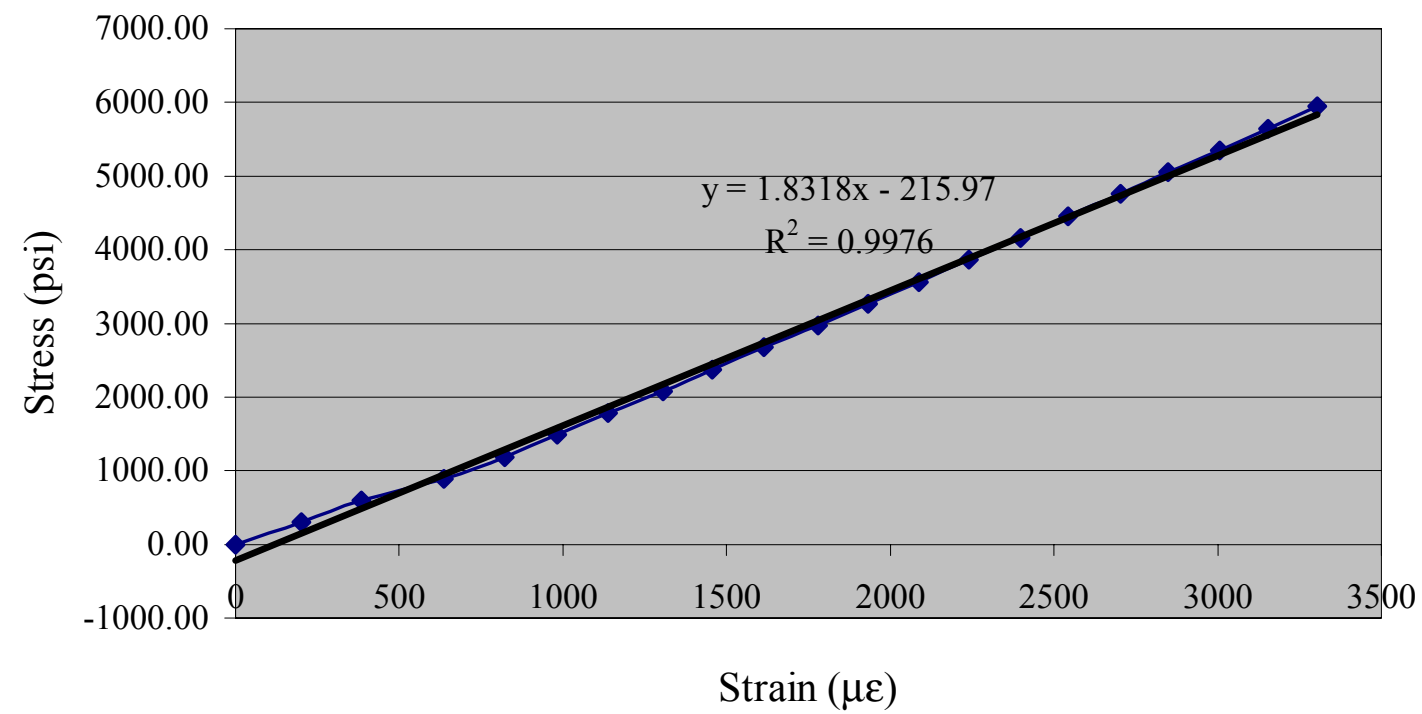

Figure 4.13 Stress VS Strain of Wrapped Specimen \# 1 (Wrap + Aging)

Note 1. $\mathrm{E}_{\text {wraptaging }}=1.83 \times 10^{6} \mathrm{psi}$ (slope from above chart)

2. Chart data are referred to Table C.4.16 


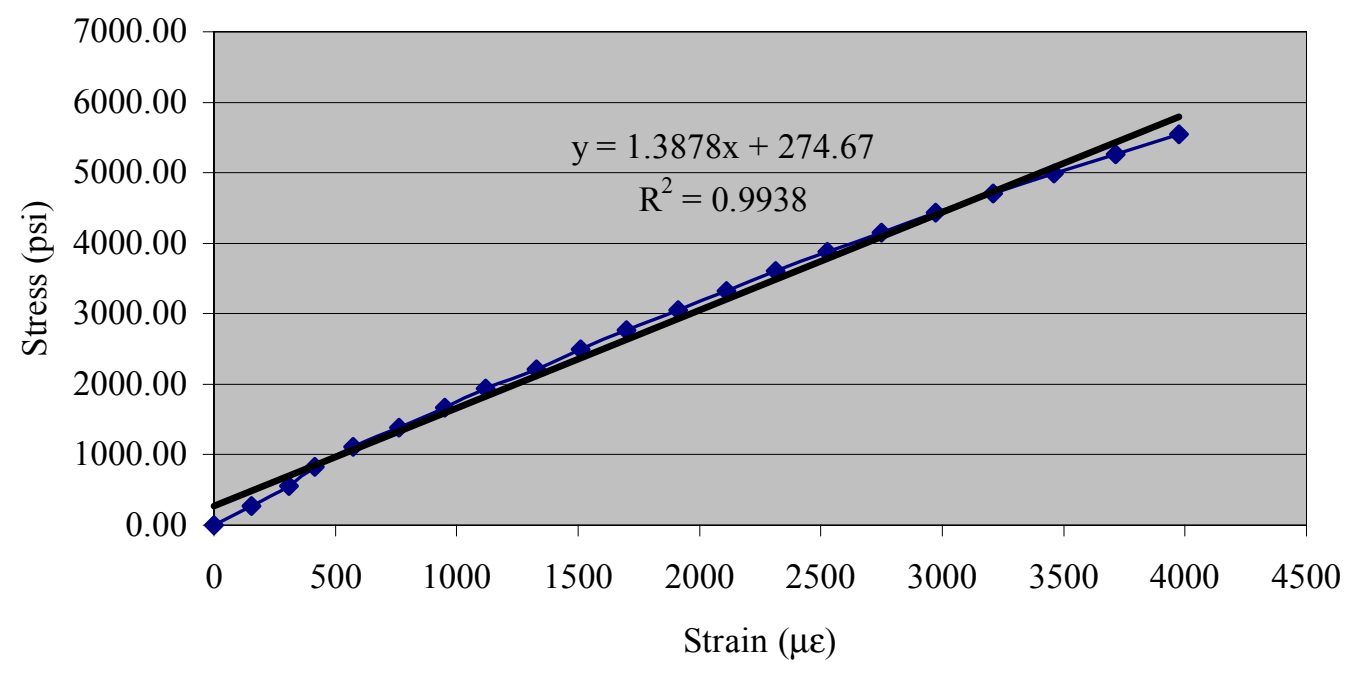

Figure 4.14 Stress VS Strain of Wrapped Specimen \# 2 (Wrap + Aging)

Note $\quad 1 . E_{\text {wraptaging }}=1.39 \times 10^{6} \mathrm{psi}$ (slope from above chart)

2. Chart data are referred to Table C.4.17 


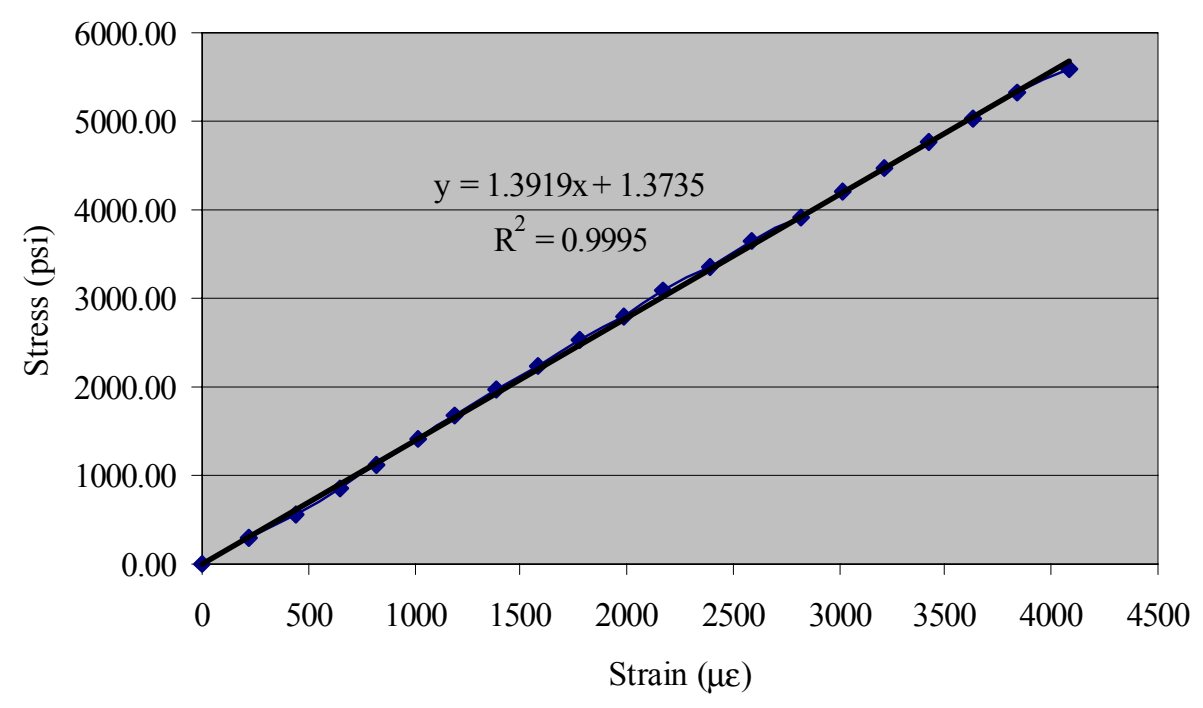

Figure 4.15 Stress VS Strain of Wrapped Specimen \# 3 (Wrap + Aging)

Note $1 . \mathrm{E}_{\mathrm{wrap}+\text { aging }}=1.39 \times 10^{6} \mathrm{psi}$ (slope from above chart)

2. Chart data are referred to Table C.4.18 


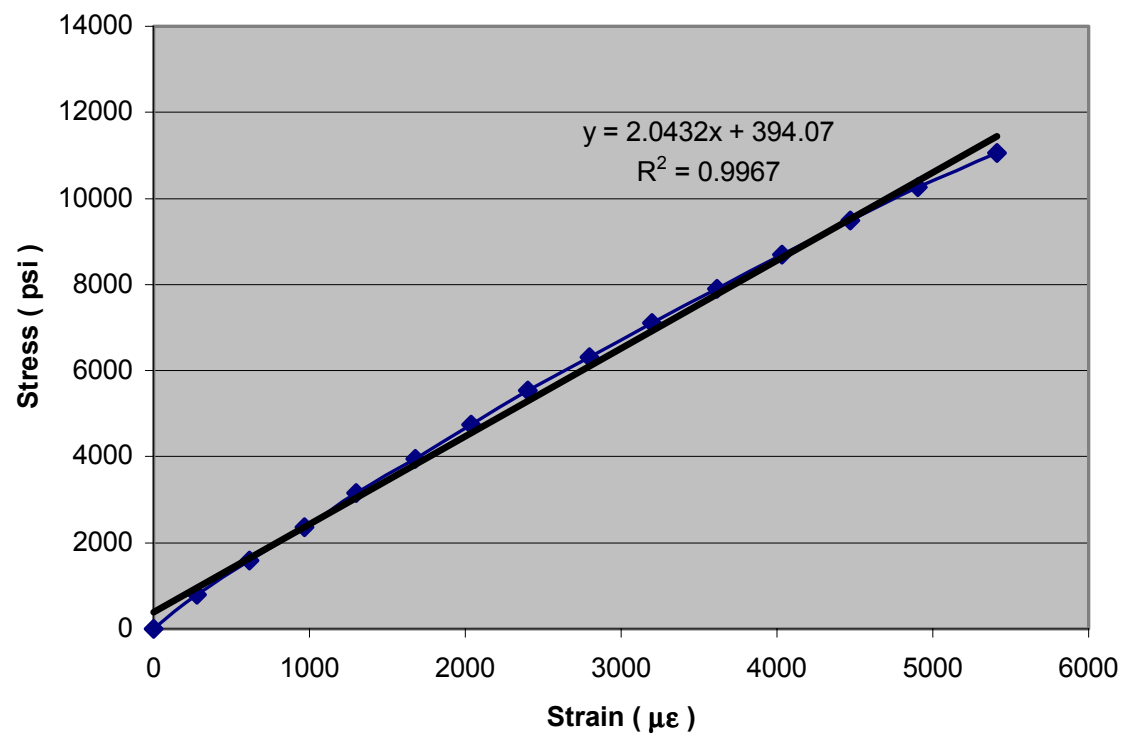

Figure 4.16 Stress VS Strain of Non-Wrap Specimen \# 4

Note $1 . E_{\text {non-wrap }}=2.04 \times 10^{6} \mathrm{psi}$ (slope from above chart)

2. Chart data are referred to Table C.4.19 


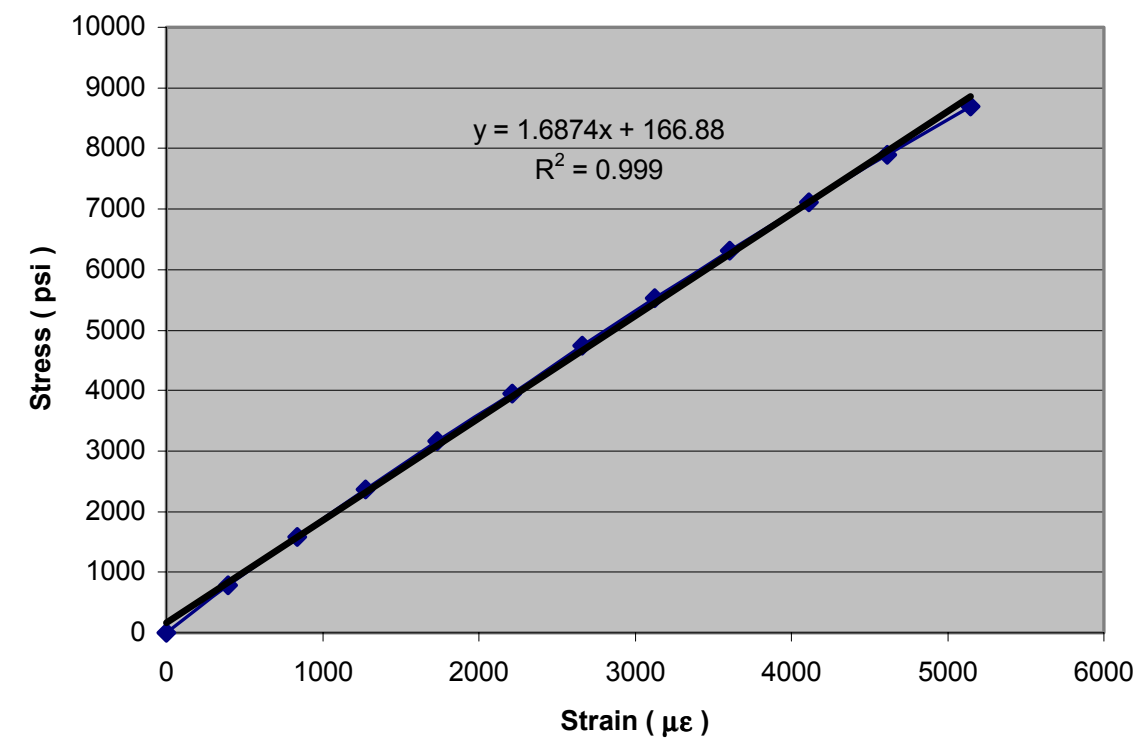

Figure 4.17 Stress VS Strain of Non-Wrapped Specimen \# 4 (With Aging)

Note $1 . E_{\text {non-wrap+aging }}=1.69 \times 10^{6} \mathrm{psi}$ (slope from above chart)

2. Chart data are referred to Table C.4.19 


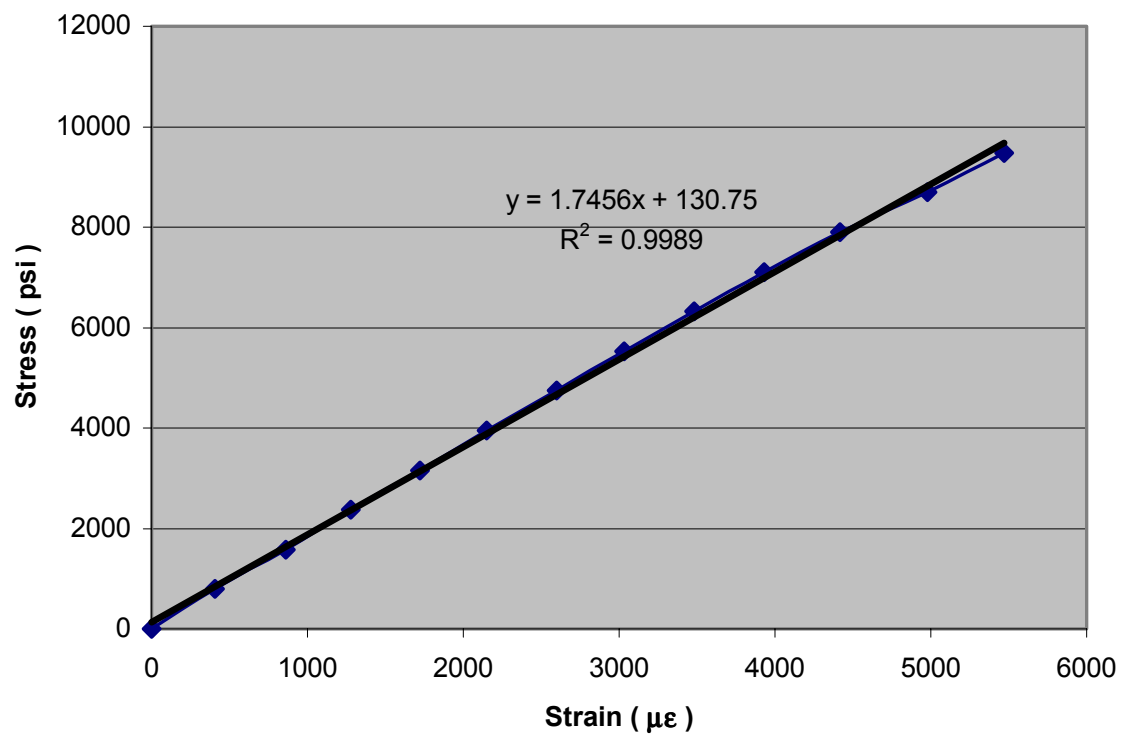

Figure 4.18 Stress VS Strain of Non-Wrapped Specimen \# 5

Note $1 . \mathrm{E}_{\text {non-wrap }}=1.75 \times 10^{6} \mathrm{psi}$ (slope from above chart)

2. Chart data are referred to Table C.4.20 


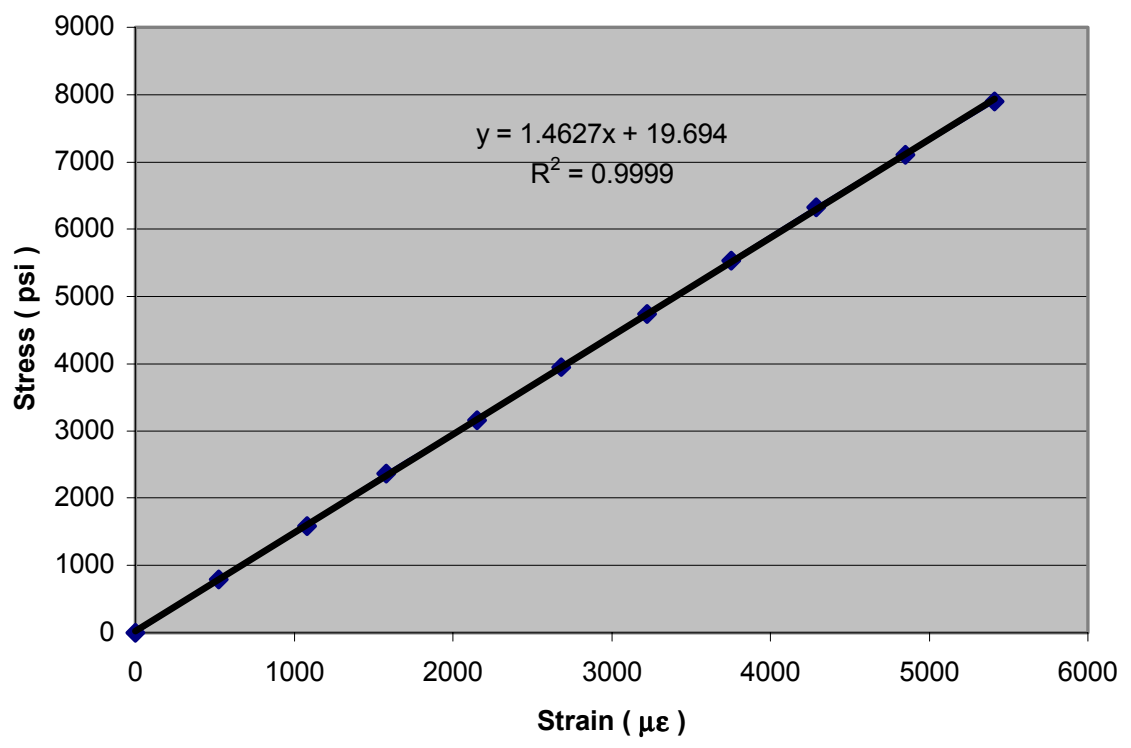

Figure 4.19 Stress VS Strain of Non-Wrapped Specimen \# 5 (With Aging)

Note $1 . E_{\text {non-wrap+aging }}=1.46 \times 10^{6} \mathrm{psi}$ (slope from above chart)

2. Chart data are referred to Table C.4.20 


\section{Chapter 5}

\section{Testing and Evaluation of Full Scale Non-Wrapped and Wrapped Crosstie Under Fatigue Loading}

\subsection{Introduction}

As stated in section 4.11, GFRC is found to improve the performance in half-scale cross ties. Therefore, full-scale cross ties were wrapped over the area under rails to study the performance.

The primer/resin combination of $\mathrm{G} 1149 \mathrm{~A} / \mathrm{G} 1131 \mathrm{~A}+\mathrm{G} 1131 \mathrm{~B}$ provides a strong and durable bond between treated wood and GFRC (refer to chapter 3). This primer/resin combination was used to wrap full-scale cross ties and their test results are described in this chapter. To study the performance of GFRC full-scale wrapped cross ties, fatigue testing was carried out on full-scale non-wrapped and GFRC wrapped specimens. .

\subsection{Objectives}

The objectives of this component of the research are to:

1) Study fatigue response of GFRC wrap on wood strength and stiffness, and

2) Evaluate the magnitude of degradation in stiffness and strength as a function of fatigue cycles and stress range.

\subsection{Scope}

The objectives in section 5.2 are achieved by testing non-wrapped and GFRC wrapped full-scale crosstie specimens embedded in ballast under flexural fatigue (Figure 5.1). Flexural 
fatigue testing was conducted because such testing induces both flexural and shear stresses, which are dominant forces in a crosstie under service conditions. Full-scale test specimens with approximate dimensions of 7 in. $x 8$ in. $x 102$ in. were used in the study. The details of fatigue test specimens, load range and number of cycles are given in Table 5.1.

One test case of non-wrapped wooden crosstie and three test cases of GFRC wrapped wooden crosstie were evaluated under fatigue loading. Strain and deflection measurements (Figure 5.2) were obtained during the test at different locations on the crosstie (Figure 5.7 through 5.10). Strain measurements were taken to evaluate the degree of integrity of GFRCwood interface, while deflection measurements helped in evaluating global stiffness of crossties. The details of fatigue test parameters are given in Table 5.1.

\subsection{Materials}

Wood Crosstie: Full-scale ( 7 in. $x 8$ in. x 102 in.) red oak crossties were used in the study. Full-scale crossties consisted of AREA grades 4 and 5 quality lumber.

GFRC System: E-glass phenolic compatible fabric was used as the wrapping material (Figure 5.3). The details of fabric orientation, number of wrap layers and length of wraps are presented in Table 5.2.

Adhesive System: Based on the shear block test results, the primer/resin combination of G1149A/G1131A+G1131B was used to bond the fabric to the crossties. While a primer was coated, certain pressure was applied using banding machine during wrapping (Figure 5.5). The above resin combination has five parts of G1131A (liquid) and one part of G1131B (powder) by weight. 


\subsection{Wrapping Procedure}

The crosstie surfaces were cleaned using air pressure, and then rounded at the corners under the rail-seat zones using electric rounder (Figure 5.4). The four faces of the new crossties at each location of the rail-seat (Figure 5.1) were sanded using electric sander. In case of the old crosstie, creosote from all faces of the old crossties at two locations, i.e., under rail-seat (Figure 5.1) was removed using electric planer. After surface preparation, primer (G1149A) was applied using a paint brush. A layer of wax paper was provided over the primer. Using a banding machine, staples and glass cloth (Figure 5.5), pressure was applied on the primed surface. The primer was cured for 24 hours under pressure at room temperature.

The crosstie with primed surface was wrapped with GFRC at each location of the railseat (Figure 5.6). The glass fabric was cut to the required dimensions using scissors. The lead end of the glass fabric ran through a resin bath and was stapled on to the crosstie (Figure 5.5). The crosstie was rotated so that the glass fabric was wrapped around the crosstie. Some tension was applied to the glass fabric using the banding machine. The tension force was retained till the resin was cured, i.e., 12 hours. After curing, the far end of the wrap was cut with scissors.

\subsection{Test Procedure}

The crosstie was placed in a wooden bin containing compacted ballast (Figure 5.1). In other words, the crosstie was supported on simulated elastic foundation made of ballast (gravel). Wide flange steel beam was placed on two steel plates resting on the tie at two rail-seat locations. Load was applied on the top of the wide flange steel beam using an actuator. The test set-up is shown in Figure 5.1. 
The test program to evaluate the fatigue performance consisted of both fatigue and intermediate static load tests. All specimens were tested under static loads in linear load range before subjecting to fatigue cycles. The static load versus deflection provided the initial stiffness of the specimen. Static tests were conducted after every 200,000 fatigue cycles for the test cases A, C and D as shown in Figure 5.7 through 5.10 and after every 400,000 cycles for the test case B (Table 5.1). The fatigue load at a rate of $1.5 \mathrm{~Hz}$ was applied on the crossties at two load points located at 21 inches from the ends of sample.

\subsection{Instrumentation}

Dial gages and electrical resistance strain gages were used (Figure 5.2) to measure deflection and strain, respectively. Strain measurements were used to establish integrity of the interface, while deflection measurements were used to determine the beam stiffness. Strains were measured on top of the fabric and crosstie, while deflections were measured at the midspan and the center of wrapped area.

In case of wrapped crossties, strain gages were mounted on both the wood surface and also on the wrap surface. This was achieved by mounting gages on the wood surface prior to wrapping. Deflections at mid-span and the center of wrapped area were measured by using dial gages. The instrumentation scheme is represented in Figures .7 through 5.10.

The load was calibrated and applied using MTS 407 controller (Figure 5.11) and a hydraulic actuator (Figure 5.1).

\subsection{Test Results}

The strain and deflection data are simplified and studied in terms of induced strain/unit load and induced deflection/unit load. The strain/unit load and deflection/unit load data are 
presented for test cases A, B, C and D in Tables 5.3 through 5.6. The strain/unit load and deflection/unit load are computed at 0 and 2 million fatigue cycles. The applied static load range considered in this computation is 10 kips to 30 kips.

The fatigue performance in terms of strength and stiffness is discussed in the following sections. The parameters considered are: (1) wrapped versus unwrapped; (2) one layer of wrap versus two layers of wrap; (3) orientation of fabric, i.e., two layers of 30-60, 0-90 degrees versus two layers of 0-90 degrees; and (4) fatigue load range, i.e., 5-35 kips versus 3-53 kips. The compositeness (integrity) between the wrap and the crosstie is addressed based on the measured strains as discussed in section 5.8.5.

\subsubsection{Performance of Wrapped Crosstie versus Non-wrapped Crosstie}

To evaluate the fatigue performance of wrapped crosstie versus non-wrapped crosstie, the strain/unit load and deflection/unit load results for test cases A and B are used. These results are presented in Tables 5.3 and 5.6.

From Table 5.3, the bending stress at mid-span of wrapped crosstie, evaluated by comparing microstrain/unit load of strain gage 1 for test cases A and B (Figure 5.7 and 5.8), is about 1.25 times the stress in non-wrapped crosstie at 0 cycles. The bending stress at mid-span of wrapped crosstie is almost same as the bending stress in non-wrapped crosstie at 2 million cycles. The bending stress degradation of wrapped crosstie at midspan from 0 cycles to 2 million cycles is less than 5 percent. The bending stress degradation of non-wrapped crosstie at midspan from 0 cycles to 2 million cycles was about 25 percent.

From Table 5.6, the global stiffness of wrapped crosstie evaluated by comparing the value of deflection/unit load at center of crosstie of test cases A and B, is about 2.2 times the global stiffness of unwrapped crosstie at 0 cycles, and about 1.13 times the global stiffness of 
non-wrapped crosstie at 2 million cycles. The global stiffness values may be not be the true values because rigid body motion of crosstie has occurred due to settlement of the ballast. In other words, for comparison purposes, measured deflections may not be the true deflection of the specimen.

\subsubsection{Performance of One Layer Wrap versus Two Layer Wrap}

The fatigue performance of one layer wrap versus two layer wrap test specimens was evaluated using the strain/unit load and deflection/unit load results for test case C. These results are presented in Tables 5.4 and 5.6. The left side of the crosstie in the test case C (Figure 5.9) had one layer of wrap while the right side of the same crosstie in the same test case had two layers of wrap.

As shown in Figure 5.9, strain gages 4 and 8 were mounted on one layer wrap and two layer wrap, respectively. From Table 5.4, the microstrain/unit load from strain gage 4 is twice that of strain gage 8 at 0 cycles and also at 2 million cycles. This indicates that the stresses in this particular test specimen (Case C) are one half when the number of wrap layers are doubled; however it should not be interpreted that the stress levels decrease in direct proportion to the number of wraps.

\subsubsection{Performance of Two layers of 30-60, 0-90 Degrees Oriented Fabric Versus Two layers of 0-90, 0-90 Degrees Oriented Fabric}

To address the effect of fabric orientation on strength and stiffness, fabric orientation (3060 degrees first layer and 0-90 degrees second layer) of right side wrap in the test case $\mathrm{C}$ is compared with the fabric orientation (0-90 degrees first layer and 0-90 degrees second layer) of 
right side wrap in the test case B. In the test case B, at 800,000 cycles, the wrap's microstrain/unit load of strain gage 2 (Refer to Figure 5.8, 0-90,0-90 degrees) is $-17.8 \mu \in / \mathrm{kip}$. In the test case $C$, at 800,000 cycles, wrap's the microstrain/unit load ratio of strain gage 7 (Refer to Figure 5.9, 30-60,0-90 degrees) is $-8.5 \mu \in / \mathrm{kip}$. From these results, the microstrain/unit load ratio of fabric orientation of $0-90 \& 0-90$ resulted in stresses which are two times higher than the stresses for fabric orientation of $30-60 \& 0-90$. This indicates that there is a better stress distribution in case of 30-60, 0-90 degrees oriented wraps compared to 0-90 \& 0-90 degrees oriented wraps. It should be noted that the first layer of 30-60 degrees and the second layer 0-90 degrees were not wrapped continuously which is different from 0-90 \& 0-90 degrees fabrics which were wrapped continuously.

\subsubsection{Performance of Wrapped Crosstie Under 5-35 kips Fatigue Load Range Versus 3 - 53 kips Fatigue Load Range}

To evaluate the effect of fatigue load range on the strength and stiffness performance, results from strain gage 6 mounted at midspan in the test case $C$ are compared with the results from strain gage 1 mounted at midspan in the test case B.

According to Tables 5.3 and 5.4, the microstrain/load ratio in test case B (5-35 kips fatigue load) is less than the microstrain/load in test case C (3-53 kips fatigue load) by 1.25 times at 2,000,000 fatigue cycles. This shows that the fatigue load range has some effect ( $25 \%$ more stress when load range was increased) on the performance of wrapped crossties. The degradation rate of wrapped crosstie will increase with increasing fatigue load range. 


\subsubsection{Compositeness (Integrity) Between the Wrap and Crosstie}

To evaluate the degree of compositeness (integrity) between the wrap and the crosstie surface, strain gages 2 and 5 of test case C (Figure 5.9) are compared. As shown in Table 5.7, the microstrain/unit load for strain gages 2 and 5 (Figure 5.9) at 0 cycles are observed to be the same, indicating that there was no loss of compositeness between the wrap and the surface of crosstie. The strain gage 5 (Figure 5.9) failed to function after 600,000 fatigue cycles. However, comparing the strain/unit load at 600,000 cycles, it is again observed that there was no loss of compositeness.

To evaluate the degree of compositeness (integrity) between the wrap and the crosstie surface at the edge of a wrap, the microstrains/unit load from strain gages 1 and 4 of test case C (Figure 5.9) at 0 cycles are found to be different. The same is true for strain gages 2 and 4 and for strain gages 5 and 7 in the test case D. These results show that there is loss of bond at the edge area of wrap even before applying any fatigue cycles. In other words, the bond between the wrap and wood surface was lost in the wrapping process. This can be attributed to shrinkage of resin during curing.

\subsubsection{Theoretical Evaluation (Finite Beam on Elastic Foundation)}

In certain applications such as a rail road crosstie, a beam of relatively small bending stiffness is placed on elastic foundation and subjected to bending loads. The loads are transferred through the beam to the elastic foundation. We assume that the elastic foundation resists the loads transmitted by the beam or crosstie in our case, in a linearly elastic manner, i.e., the pressure developed at any point between the beam and the foundation is proportional to the deflection and bending moment of the beam at that point (Boresi and Schmidt, 1993). The 
assumption that the foundation responds linearly with beam deflection is fairly accurate for small deflections; however, in cases where deflections are large, the elastic foundation resistance may not remain linearly proportional to the beam deflection.

\subsubsection{Comparison between experimental deflection and theoretical deflection using finite}

\section{beam on elastic foundation theory}

Experimental deflection data of test case D at 30 kips load (at 400,000 fatigue cycles) was used to compare to theoretical deflection, using finite beam on elastic foundation theory (Hetenyi, 1983)

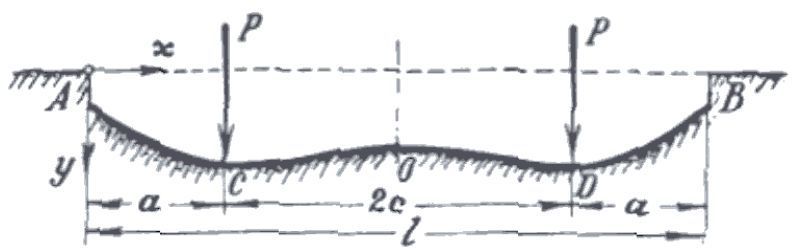

Modulus of Elasticity of Crosstie, $\mathrm{E}=1.1 \times 10^{6}$ psi. (From the experiment)

Modulus of foundation, $\mathrm{k}_{0}=200 \mathrm{lbs} . /$ in. $^{3}$ (field data, Hetenyi 1983)

Moment of Inertia, $I=\frac{b h^{3}}{12}=298.67 \mathrm{in}^{4} \quad(b=8$ in,$h=7$ in $)$

c $=30$ in. (Distance Between Center and Load)

$\mathrm{a}=21$ in. (Distance Between Load and Near End)

$1=102$ in. (Length of Crosstie)

$\mathrm{P}=15$ kips (Applied Single Load)

$\lambda=\sqrt[4]{\frac{k}{4 E I}}=\sqrt[4]{\frac{1600}{4\left(1.5 \times 10^{6}\right)(228.67)}}=0.03286 \mathrm{in}^{-1}$ 


$$
\begin{aligned}
& y_{C}=y_{D}=\frac{P \lambda}{2 k} \frac{1}{\sinh \lambda I+\sin \lambda I}\left\{\begin{array}{l}
2 \cosh ^{2} \lambda a(\cos \lambda c+\cosh \lambda I)+2 \cos ^{2} \lambda a(\operatorname{Cosh} 2 \lambda c+\cos \lambda I) \\
+\sinh 2 \lambda a(\sin \lambda c-\sinh \lambda I)-\sin \lambda a(\sinh 2 \lambda c-\sin \lambda)
\end{array}\right\} \\
& \therefore y_{C}=02014 \text { in (Theoretical Deflection) } \\
& y_{C}=0.2155 \text { in (Experimental Deflection) }
\end{aligned}
$$

Since the experimental deflection was only 7 percent higher than theoretical deflection it can be concluded that there was a good correlation between our test results and these from theory based on beam on elastic foundation. Shear deflection is neglected.

\subsubsection{Comparison between experimental bending moment and theoretical bending moment using finite beam on elastic foundation theory}

Experimental strain data (strain gage \# 3) of test case D at 30 kips load (at 400,000 fatigue cycles) was used to determine experimental bending moment, using finite beam on elastic foundation theory (Hetenyi, 1983)

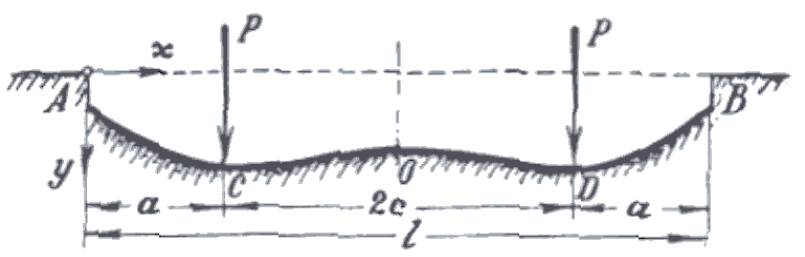

Modulus of Elasticity of Crosstie, $\mathrm{E}=1.1 \times 10^{6}$ psi. (From the experiment)

Modulus of foundation, $\mathrm{k}_{0}=200 \mathrm{lbs} . /$ in. $^{3}$

Moment of Inertia, $I=\frac{b h^{3}}{12}=298.67 \mathrm{in}^{4} \quad(b=8$ in,$h=7$ in $)$

c $=30$ in. (Distance Between Center and Load)

$\mathrm{a}=21$ in. (Distance Between Load and Near End) 
$1=102$ in. (Length of Crosstie)

$\mathrm{P}=15$ kips (Applied Single Load)

$\lambda=\sqrt[4]{\frac{k}{4 E I}}=\sqrt[4]{\frac{1600}{4\left(1.5 \times 10^{6}\right)(228.67)}}=0.03286 \mathrm{in}$

$M_{C}=M_{D}=\frac{P}{4 \lambda} \frac{1}{\sinh \lambda I+\sin \lambda I}\left[\begin{array}{l}2 \operatorname{Cosh}^{2} \lambda a(\cos \lambda c+\operatorname{Cosh} \lambda I)-2 \cos ^{2} \lambda a(\operatorname{Cosh} 2 \lambda c+\cos \lambda I) \\ -\sinh \lambda \lambda_{a}\left(\sin \lambda_{C}+\sinh \lambda I\right)-\sin \lambda a\left(\sinh \lambda \lambda_{C}+\sin \lambda I\right)\end{array}\right]$

$\therefore M_{C}=70,1131 \mathrm{bs}-$ in (Theoretical Bending Moment)

The following procedure is used to convert strain data into bending moment.

$$
\begin{aligned}
\sigma & =\frac{M C}{I} \\
\therefore M & =\frac{\sigma I}{C}=\frac{(E \varepsilon)(I)}{C}
\end{aligned}
$$

Substitute I,C and E to the above equation

Therefore $M=\frac{\left.\left(1.1 \times 10^{6}\right) 228.67\right) \varepsilon}{3.5}=7.84 \times 10^{7} \varepsilon \quad 1 . b s-$ in

Experimental strain data of test case $\mathrm{D}$ at 30 kip load $(\mathrm{P}=15$ kips.) was $997 \mu \varepsilon$.

$\left.\therefore M=\left(7.84 \times 10^{7}\right) 997 \times 10^{6}\right)=78,165$ 1bs- in (Experimental Bending Moment)

The experimental bending moment was higher than the theory by $11 \%$. The above comparison showed that there was a good correlation between the experimental bending moment and theoretical bending moment since the error was around 11 percent only.

\subsection{Conclusions}

Based on the limited fatigue test results, it can be concluded that: 
- Bending stress degradation of wrapped crosstie at midspan from 0 cycles to 2 million cycles was less than 5 percent while the degradation of non-wrapped crosstie was about 25 percent. ;

- Bond between wrap and crosstie is unaffected up to 600,000 fatigue cycles;

- No visible damage to the wrap or crosstie was noted up to 2 million fatigue cycles;

- Good correlation existed between test results and the results obtained from beams on elastic foundation theory. 
Table 5.1 Details of Fatigue Test Specimens and Parameters

\begin{tabular}{|c|c|c|c|c|c|}
\hline $\begin{array}{c}\text { Specimen } \\
\text { Number }\end{array}$ & $\begin{array}{c}\text { Test } \\
\text { Case }\end{array}$ & $\begin{array}{c}\text { Fatigue Load } \\
\text { Range (kips) }\end{array}$ & $\begin{array}{c}\text { Static Load } \\
\text { Range (kips) }\end{array}$ & $\begin{array}{c}\text { Total Number of } \\
\text { Fatigue Cycle } \\
\text { Applied }\end{array}$ & $\begin{array}{c}\text { Intervals at which } \\
\text { Static Tests are } \\
\text { Conducted }\end{array}$ \\
\hline 1 & A & 5 to 35 & 0 to 30 & $2,000,000$ & 200,000 \\
\cline { 2 - 6 } & B & 5 to 35 & 0 to 50 & $2,000,000$ & 400,000 \\
\hline 2 & C & 3 to 53 & 0 to 50 & $2,000,000$ & 200,000 \\
\hline 3 & D & 3 to 53 & 0 to 50 & $2,000,000$ & 200,000 \\
\hline
\end{tabular}

Note: 1 . Size 7 in. $x 8$ in. $x 102$ in. with additional details in Table 5.2

2. Maximum applied strain for test case A and B is $625 \mu \varepsilon$.

3. Maximum applied strain for test case $\mathrm{C}$ and $\mathrm{D}$ is $1200 \mu \varepsilon$.

Table 5.2 Details of GFRC Wrap in Different Specimens

\begin{tabular}{|c|c|c|c|c|c|c|c|}
\hline \multirow[t]{2}{*}{$\begin{array}{c}\text { Specimen } \\
\#\end{array}$} & \multirow[t]{2}{*}{$\begin{array}{l}\text { Test } \\
\text { Case }\end{array}$} & \multirow[t]{2}{*}{$\begin{array}{c}\text { Type of } \\
\text { Specimen }\end{array}$} & \multirow[t]{2}{*}{$\begin{array}{l}\text { Width of } \\
\text { Wrap (in.) }\end{array}$} & \multicolumn{2}{|c|}{ No. of Layers } & \multicolumn{2}{|c|}{$\begin{array}{c}\text { Fabric Orientation } \\
\text { (degrees) }\end{array}$} \\
\hline & & & & $\begin{array}{l}\text { Left } \\
\text { side }\end{array}$ & $\begin{array}{l}\text { Right } \\
\text { side }\end{array}$ & $\begin{array}{l}\text { Left } \\
\text { side }\end{array}$ & Right Side \\
\hline \multirow[t]{2}{*}{1} & A & $\begin{array}{l}\text { New non- } \\
\text { wrapped } \\
\text { crosstie }\end{array}$ & 16 & - & - & - & - \\
\hline & B & $\begin{array}{l}\text { New wrapped } \\
\text { crosstie }\end{array}$ & 16 & 2 & 2 & $0-90$ & $0-90$ \\
\hline 2 & $\mathrm{C}$ & $\begin{array}{l}\text { New wrapped } \\
\text { crosstie }\end{array}$ & 16 & 1 & 2 & $0-90$ & $30-60,0-90$ \\
\hline 3 & $\mathrm{D}$ & $\begin{array}{l}\text { Old wrapped } \\
\text { crosstie }\end{array}$ & 20 & 2 & 2 & $0-90$ & $0-90$ \\
\hline
\end{tabular}

Note 1 . Weight of glass fabric is $21 \mathrm{oz} . / \mathrm{yd}^{2}$.

2. The glass fabric weight in both different directions $(0-90,30-60)$ is equal. 
Table 5.3 Experimental Microstrain/Unit Load For Test Cases A and B

\begin{tabular}{|c|c|c|c|}
\hline \multicolumn{3}{|c|}{ Microstrain/Unit Load ( $\mu \in /$ kip) } \\
(Strain Gage 1 in Figures 5.7 and 5.8) \\
\hline $\begin{array}{c}\text { Non-wrapped crosstie } \\
(\text { Test Case A) }\end{array}$ & \multicolumn{2}{c|}{$\begin{array}{c}\text { Wrapped crosstie } \\
\text { (Test Case B) }\end{array}$} \\
\hline 0 Cycle & $2,000,000$ Cycles & 0 Cycle & $2,000,000$ Cycles \\
\hline 8.85 & 11.25 & 11.2 & 11.75 \\
\hline
\end{tabular}

Note 1. Negative sign means compressive stress.

2. Positive value means tensile stress. 
Table 5.4 Experimental Microstrain/Unit Load For Test Case C

\begin{tabular}{|c|c|c|}
\hline \multirow{2}{*}{$\begin{array}{c}\text { Strain Gage Number } \\
\text { Refer to Figure 5.9) }\end{array}$} & \multicolumn{2}{|c|}{ Microstrain/Unit Load $(\mu \in /$ kip) } \\
\cline { 2 - 3 } & 0 Cycle & $2,000,000$ Cycles \\
\hline 1 & -18.9 & -13.60 \\
\hline 2 & -11.95 & Strain Gage Not Working \\
\hline 3 & -1.60 & 2.20 \\
\hline 4 & -14.35 & -9.85 \\
\hline 5 & -11.95 & Strain Gage Not Working \\
\hline 6 & 18.10 & Strain Gage Not Working \\
\hline 7 & -11.55 & -2.65 \\
\hline 8 & -7.55 & -3.15 \\
\hline 9 & -4.90 & \\
\hline
\end{tabular}

Note 1. Microstrain/unit load of strain gage numbers 3,8 and 9 are small and may be susceptible to experimental inaccuracies.

2. Negative sign means compressive stress.

3. Positive value means tensile stress. 
Table 5.5 Experimental Microstrain/Unit Load For Test Case D

\begin{tabular}{|c|c|c|}
\hline \multirow{2}{*}{$\begin{array}{c}\text { Strain Gage Number } \\
\text { Refer to Figure 5.10) }\end{array}$} & \multicolumn{2}{|c|}{ Microstrain/Unit Load $(\mu \in /$ kip) } \\
\cline { 2 - 3 } & 0 Cycle & $2,000,000$ Cycles. \\
\hline 1 & 11.65 & Strain Gage Not Working \\
\hline 2 & 3.10 & Strain Gage Not Working \\
\hline 3 & Strain Gage Not Working & 2.70 \\
\hline 4 & 5.35 & -7.50 \\
\hline 5 & -1.60 & Strain Gage Not Working \\
\hline 6 & 24.10 & -4.20 \\
\hline 7 & Strain Gage Not Working & 24.85 \\
\hline 8 & & \\
\hline & &
\end{tabular}

Note 1. Microstrain/unit load of strain gage numbers 5 and 7 are small and may be susceptible to experimental inaccuracies.

2. Negative sign means compressive stress.

3. Positive value means tensile stress. 
Table 5.6 Experimental Deflection/Unit Load For Test Case A, B, C and D

\begin{tabular}{|c|c|c|c|c|}
\hline \multirow{2}{*}{ Test Case } & \multicolumn{3}{|c|}{ Deflection/Unit Load (in./kip) } \\
\cline { 2 - 5 } & \multicolumn{3}{|c|}{ 0 Cycle } & $2,000,000$ Cycles \\
\cline { 2 - 5 } & Wrap Location & Center of Crosstie & Wrap Location & Center of Crosstie \\
\hline A & - & 0.0011 & - & 0.0009 \\
\hline B & - & 0.0005 & - & 0.0008 \\
\hline C & 0.0026 & 0.0036 & 0.0021 & 0.0031 \\
\hline D & 0.0059 & 0.0074 & 0.0035 & 0.0046 \\
\hline
\end{tabular}

Table 5.7 Experimental Microstrain/Unit Load of Strain Gage \# 2, 5 for Test Case C

\begin{tabular}{|c|c|c|c|c|}
\hline $\begin{array}{c}\text { Strain Gage \# } \\
\text { (Test Case C ) }\end{array}$ & \multicolumn{4}{|c|}{ Microstrain/Unit Load ( $\mu \varepsilon /$ kip) } \\
\cline { 2 - 5 } & $\begin{array}{c}0 \\
\text { cycle }\end{array}$ & $\begin{array}{c}200,000 \\
\text { cycles }\end{array}$ & $\begin{array}{c}600,000 \\
\text { cycles }\end{array}$ & $\begin{array}{c}800,000 \\
\text { cycles }\end{array}$ \\
\hline$\# 2$ (on wood ) & -11.95 & -10.95 & -6.3 & -9.45 \\
\hline$\# 3$ (on wrap) & -11.95 & -9.9 & -6.05 & Failed \\
\hline
\end{tabular}

Note 1. Negative sign means compressive stress.

2. Positive sign means tensile stress. 


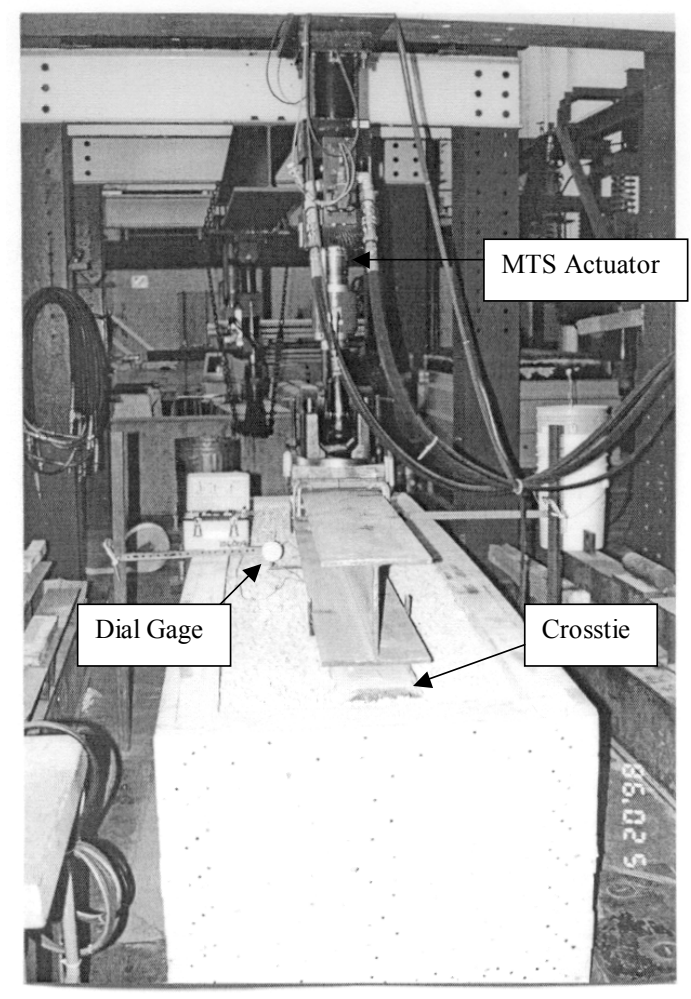

Figure 5.1 Fatigue Test Set-up

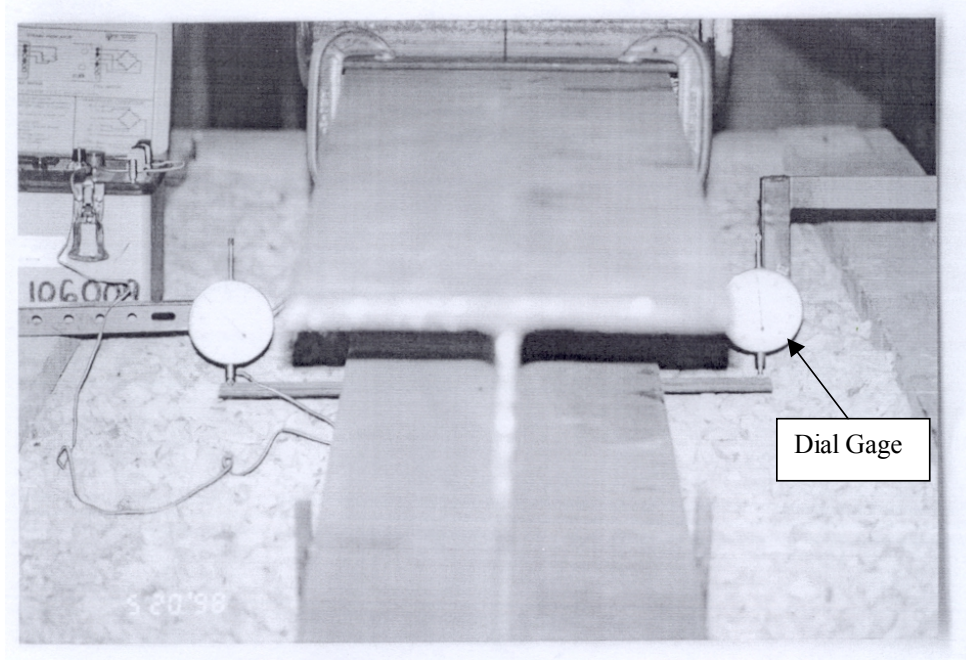

Figure 5.2 Instrumentation 


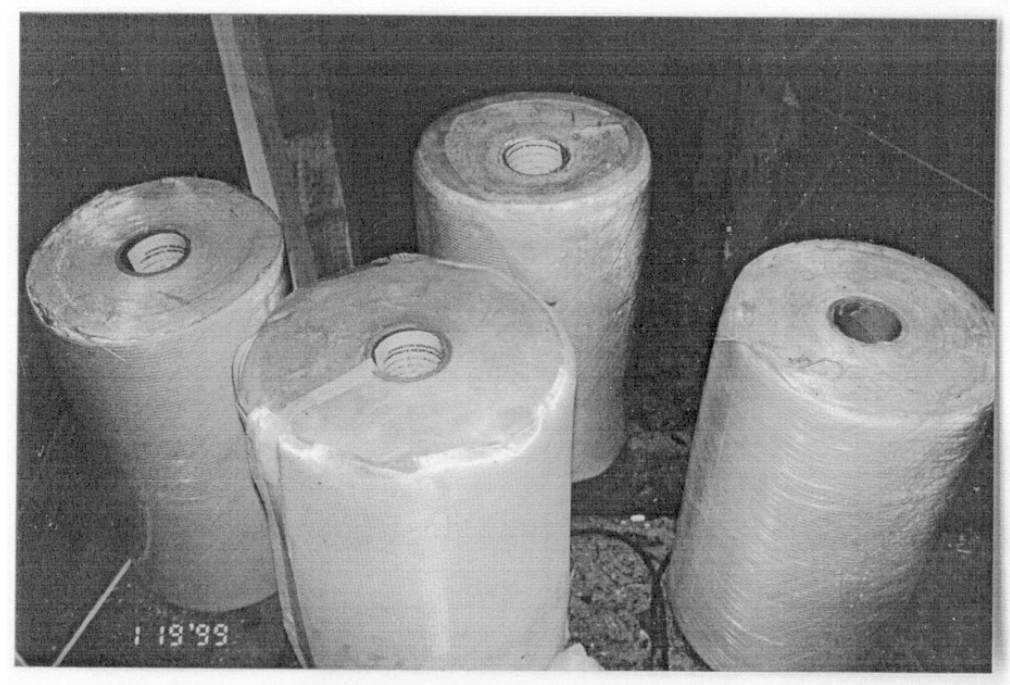

Figure 5.3 Glass Fabric Used for Wrapping

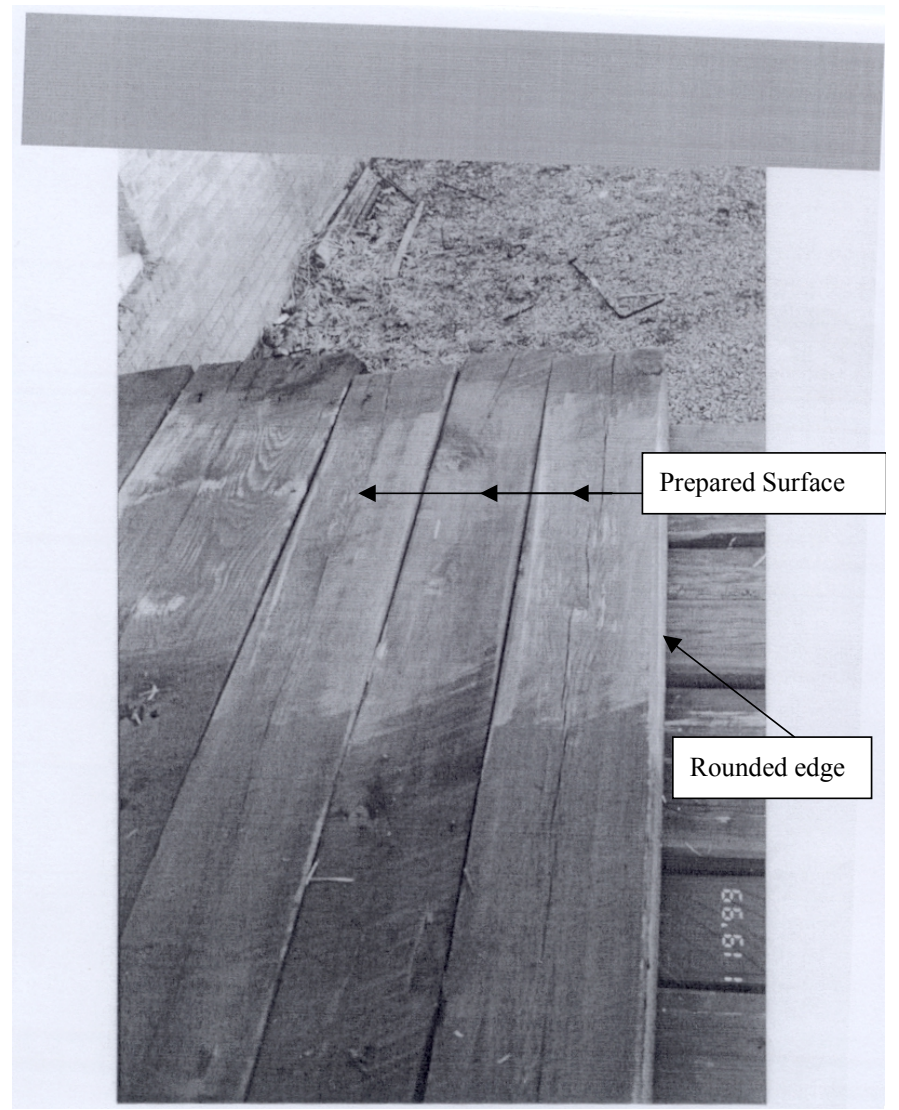

Figure 5.4 Crossties with Prepared Surface and Rounded Edges 


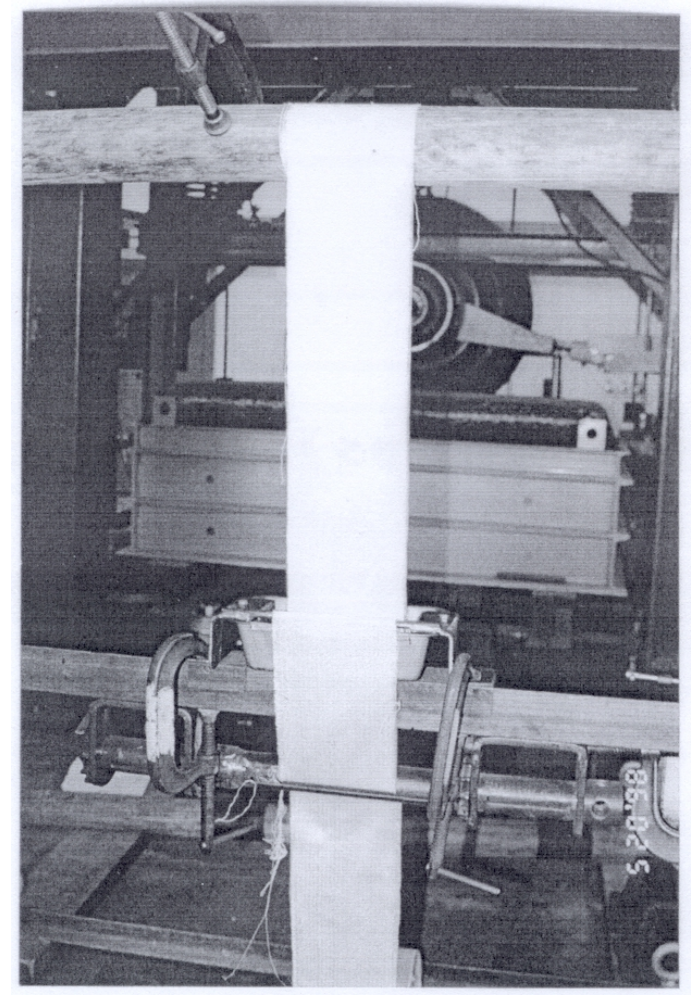

Figure 5.5 Banding Machine Used for Wrapping

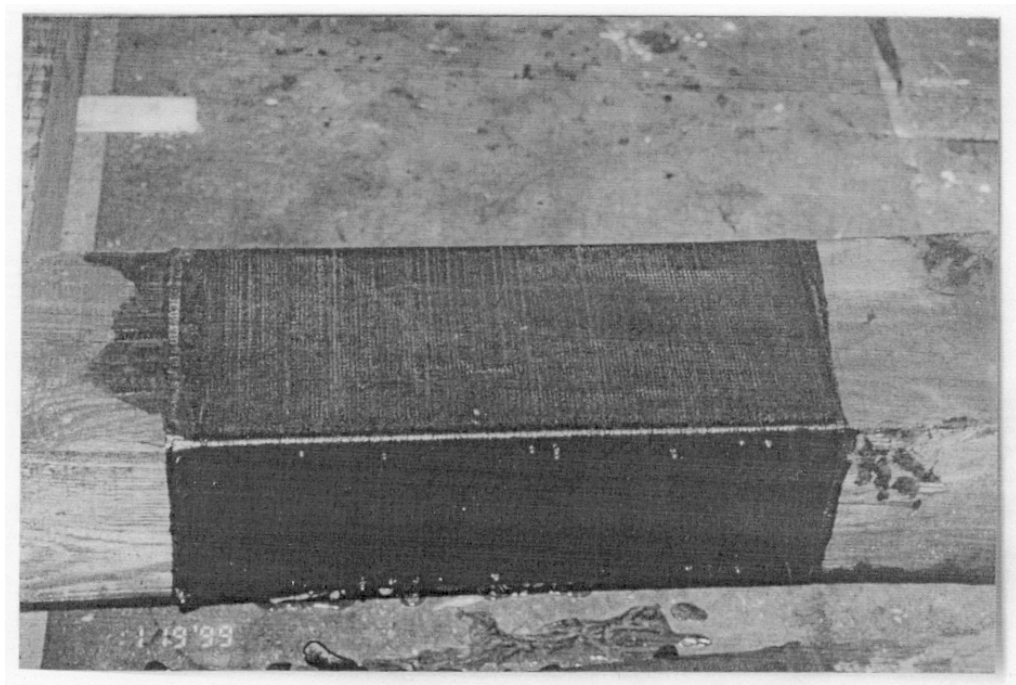

Figure 5.6 Crosstie Wrapped at Rail-Seat Location 


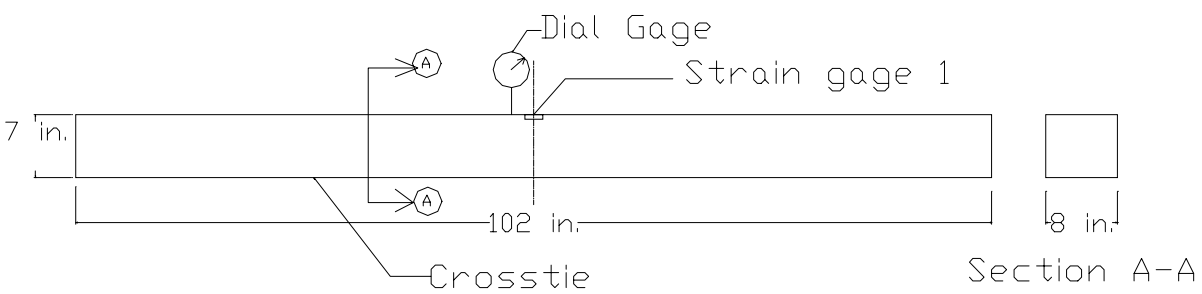

Fig. 5.7 Detall of Specimem 1 for Test Case A

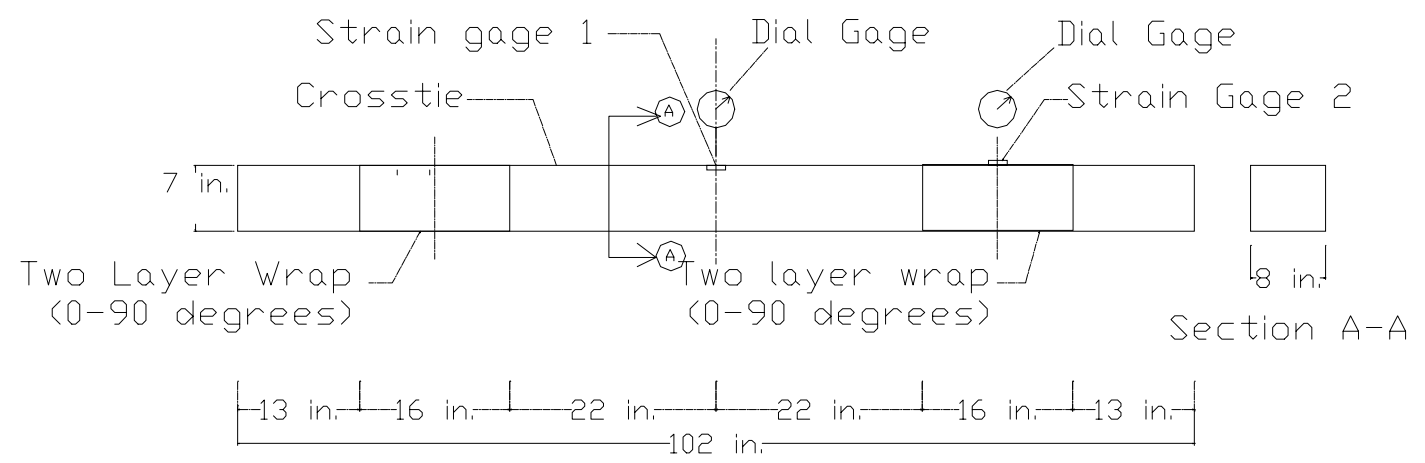

Fig. 5.8 Detail of Specimem 1 for Test Case B 


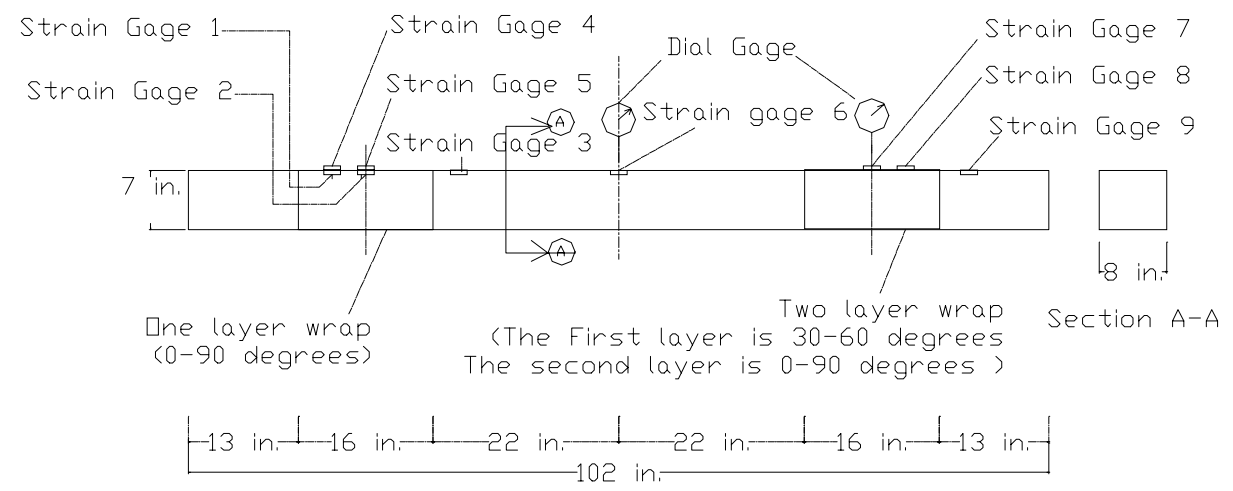

Fig. 5.9 Detail of Specimem 2 for Test Case C

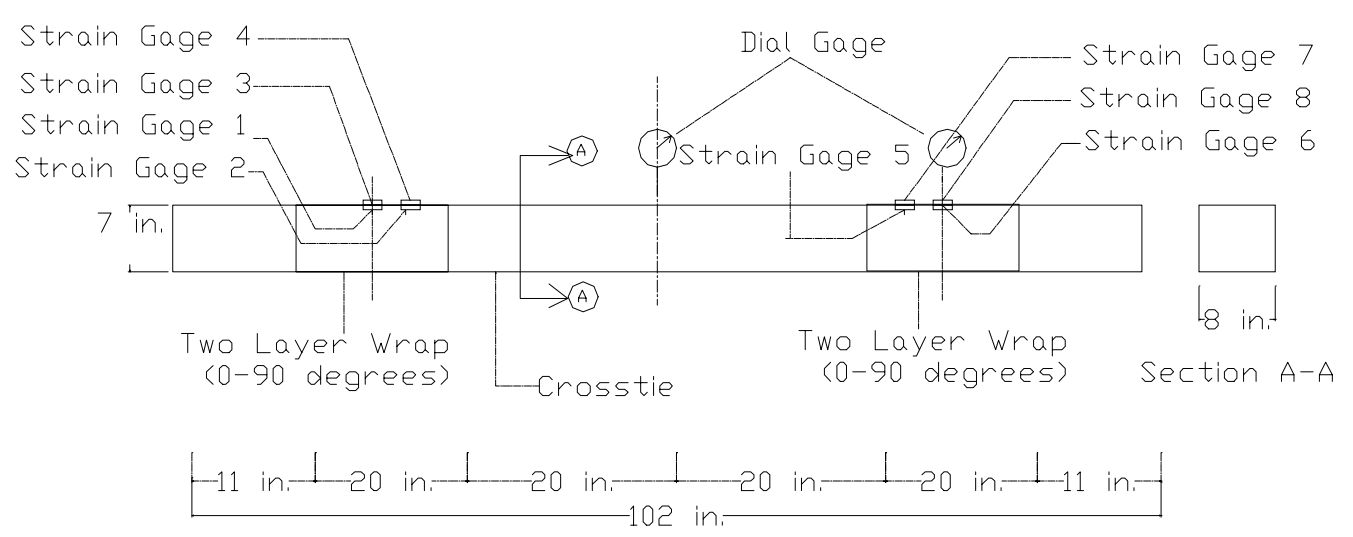

Fig. 5.10 Detail of Specimem 3 for Test Case D 


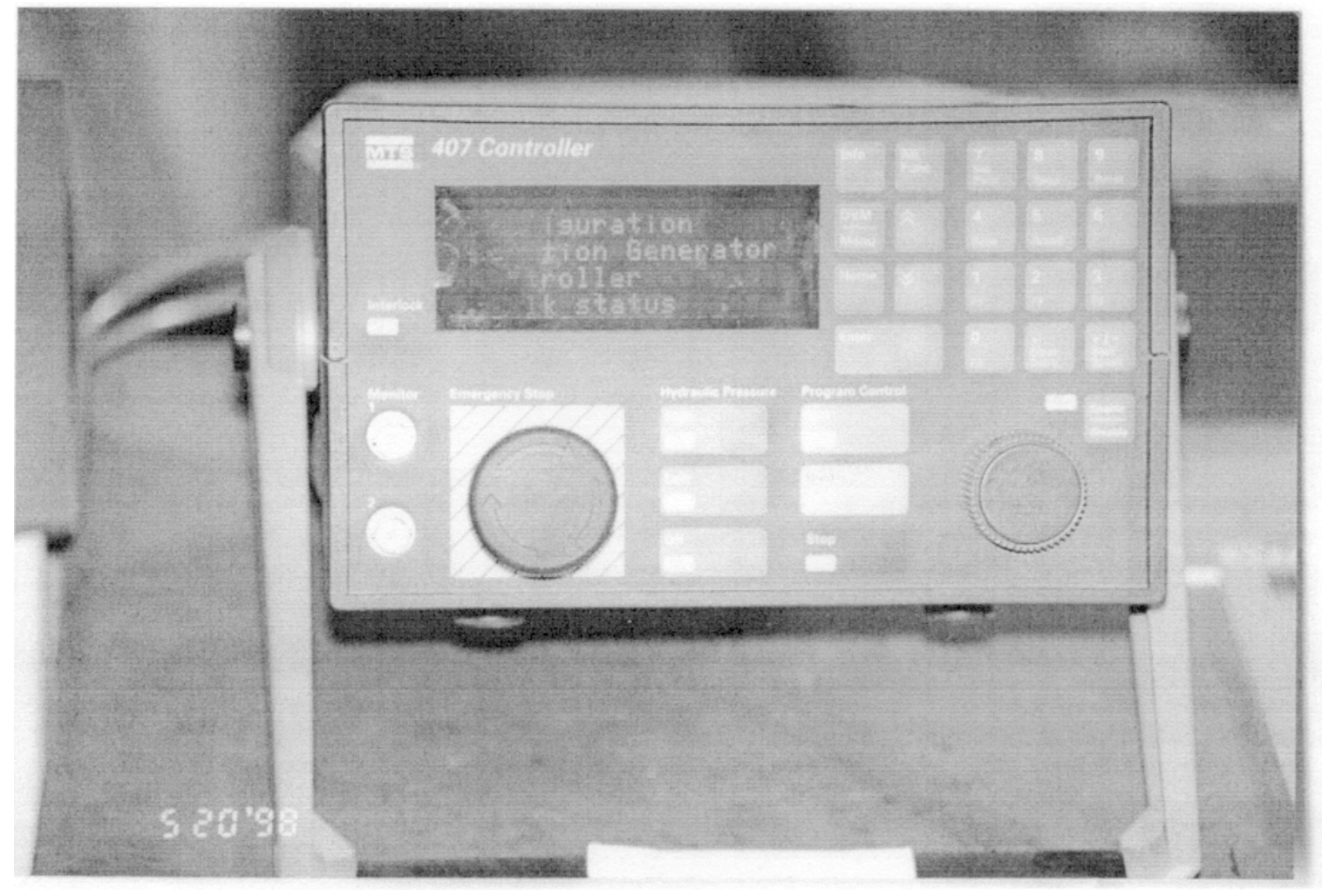

Figure 5.11 MTS 407 Load Controller 


\section{Chapter 6}

\section{Installation and Monitoring of Full Scale GFRC Crosstie in the Field}

\subsection{Introduction}

The replacement of the ties is done by visual judgment. Inspectors use visual judgment to decide on the replacement scheme. Splitting, decay and plate cutting of ties are the main damages, which usually occur on ties. To improve the durability and service life of a crosstie, GFRC wood crosstie was studied and installed in the field to monitor.

\subsection{Objective of this component of the research are :}

6.2.1 To install full scale GFRC wood crosstie in the field.

6.2.2 To monitor the performance of GFRC wrapped crosstie in terms of their field durability.

\subsection{Installation of Crossties}

Spikes were removed from field installed ties using a spike puller. Old ties were cut into smaller sections, which are easily removed from the track. Workers cleaned the space in the ballast shoulder to make room for new ties before their placement. Tie plates were replaced and respiked. Careful supervision was required to insure that the ties were square with the track.

\subsubsection{Materials}

Full Scale Crosstie : Red oak wood crosstie was used to wrap and install in the track. The dimension of each wrapped crosstie was 7 in. $x 9$ in. $x 102$ in..

GFRC System : E-glass fabric $\left(0-90^{\circ}\right.$ degree $)$ with appropriate sizing was used to wrap in two layers. 
Adhesive System : Resorcinol Formaldehyde, G1149-A, was used as primer. A combination of G1131-A and G1131-B was used as resin.

\subsection{Instrumentation}

Strain Gages (CEA-06-500uw-120): Since the crossties have to be monitored for several years, traditional strain gages might not survive in harsh environments. Hence, by increasing contact area between strain gage and crosstie might increase the durability of strain gage in the field. Therefore, the strain gages were mounted on a thin aluminum strip (0.75 in.x2.00 in.x0.004 in. thickness) and calibrated before installing in the field. The calibration method is described in section 6.4.1.

Dial Gages : Dial gage was used to measure deflection.

Locomotive : Locomotive (E-180) was used to apply load in the field.

\subsubsection{Calibration test for strain on thin metal strip}

A beam sample ( 3.75 in. $x 2.75$ in. x 51 in. long ) was made from red oak. Strain gages without metal strip was mounted on the beam sample at one third of the beam from the end. The strain with metal strip was mounted on the beam at one third of the beam from the other end. A three point bending test was conducted on the beam sample. The strains (compressive and tensile ) were measured at both ends. The results are shown in Figures 6.1 and 6.2 


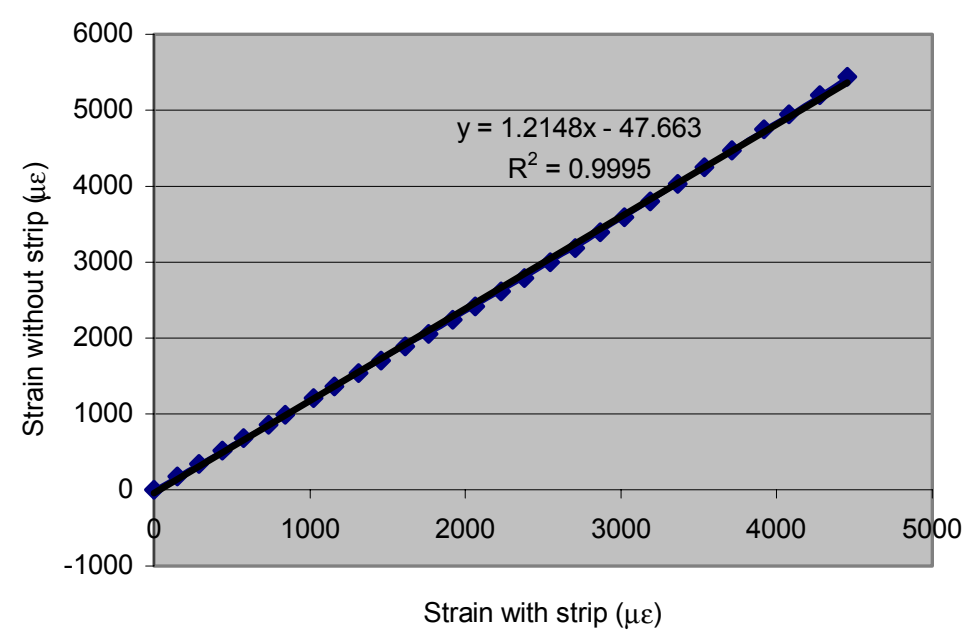

Figure 6.1 Tensile Strain with aluminum strip Versus without aluminum strip

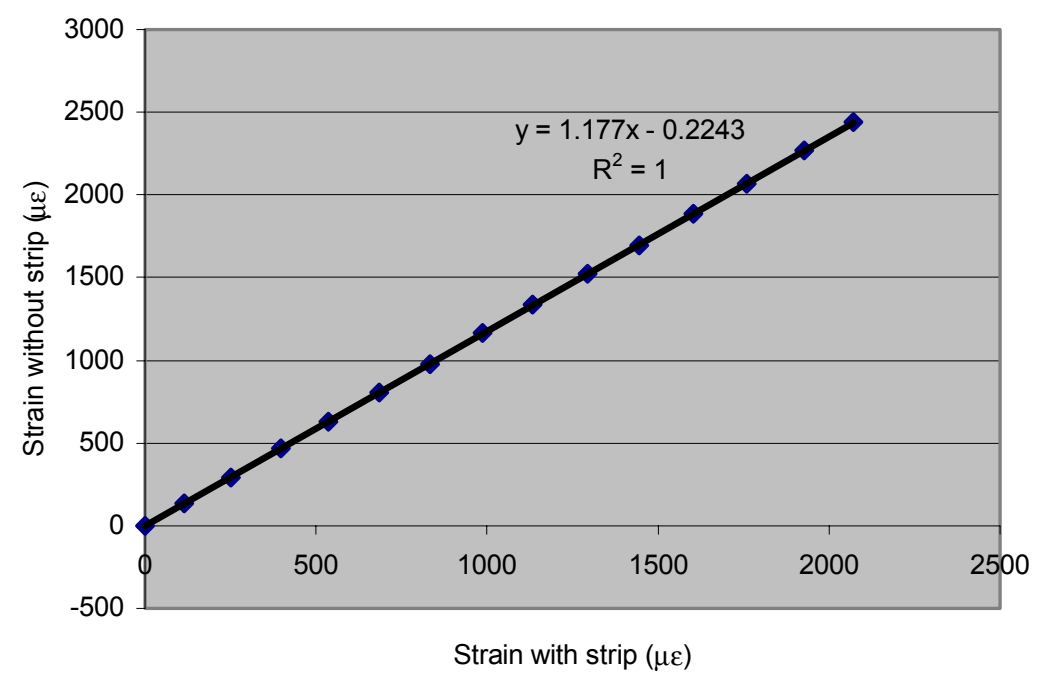

Figure 6.2 Compressive Strain with aluminum strip Versus without aluminum strip

According to Figures 6.1 and 6.2, we get two equations for compressive and tensile strain.

In case of Tensile Strain $\quad: y=1.2148 x-47.66$

In case of Compressive Strain : $y=1.177 x-0.2243$ 
Note $\quad y=$ strain without aluminum strip

$x=$ strain with aluminum strip

\subsection{Monitoring Procedure}

The experimental program consisted of monitoring deflection, strain, lateral movement, gage change, spike-pulling force and moisture content of non-wrapped and wrapped crossties. The crossties were monitored at frequent periods. Details of the types of measurements are shown in Table 6.1. The crossties

Table 6.1 Detail of various types of measurement

\begin{tabular}{|l|c|c|}
\hline \multirow{2}{*}{ Types of Measurement } & \multicolumn{2}{|c|}{ Number of Crossties Monitored } \\
\cline { 2 - 3 } & Non-Wrapped Crosstie & Wrapped Crosstie \\
\hline 1. Deflection and Strain Measurement & 2 & 4 \\
\hline 2. Lateral Movement Measurement & 1 & 1 \\
\hline 3. Gage Change Measurement & 1 & 2 \\
\hline 4. Spike Pulling Force Measurement & 2 & 1 \\
\hline 5. Moisture Content Measurement & - & \\
\hline
\end{tabular}

6.5.1 Deflection and Strain Measurement : Deflections and strains were measured on four wrapped crossties and two non-wrapped crossties. The locations of deflection and strain measurements for wrapped and non-wrapped crossties are shown in Figure 6.3 and Figure 6.4 respectively. Deflections and strains were measured without locomotive on the crossties, and with the rear axis of a locomotive on the crossties. 


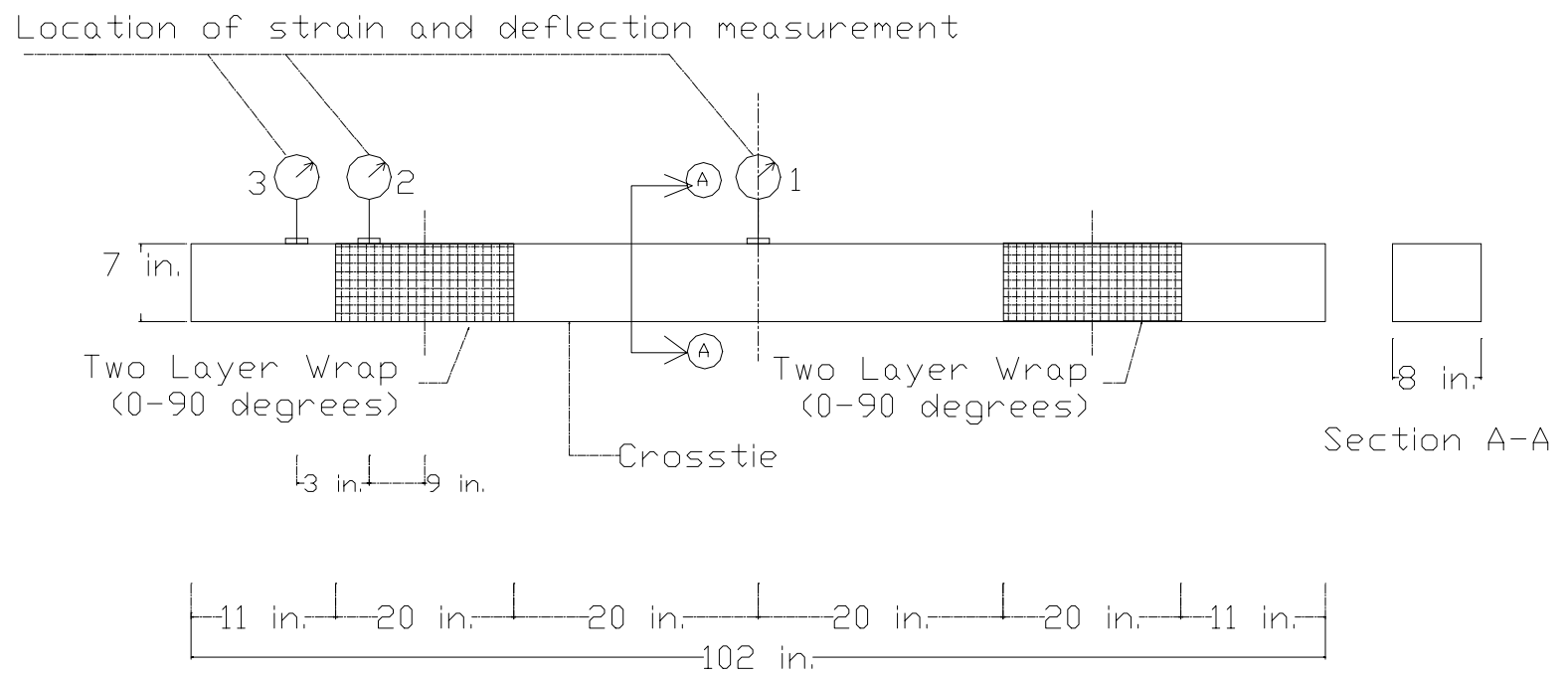

Figure 6.3 Location of Strain and Deflection Measurement for Wrapped Crosstie

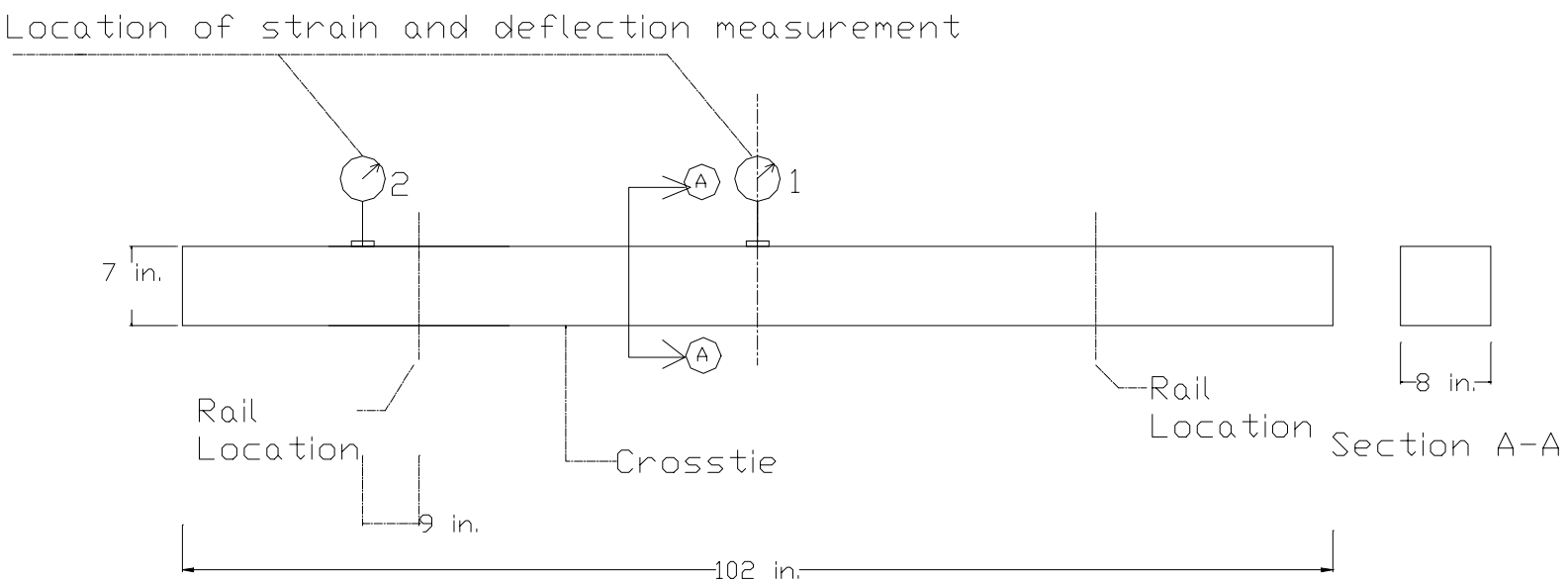

Figure 6.4 Location of Strain and Deflection Measurement for Non-Wrapped Crosstie 
6.5.2 Lateral Movement Measurement : The lateral movements of crossties were measured on non-wrapped and wrapped crossties. To find the lateral movement, a steel rod was driven into the ground as a reference point ( Figure 6.5 ). The distance ' $d 1$ ' between the reference point (steel rod) and the edge of crosstie (a non-wrapped and a wrapped crosstie) was measured at certain time intervals as shown in table 6.6.3.

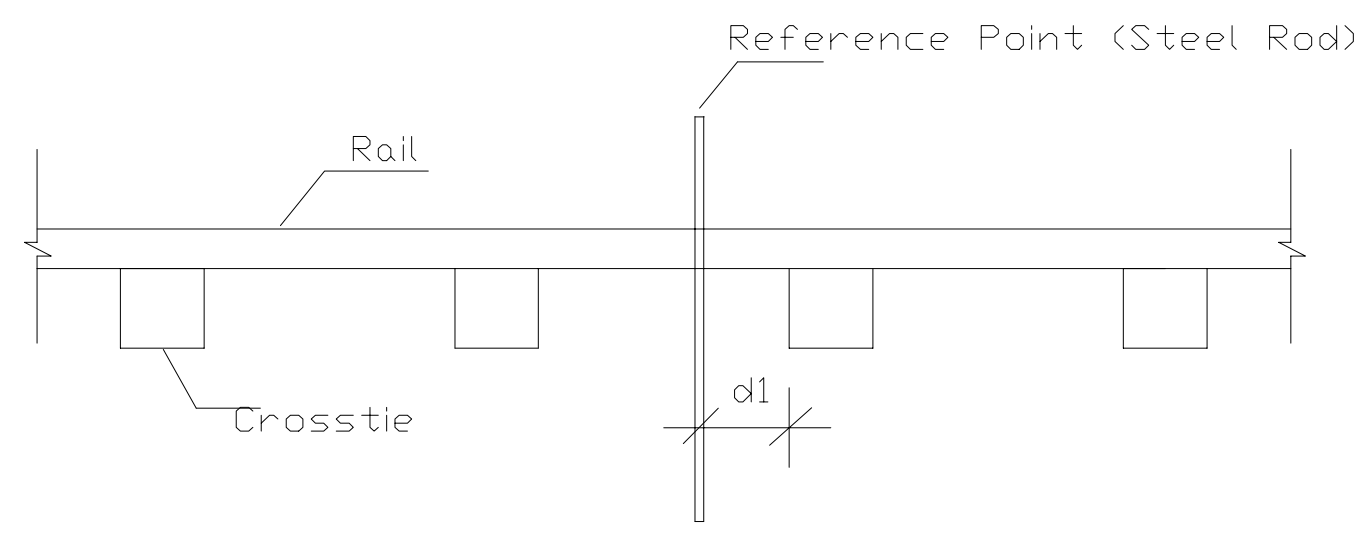

Figure 6.5 Details of Lateral Movement Measurement

6.5.3 Gage Change Measurement : Gage length between the rails was measured using a turn buckle (Figure 6.6). First, the initial length (L) of a turn buckle was measured. A reference point was marked on the rails. The turn buckle was then fixed between the reference points (marked on the rails) to measure the distance ' $\mathrm{d} 2$ '. The gage length between the rails was taken as ' $\mathrm{L}+\mathrm{d} 2$ '. The change in gage length was measured at frequent periods to obtain gage change in the crossties. 


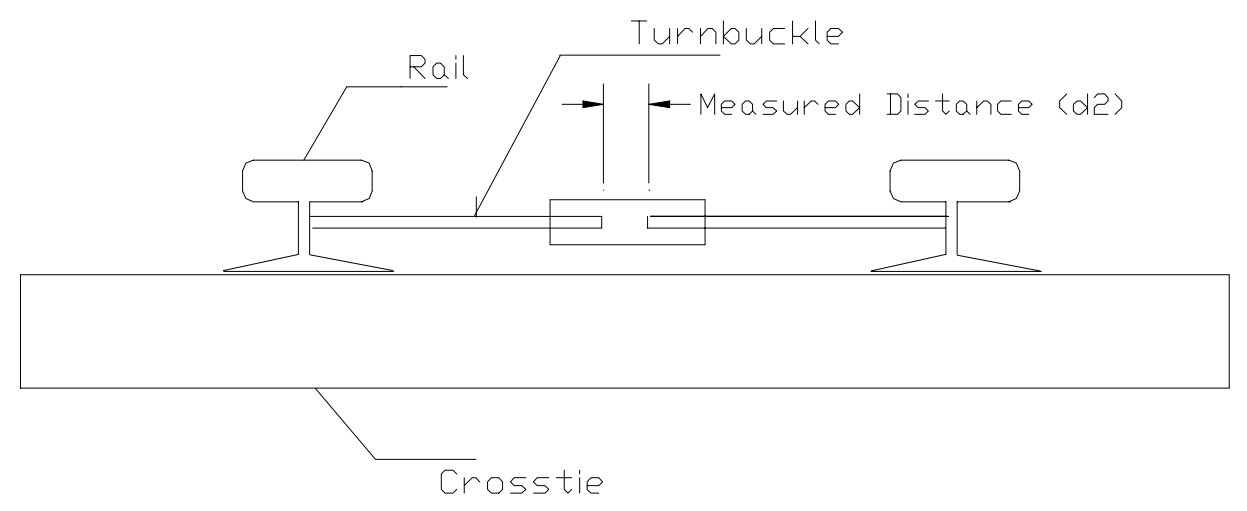

Figure 6.6 Details of Gage Length Measurement

6.5.4 Spike Pulling Force Measurement : Spike pulling force measurement was conducted on two non-wrapped and wrapped crossties. To determine the spike pulling force, the spikes were driven into crosstie through steel plate and pulled out while the force was measured. A bolt and a nut were attached to the spike to insert a threaded rod that was used to pull the spike out. The nut ( 1 in. diameter) was welded on the top of the spike (Figure 6.7). The bolt was then tightened to the nut, which was welded to the spike, to distribute the hammer impact over the bolt while the spike was driven into the crosstie.

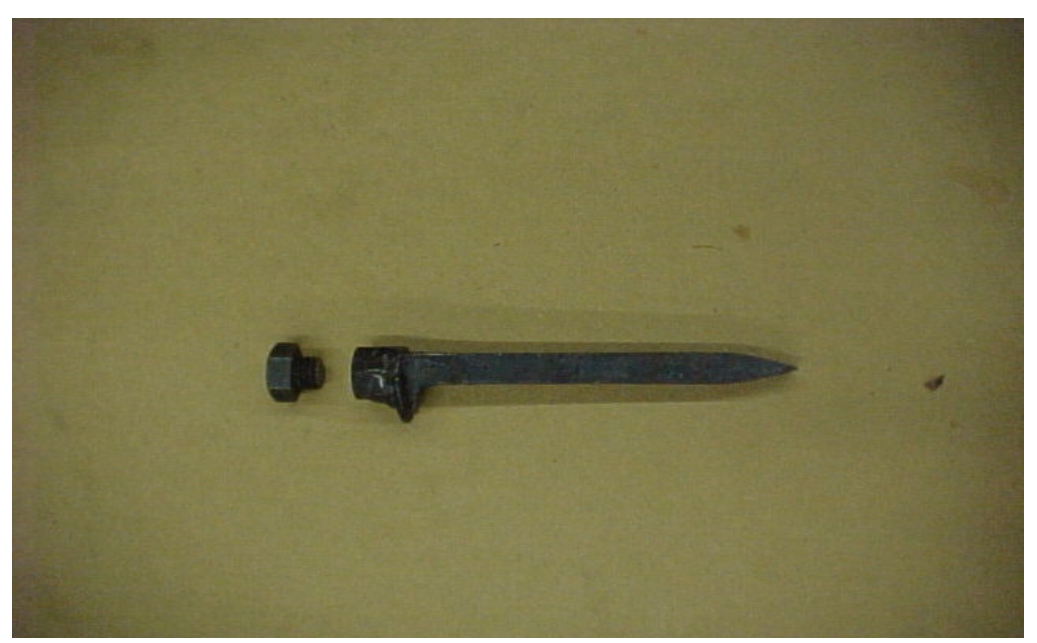

Figure 6.7 Spike and Bolt 
After the spike was driven in to crosstie, the bolt was loosened and a threaded rod was screwed into the nut as shown in Figure 6.8. A steel frame was built to support the threaded rod, load cell and hydraulic jack. The spike was pulled out by hydraulic jack and the spike pulling force was measured using the load cell.

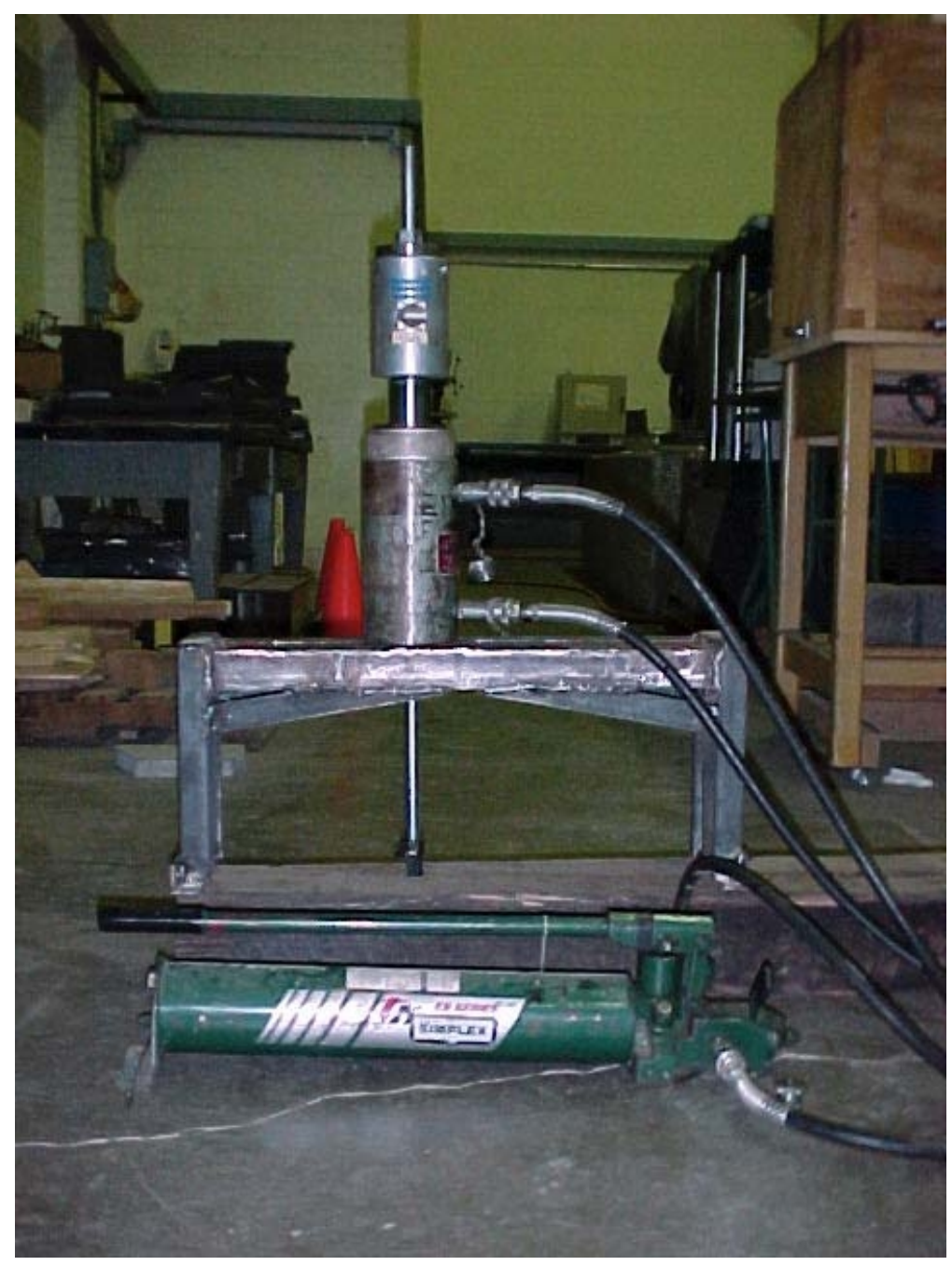

Figure 6.8 Set up of Pulling Spike Force

6.5.5 Moisture Content Measurement : Moisture content is the amount of water contained in the wood, usually expressed as a percentage of the mass of the oven-dry wood. The moisture content measurement was conducted on two wrapped crossties. Two cylindrical 
samples (1/2" dia. X 1" deep) were cut from each wrapped crosstie, one at midspan of a crosstie (which is non-wrapped area) and the other at the end of a crosstie (which is wrapped area) as shown in Figure 6.9. Moisture content was measured in the two samples as per ASTM D444292, Method B (Appendix B).

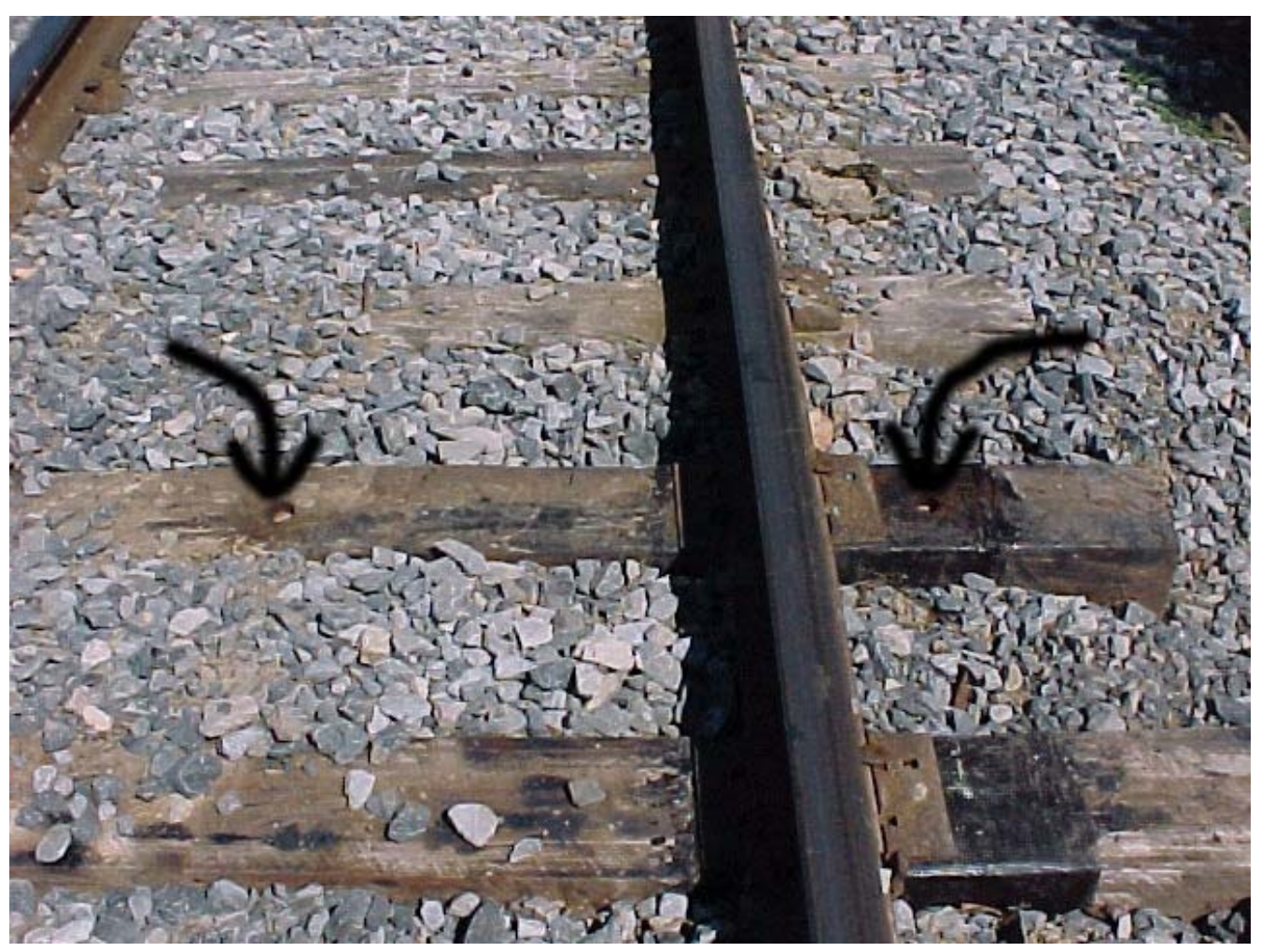

Figure 6.9 The location of two cylindrical samples cut from wrapped crosstie (See Arrow) 
6.6 Results

Table 6.6.1 Strain Measurement (See Figure 6.3 and 6.4 for point 1, 2, 3)

\begin{tabular}{|l|c|c|c|c|c|c|c|c|c|}
\hline \multirow{2}{*}{ Specimen No. } & \multicolumn{9}{|c|}{ Strain $(\mu \varepsilon)$ at } \\
\cline { 2 - 12 } & \multicolumn{3}{|c|}{ July 15,00 } & \multicolumn{3}{c|}{ Aug 29,00 } & \multicolumn{3}{c|}{ Oct 18,00 } \\
\cline { 2 - 11 } & Point 1 & Point 2 & Point 3 & Point 1 & Point 2 & Point 3 & Point 1 & Point 2 & Point 3 \\
\hline 1. Wrap \#1 & -2 & -60 & -13 & -1 & -53 & -14 & -39 & -52 & -16 \\
\hline 2. Wrap \#2 & 422 & -112 & -80 & 452 & -145 & -88 & 343 & -161 & -86 \\
\hline 3. Non-Wrap \#3 & 673 & -21 & - & 641 & -52 & - & 563 & -48 & - \\
\hline 4. Wrap \#4 & 437 & -100 & -5 & 311 & -76 & -4 & 317 & -272 & -24 \\
\hline 5. Wrap \#5 & 74 & -312 & -46 & 140 & -241 & -35 & 147 & -326 & -31 \\
\hline 6. Non-Wrap \#6 & 287 & -245 & - & 570 & -689 & - & 109 & -481 & - \\
\hline
\end{tabular}

Note + sign means tensile stress

- sign means compressive stress 
Table 6.6.2 Deflection Measurement (See Figure 6.3 and 6.4 for point 1, 2, 3)

\begin{tabular}{|l|c|c|c|c|c|c|c|c|c|}
\hline \multirow{2}{*}{ Specimen No. } & \multicolumn{7}{|c|}{ Deflection (0.001) at } \\
\cline { 2 - 11 } & \multicolumn{3}{|c|}{ July 15,00 } & \multicolumn{3}{|c|}{ Aug 29,00 } & \multicolumn{3}{c|}{ Oct 18,00 } \\
\cline { 2 - 12 } & Point 1 & Point 2 & Point 3 & Point 1 & Point 2 & Point 3 & Point 1 & Point 2 & Point 3 \\
\hline 1. Wrap \#1 & 101 & 70 & 68 & 100 & 66 & 56 & 98 & 64 & 65 \\
\hline 2. Wrap \#2 & 89 & 304 & 352 & 116 & 334 & 330 & - & - & - \\
\hline 3. Non-Wrap \#3 & 33 & 116 & - & 33 & 234 & - & 34 & 97 & - \\
\hline 4. Wrap \#4 & 108 & 206 & 220 & 121 & 235 & 247 & 120 & 189 & 190 \\
\hline 5. Wrap \#5 & 30 & 49 & 52 & 21 & 70 & 84 & 26 & 30 & 28 \\
\hline 6. Non-Wrap \#6 & - & - & - & 204 & 403 & $*$ & $*$ & $*$ & $*$ \\
\hline
\end{tabular}

Note $*=$ Measurements could not be taken due to large foundation settlement.

Table 6.6.3 Lateral Movement

\begin{tabular}{|l|c|c|c|c|c|}
\hline \multirow{2}{*}{ Specimen No. } & \multicolumn{5}{|c|}{ Distance, d (in.) } \\
\cline { 2 - 6 } & Mar 31,00 & May 30,00 & July 8,00 & Aug 29,00 & Oct 18,00 \\
\hline 1. Wrap \#1 & 3.42 & 3.37 & 3.36 & 3.38 & 3.37 \\
\hline 2. Non-Wrap \#1 & 4.84 & 4.92 & 4.89 & 4.84 & 4.88 \\
\hline
\end{tabular}


Table 6.6.4 Gage Change Measurement

\begin{tabular}{|l|l|l|l|l|c|}
\hline \multirow{2}{*}{ Specimen No. } & \multicolumn{5}{|c|}{ Gage Length of Crosstie (in.) } \\
\cline { 2 - 6 } & Mar 31,00 & May 30,00 & July 8,00 & Aug 29,00 & Oct 18,00 \\
\hline 1. Wrap \#1 & 57.14 & 59.67 & 59.67 & 59.65 & 58.24 \\
\hline 2. Non-Wrap \#1 & 56.62 & 58.84 & 59.03 & 58.88 & 57.74 \\
\hline
\end{tabular}

Table 6.6.5 Spike-Pulling Force Measurement

\begin{tabular}{|l|c|c|c|}
\hline \multirow{2}{*}{ Specimen No. } & \multicolumn{3}{|c|}{ Spike- Pulling Force (kips) } \\
\cline { 2 - 4 } & Mar 31,00 & May 30,00 & July 8,00 \\
\hline 1. Wrap \#1 & - & 7.04 & 9.8 \\
\hline 2. Non-Wrap \#1 & - & 4.04 & 7.4 \\
\hline
\end{tabular}

Table 6.6.6 Moisture Content Measurement

\begin{tabular}{|l|l|c|c|c|c|}
\hline \multirow{2}{*}{ Specimen No. } & \multirow{2}{*}{ Location of Sample } & \multicolumn{4}{|c|}{ Moisture Content (\%) } \\
\cline { 3 - 6 } & & Mar 31,00 & May 30,00 & July 8,00 & Dec 1,00 \\
\hline 1. Wrap \#1 & Wrap Area & 15.52 & 13.46 & - & 14.45 \\
\cline { 2 - 6 } & Non-Wrap Area & 14.26 & 12.34 & - & 13.33 \\
\hline 2. Wrap \#2 & Wrap Area & 23.37 & 18.44 & - & 19.30 \\
\cline { 2 - 6 } & Non-Wrap Area & 22.88 & 17.11 & - & 18.21 \\
\hline
\end{tabular}




\subsection{Conclusion}

- Over a period of 6 months, there was no significant lateral movement in crossties for both non-wrapped and wrapped cases (Table 6.6.3).

- The change in gage length over a period of 6 months is less than $4 \%$ for both nonwrapped and wrapped crossties (Table 6.6.4). This might be attributed to the temperature changes.

- $\quad$ Spike pulling force for a wrapped crosstie was about $30 \% \sim 70 \%$ more than the non-wrapped crossties (Table 6.6.5). This might be contributed to the enhancement in strength in the wrapped crossties.

- The moisture content of the samples taken from the wrapped area is about $2 \%$ to $9 \%$ more than that of samples taken from the non-wrapped area (Table 6.6.6). It is because moisture cannot escape from the wrapped area as fast as in non-wrapped area.

- Deflection of non-wrapped crosstie \#6 (Table 6.6.2) was relatively higher than that of wrapped crossties. It may be due to the fact that the foundation under crosstie \#6 may not have uniform stiffness or full contact area.

- Bending stresses of crossties \# 2,3 and 4 (Table 6.6.1) at point 1 (midspan) were higher than those at other points in the same crosstie. It might be thought that glass fabric should be wrapped at midspan region also because of higher induced bending stress in that region.

- The crossties have to be monitored continuously to obtain additional strain and deflection data for better understanding of durability of wrapped crossties over nonwrapped crossties. 


\section{Chapter 7}

\section{Conclusions and Recommendations}

The following sections describe conclusions and recommendation on the current work.

\subsection{Conclusions}

- The primer/resin combination of G1149A/G1131A + G1131B is recommended for wrapping crossties because they have high bond strength and high percentage of wood failure for creosote treated wooden crossties compared to other primer/resin combinations (Table 3.3).

- The primer/resin combination of G1260/Epoxy did not survive the stresses induced under accelerated aging process.

- During wrapping of crossties, tension should be applied uniformly to glass fabric (wrap materials) to ensure good bond between the wrap and the crossties.

- Glass fiber should be saturated thoroughly with low viscosity resin while crossties are wrapped.

- For a half scale crossties, glass fiber reinforcement enhanced flexural rigidity by 44 percent and shear modulus by 18 percent.

- In the half scale wrapped crossties, no significant change is noted in flexural rigidity before and after applying accelerated aging technique.

- The wrapped crossties were able to withstand fatigue to 2 million fatigue cycles without any damage. 
- In full scale wrapped crossties, there was no debonding between glass fabric and crosstie up to 600,000 fatigue cycles.

- There is a good correlation in deflection and bending moment of crossties between the experimental and theoretical results (using finite beam theory on elastic foundation).

- The lateral movement and gage change of crossties were not affected in the field over a period of 6 months.

- The moisture content of test samples taken from the wrapped area was about $2 \%$ to $9 \%$ more than that of samples taken from the non-wrapped area (Table 6.6.6) because moisture cannot evaporate in the wrapped area as quickly as in the non- wrapped area.

- Spike pulling force for a wrapped crosstie was about 30\% 70\% more than the nonwrapped crossties (Table 6.6.5). This might be attributed to the enhancement in strength in the wrapped crossties.

\subsection{Recommendations}

- The crossties have to be monitored continuously for strain and deflection to study their long term structural performance.

- The dynamic response of crossties with wrap should be evaluated to ensure adequate damping of wrapped crossties.

- Accelerated aging technique should be applied on a full scale specimen to obtain trends in performance reduction if any, and then simulate that data with those from the field. 
- Cost effectiveness of refurbished crossties has to be evaluated after collecting inservice performance data over a five year period. 


\section{References}

1. American Society of Testing and Materials, 1980, Standard Method of Test for Shear of Adhesive by Compression Loading, ASTM D 905, Philadelphia, PA

2. American Society of Testing and Materials, 1980, Standard Test Methods for Direct Moisture Content Measurement of Wood and Wood-Base Materials, ASTM D 4442-92, Philadelphia, PA

3. A.N. Talbot (1920), "Second Progress Report of Special Committee to Report on Stresses in Railroad Track", Proceeding of the AREA, Vol. 21 pp 645-814.

4. Chang B. An (M.S. Thesis, 1993), "Experimental Investigation of Fatigue Behavior of Stress-Laminated Timber Deck”, West Virginia University

5. Caster, D.W. (August 1981), Testing and Evaluation of Adhesives and Bonded Products, "Adhesive Bonding of Wood and Other Structural Materials", Clark C. Heritage Memorial Workshop on Wood, Madison, WI

6. Damodar R. Talakanti (M.S. Thesis, 1997 ), "Testing and Evaluation of Wood-GFRC Adhesive Interface Integrity Under Accelerated Aging and Mechanical Fatigue”, West Virginia University

7. M. Hetenyi (1983 ), "Beams on Elastic Foundation”, pp 38-47 and pp 56-58

8. M. L. Selbo, "Adhesive Bonding of Wood”, Forest Products Laboratory - Forest Service U.S. Department of Agriculture, pp 65, August 1975

9. Poo Chow, S. L. Lewis, A. J. Reinschmidt, E. J. Barenberg (1987), “Effects of Natural and Accelerated Aging on Oak Crossties", American Wood-Preservers' Association Proceedings 
10. Rowlands, R. E. (1986) , R. P. Van Deweghe, T. L. Laufenberg, and G.P. Krueger, “Fiber-Reinforced Wood Composites" Wood Fiber and Science pp 39-57

11. Talbot, Arthur N., Chairman, "Second Progress Report of the Special Committee to Report on Stresses in Railroad Track," Proceedings of the AREA, Vol. 21, 1920; and Transactions ASCE, Vol.83, 1920.

12. William W. Hay (1982), “Cross ties”, Railroad Engineering, pp436-469 


\section{Appendix A}

\section{ASTM D 905}

\section{Standard Test Method for Strength Properties of Adhesive Bonds in Shear by Compression Loading}

\section{A.1 Scope}

A.1.1 This test method covers the determination of the comparative shear strengths of adhesive bonds of different types of adhesives used for bonding wood and other similar materials, when tested on a standard specimen under specified conditions of preparation, conditioning, and loading in compression. This test method is intended primarily as an evaluation of adhesives for wood.

A.1.2 The values stated in SI units are to be regarded as the standard. The values given in parentheses are provided for information purposes only.

A.1.3 This standard does not purport to address all of the safety concerns, if any, associated with its use. It is the responsibility of the user of this standard to establish appropriate safety and health practices and determine the applicability of regulatory limitations prior to use.

\section{A.2 Referenced Document}

A.2.1 ASTM Standard : - D 143 Methods of Testing Small Clear Specimens of Timber and D 907 Terminology of Adhesives

\section{A.3 Terminology}

A.3.1 Definitions - Many terms in this test method are defined in Terminology D907 
A.3.1.1 Shear, n-in an adhesively bonded joint, stresses, strain, or failure resulting from applied forces that cause adjacent planes of a body to slide parallel in opposite directions.

\section{A.4 Significance and Use}

A.4.1 It cannot be assumed that this test method measures the true shear strength of the adhesive bond. Many factors interfere or bias the measurement including the strength of the wood, the specimen, the shear tool designs themselves, and the rate of loading.

A.4.1.1 Wood failure is very common in joints made with strong adhesives. Although high wood failure is normally desired, when it occurs the measured strength is lower than the true adhesive bond strength.

A.4.1.2 Stress concentrations at the notches of the specimen tend to lower the measured strength. In a similar test for the shear strength of solid wood, ASTM Methods such as D 143, these effects are self correcting so that the measured strength is close to the true shear strength of the wood. By analogy the same may be true in this test method, however, other factors are also involved and may alter the relationship.

A.4.1.3 The rate of loading affects the strength of an adhesive bond according to the adhesive's properties. The higher viscoelastic nature of the adhesive will lead to greater effect or strength. Thermosetting adhesives like urea- and phenol-formaldehyde are elastic. Their bond strengths can be measured over a range of loading rate from 0.038 to $1.27 \mathrm{~cm} / \mathrm{min}(0.015$ to $0.5 \mathrm{in} . / \mathrm{min}$ ) with no apparent affect. Thermoplastic adhesives like polyvinyl acetate, hot melts, and elastomer-based adhesives exhibit a broad range of elastic, viscoelastic, and plastic behaviors. Their bond strengths will be affected to varying degrees by changing the loading rate. Generally, increasing the rate of loading increases the measured strength. 
A.4.2 This test method is suitable for product research and development, qualifying adhesives in accordance with certain product or performance specifications, and monitoring bonding process control. This test method may be suitable for comparing and selecting adhesives, however, such comparisons must be made with caution since the measured strength of some adhesives may be different in different types of joints. Strength values obtained by this test method are not suitable as design shear strengths values without adjustment by certain engineering design factors.

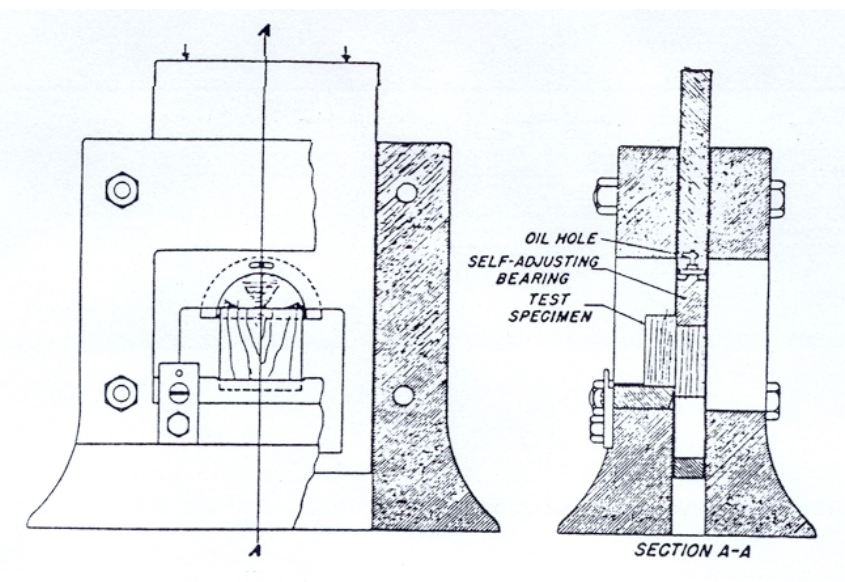

Figure A.1 Shearing Tool

\section{A.5 Apparatus}

A.5.1 The testing machine shall have a capacity of not less than $6,810 \mathrm{~kg}(15,000 \mathrm{lb})$ in compression and shall be fitted with a shearing tool containing a self-aligning seat to ensure uniform lateral distribution of the load. The machine shall be capable of maintaining a uniform rate of loading such that the load may be applied with a continuous motion of the movable head to maximum load at a rate of $5 \mathrm{~mm}(0.20 \mathrm{in}$.)/min with a permissible variation of $\pm 25 \%$. The shearing tool shown in Figure A.1 has been found satisfactory. The testing machine shall be 
located in an atmosphere such that the moisture content of the specimens developed under the conditions prescribed in Section 8 is not noticeably altered during testing.

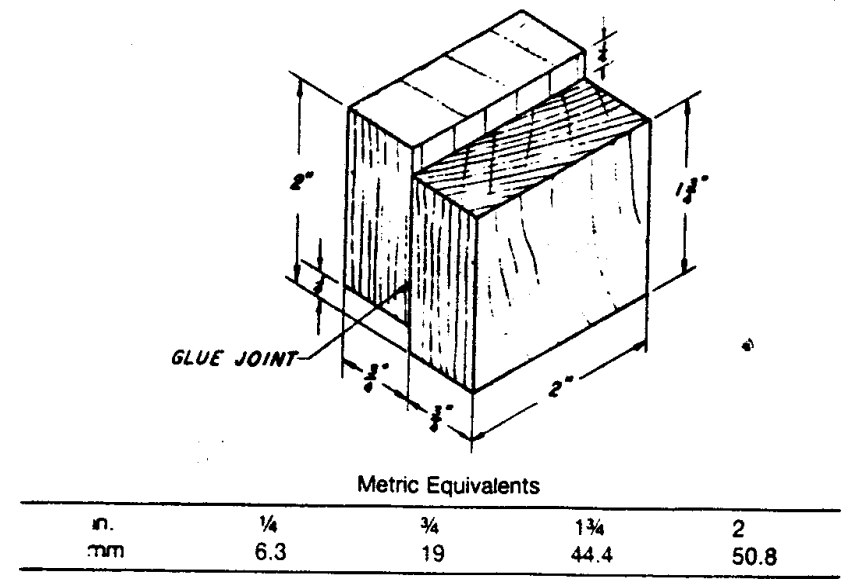

Figure A.2 Form and Dimensions of Test Specimen

\section{A.6 Test Specimens}

A.6.1 Test Specimens shall conform to the form and dimensions as shown in Fig A.2. The specimens shall be cut from test joints prepared as described in Sections A.7 and A.8.

A.6.2 At least 20 specimens shall be tested, representing at least four different joints.

\section{A.7 Preparation of Test Joints}

A.7.1 Hard maple blocks (Acer saccharum or Acer nigrum), having a minimum specific gravity of 0.65 based on oven-dry weight and volume shall be selected (see Note). These blocks shall be of straight grain and free from defects including knots, birdseye, short grain, decay, and any unusual discolorations within the shearing area. The blocks shall be of suitable size preferably so that five test specimens may be cut from one test joint as shown in Figure A.3. Blocks approximately 19 by 63.5 by $304 \mathrm{~mm}$. ( 0.75 by 2.50 by $12 \mathrm{in}$.) have been found to be 
satisfactory for this purpose. The grain direction shall be parallel to the longest dimension of the block. The blocks shall be at the equilibrium moisture content recommended by the manufacturer of the adhesive. In the absence of such recommendation, the moisture content shall be from 10 to $12 \%$ based on oven-dry weight as determined on representative samples in accordance with the “Moisture Determination" section of Methods D 143. The blocks shall be surfaced, just prior to gluing, preferably with a hand-feed jointer, and the blocks weighed and assembled in pairs so that blocks of approximately the same specific gravity are glued together. The surfaces shall remain unsanded and shall be free from dirt.

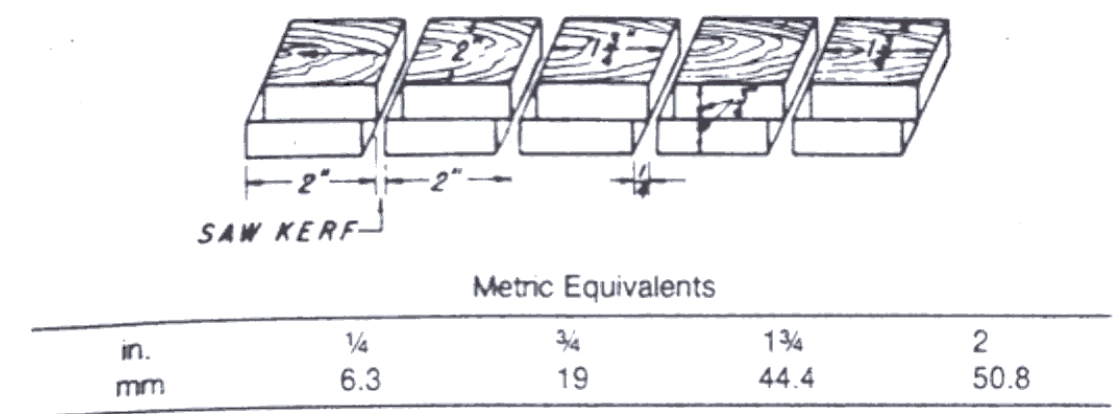

Figure A.3 Test Joint Showing Method of Cutting Five Test Specimens

Note- A method for selecting maple blocks of satisfactory specific gravity is described in the Appendix to this method. For referee tests, the specific gravity described in the "Specific Gravity and Shrinkage in Volume" section of Methods D143.

A.7.2 The adhesive shall be prepared and applied to the blocks in accordance with the procedure recommended by the manufacturer of the adhesive. The glue-coated blocks shall then be assembled and pressed, likewise in accordance with the recommendations of the manufacturer of the adhesive. 


\section{A.8 Conditioning of Test Joints}

A.8.1 The joints, upon removal from pressure shall be conditioned at a relative humidity of $50 \pm 2 \%$ and at a temperature of $23 \pm 1^{\circ} \mathrm{C}\left(73.4 \pm 2^{\circ} \mathrm{F}\right)$ either for a period of 7 days or until specimens reach equilibrium as indicated by no progressive changes in weight, whichever is the shorter period. The length of this period of conditioning may be extended beyond this limit by written agreement between the purchaser and the manufacturer of the adhesive.

\section{A.9 Preparation of Specimens}

A.9.1 Cut the specimens as shown in Figure A.3 so that the grain direction is parallel to the direction of loading during test. Take care in preparing the test specimens to make the loaded surfaces smooth and parallel to each other and perpendicular to the height. Take care also in reducing the lengths of the laminations to $44.4 \mathrm{~mm}$. (1.75 in.) to ensure that the saw cuts extend to, but not beyond, the glue line. Measure the width and length of the specimen at the glue line to nearest $0.25 \mathrm{~mm}(0.010 \mathrm{in}$.$) to determine the shear area.$

A.9.2 Retain specimens in the conditioning atmosphere described in Section A.8 until tested, except during the cutting operations.

\section{A.10 Procedure}

A.10.1 Place the test specimen in the shearing tool so that the load may be applied as described in Section A.5. The position of the specimen in one type of shearing tool is shown in Figure A.1. Apply the loading with a continuous motion of the movable head at a rate of $5 \mathrm{~mm}$ (0.20 in.)/min to failure as prescribed in Section A.5. 


\section{A.11 Calculation}

A.11.1 Calculate the shear stress at failure in pounds-force per square inch (or kilopascals) based on the glue line area between the two laminations measured to the nearest

$0.06 \mathrm{~cm}^{2}\left(0.01\right.$ in. $\left.^{2}\right)$, and report for each specimen together with the estimated percentage of wood failure. 


\section{Appendix B}

\section{ASTM D 4442-92}

\section{Standard Test Methods for Direct Moisture Content Measurement of Wood}

\section{(For Method A)}

\section{B.1. Scope}

B.1.1 These test methods cover the determination of the moisture content (MC) of solid wood, veneer, and other wood-base materials, including those that contain adhesives and chemical additives. The test methods below describe primary (A) and secondary (B through D) procedures to measure moisture content :

$$
\begin{aligned}
& \text { Method A - Primary Oven-Drying Method } \\
& \text { Method B - Secondary Oven-Drying Method } \\
& \text { Method C - Distillation (Secondary) Method } \\
& \text { Method D - Other Secondary Methods }
\end{aligned}
$$

B.1.2 The primary oven-drying method (Method A) is intended as the sole primary method. It is structured for research purposes where the highest accuracy or degree of precision is needed.

B.1.3 The secondary method (B through D) are intended for special purposes or under circumstances where the primary procedure is not desired or justified. In these procedures, moisture content values cannot be reported with an accuracy greater than integer percentage values. However, a greater level of accuracy may be reported if the appropriate primary procedures are used. 
B.1.4 Distillation (secondary) method is intended for use with materials that have been chemically treated or impregnated such that the oven-drying procedures introduce greater error than desired in the results.

B.1.5 This standard does not purport to address all of the safety concerns, if any, associated with its use. It is the responsibility of the user of this standard to establish appropriate safety and health practices and determine the applicability of regulatory limitations prior to use.

\section{B.2 Referenced Documents}

\section{B.2.1 ASTM Standards}

D9 Terminology Relating to Wood

D 4933 Guide for Moisture Conditioning of Wood and Wood-Base Materials

\section{B.3 Terminology}

\section{B.3.1 Definition :}

B.3.1.1 Moisture content - the amount of water contained in the wood, usually expressed as a percentage of the mass of the oven-dry wood (in accordance with Terminology D 9).

B.3.1.1.1 Discussion - The moisture content of wood or other wood-based materials can be expressed on either as a percentage of oven-dry mass of the sample (oven-dry basis) or as a percentage of initial mass (wet basis). The methods described in this standard refer to the ovendry basis. Because oven-dry mass is used, moisture content values may exceed $100 \%$. The term moisture content when used with wood-based materials can be misleading since untreated wood frequently contains varying amounts of volatile compounds (extractives which are evaporated when determining moisture content). Definition of the moisture content of wood is 
further complicated when determined by a thermal method because of thermal degradation, which causes the final moisture-free mass to decrease from small but continuous losses.

\section{B.4 Significance and Use}

Moisture content is one of the most important variables affecting the properties of wood and wood-base materials. The procedures in these test methods are structured to permit the full range of use from fundamental research to industrial processing. Method $\mathrm{A}$ is designed for obtaining the most precise values of moisture content consistent with the needs of the user. It also provides means of assessing variability contributed by the oven or specimen hygroscopicity , or both. In addition, criteria are described for defining the endpoint in oven-drying. Method A is the reference (primary) standard for determining moisture content of wood and wood-base materials. Methods B through D are secondary methods to permit relatively simple procedures of measuring moisture content, but with less precision than Method A. However, greater precision may be obtained with supporting data by using the appropriate procedures in Method A.

\section{B.5 Method A - Oven-Drying (Primary)}

B.5.1 Apparatus

B.5.1.1Oven- A forced-convection oven that can be maintained at a temperature of $103 \pm 2{ }^{\circ} \mathrm{C}$ throughout the drying chamber for the time required to dry the specimen to endpoint shall be used. Ovens shall be vented to allow the evaporated moisture to escape.

Note 1 - The ratio of sample to chamber volume and the air velocity within the oven are not critical as long as temperature and relative humidity within the oven are constant. Room relative humidity should be less than $70 \%$ relative humidity, at which condition the oven 
is at $1.7 \%$ relative humidity. For best precision, drying should be carried out in a constant relative humidity room with the relative humidity as low as possible.

B.5.1.2 Balance - Based on a 10-g (oven-dry) specimen, minimum readability of the balance shall be determined by the desired reporting level of precision:

$\begin{array}{cc}\text { Reporting Precision Level. MC \% } & \text { Minimum Balance Readability, mg } \\ 0.01 & 1 \\ 0.05 & 5 \\ 0.1 & 10 \\ 0.5 & 50 \\ 1.0 & 100\end{array}$

For the other-dry mass levels, the sensitivity requirement shall be scaled approximately.

B.5.2 Test Material - Any conveniently sized wood or wood-based material can be used, consistent with the use of closed weighing jars (B.5.4.6) and the balance readability (B.5.1.2).

Note 2 - If specimens contain any degree of volatilizable material other than water, it may be necessary to either use Method C or run Method A and C concurrently.

B.5.3 Calibration and Standardization - Determination of specimen variability requires a separate measurement of the contribution of variability within the oven.

B.5.3.1 Determination of Oven Variability - This section permits a separate evaluation of the oven variability from that of specimens distributed in the oven.

B.5.3.1.1 Specimen Selection and Preparation- Douglas-fir shall be ground to sawdust and that fraction contained in a 40/60 mesh screen used. The sample origin or drying history is not critical. The sawdust shall be tumbled in a closed container until thoroughly mixed. All replicates shall be prepared at the same time from the same batch of material. All material shall be transferred and stored in air-tight weighing jars. 
B.5.3.1.2 Equilibration - The moisture content of the specimen is not important if the preparation techniques described under B.5.3.1.1 are used. Equilibration is not required, although it is preferable that the material be as uniform as possible in moisture content.

B.5.3.1.3 Number and Location of Specimens - Each test shall consist of a set of eight replicated specimens. These shall be located at third-point positions with respect to height, width, and depth of the oven cavity. With this scheme four samples will be positioned on each of two shelves at one third and two thirds of the cavity height.

B.5.3.2 Determination of Combined Specimen and Oven Variability- Procedures are the same as B.5.3.1.1 through B.5.3.1.3 except that specimens of any origin and size or shape can be used. Calculate variability by the equation in 5.5.2.

B.5.3.3 Procedure - Use the primary oven-drying procedure (B.5.4)

\section{B.5.4 Procedure}

B.5.4.1 Specimens to be equilibrated shall be processed as in Guide D 4933

B.5.4.2 Store specimens in individual vapor-tight containers if any delay could occur between sampling and weighing.

B.5.4.3 Weigh the specimens using a balance consistent with the desired precision (see B.5.1.2).

B.5.4.4 Place specimens in the oven within the volume tested for oven precision.

B.5.4.5 Endpoint-Assume that the endpoint has been reached when the mass loss in a 3-h interval is equal to or less than twice the selected balance sensitivity. For example, with a $10-\mathrm{g}$ 
(oven-dry) specimen, the balance sensitivity for $0.01 \% \mathrm{MC}$ precision is $0.1 \mathrm{mg}$ (see B.5.1.2), therefore, dry to $0.2 \mathrm{mg}$ or less mass loss in a 3-h period.

B.5.4.6 Handling and Weighing Procedures - Dried samples shall be stored in a desiccator with fresh desiccant until they have reached room temperature. All weighings shall be carried out using closed weighing jars.

\section{B.5.5 Calculations:}

B.5.5.1 Calculate moisture content as follows :

$$
\mathrm{MC}, \%=(\mathrm{A}-\mathrm{B}) / \mathrm{B} \times 100
$$

Where :

$\mathrm{A}=$ original mass, $\mathrm{g}$, and

$\mathrm{B}=$ oven-dry mass, $\mathrm{g}$.

Example - A specimen of wood weighs 56.70 g. After oven-drying, the mass is $52.30 \mathrm{~g}$.

$\mathrm{MC}, \%=(56.70-52.30) / 52.30 \times 100$

$$
=(4.40 / 52.30) \times 100=8.4 \%
$$

Note 3 - If wood has been treated with a nonvolatile chemical and if the mass of the retained chemical is known, the moisture content may be determined as follows:

$$
\mathrm{MC}, \%=(\mathrm{A}-\mathrm{B}) / \mathrm{D} \times 100
$$

Where :

$\mathrm{D}=\mathrm{B}$ minus mass of retained chemical in sample. 


\section{Appendix C}

\section{Experimental Data for Chapter 4}

$\underline{\text { Table C.4.1 }}$

\section{All data on Specimen\# 1 ( 38 in. span)}

\begin{tabular}{|c|c|c|c|c|c|c|c|c|c|}
\hline Load & \multicolumn{3}{|c|}{$\begin{array}{c}\text { Strain on Wood } \\
(\mu \varepsilon)\end{array}$} & \multicolumn{2}{|c|}{$\begin{array}{c}\text { Strain on Fabric } \\
(\mu \varepsilon)\end{array}$} & \multicolumn{3}{|c|}{$\begin{array}{l}\text { Deflection } \\
\text { (in ) }\end{array}$} & \multirow{2}{*}{$\begin{array}{l}\text { Load } \\
\text { (kips) }\end{array}$} \\
\hline (kips) & $\begin{array}{l}\text { Non- } \\
\text { Wrap }\end{array}$ & Wrap & $\begin{array}{c}\text { Wrap }+ \\
\text { Aging }\end{array}$ & Wrap & $\begin{array}{c}\text { Wrap } \\
+ \\
\text { Aging }\end{array}$ & $\begin{array}{l}\text { Non- } \\
\text { Wrap }\end{array}$ & Wrap & $\begin{array}{c}\text { Wrap } \\
+ \\
\text { Aging }\end{array}$ & \\
\hline 0 & 0 & 0 & & 0 & 0 & 0 & 0.000 & 0.000 & 0 \\
\hline 0.25 & 151 & 88 & & 106 & 201 & 0.025 & 0.007 & 0.025 & 0.25 \\
\hline 0.50 & 290 & 170 & & 210 & 385 & 0.043 & 0.017 & 0.047 & 0.50 \\
\hline 0.75 & 409 & 266 & & 331 & 636 & 0.057 & 0.029 & 0.075 & 0.75 \\
\hline 1.00 & 564 & 366 & & 456 & 821 & 0.074 & 0.040 & 0.094 & 1.00 \\
\hline 1.25 & 740 & 466 & & 586 & 982 & 0.093 & 0.052 & .108 & 1.25 \\
\hline 1.50 & 871 & 566 & & 715 & 1139 & 0.106 & 0.062 & 0.123 & 1.50 \\
\hline 1.75 & 1030 & 661 & & 837 & 1307 & 0.123 & 0.073 & 0.136 & 1.75 \\
\hline 2.00 & 1180 & 760 & & 965 & 1455 & 0.138 & 0.085 & 0.150 & 2.00 \\
\hline 2.25 & 1357 & 867 & & 1101 & 1615 & 0.157 & 0.096 & .165 & 2.25 \\
\hline 2.50 & 1500 & 970 & & 1228 & 1780 & 0.172 & 0.107 & 0.180 & 2.50 \\
\hline 2.75 & 1661 & 1077 & & 1364 & 1933 & 0.189 & 0.118 & .195 & 2.75 \\
\hline 3.00 & 1818 & 1197 & & 1512 & 2086 & 0.204 & 0.131 & 0.208 & 3.00 \\
\hline 3.25 & 1973 & 1301 & & 1639 & 2241 & 0.219 & 0.142 & .220 & 3.25 \\
\hline 3.50 & 2133 & 1416 & & 1779 & 2398 & 0.236 & 0.153 & .235 & 3.50 \\
\hline 3.75 & 2291 & 1530 & & 1924 & 2543 & 0.251 & 0.165 & .247 & 3.75 \\
\hline 4.00 & 2455 & 1656 & & 2079 & 2704 & 0.268 & 0.177 & 0.260 & 4.00 \\
\hline 4.25 & 2603 & 1768 & & 2220 & 2849 & 0.284 & 0.190 & 0.275 & 4.25 \\
\hline 4.50 & 2761 & 1896 & & 2376 & 3006 & 0.299 & 0.204 & .289 & 4.50 \\
\hline 4.75 & 2945 & 2022 & & 2531 & 3155 & 0.318 & 0.216 & 0.301 & 4.75 \\
\hline 5.00 & 3098 & 2170 & & 2706 & 3303 & 0.334 & 0.231 & 0.315 & 5.00 \\
\hline 5.25 & - & 2294 & & 2840 & 3445 & & 0.244 & 0.327 & 5.25 \\
\hline 5.50 & 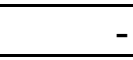 & 2423 & & 2988 & 3601 & & 0.257 & 0.342 & 5.50 \\
\hline 5.75 & - & 2560 & & 3156 & 3748 & - & 0.272 & 0.354 & 5.75 \\
\hline 6.00 & - & 2707 & & 3306 & 3906 & & 0.287 & 0.368 & 6.00 \\
\hline 6.25 & & 2851 & & 3502 & 4063 & 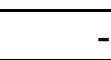 & 0.302 & 0.383 & 6.25 \\
\hline 6.50 & 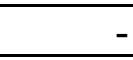 & 3013 & & 3708 & 4212 & & 0.317 & 0.396 & 6.50 \\
\hline 6.75 & - & 3172 & & 3896 & 4375 & - & 0.334 & 0.410 & 6.75 \\
\hline 7.00 & 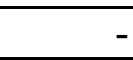 & 3330 & & 4082 & 4527 & 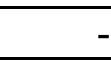 & 0.350 & 0.423 & 7.00 \\
\hline 7.25 & & & & 4245 & 4677 & - & 0.365 & 0.436 & 7.25 \\
\hline 7.50 & & & & 4449 & 4847 & & 0.382 & 0.453 & 7.50 \\
\hline
\end{tabular}


$\underline{\text { Table C.4.2 }}$

\section{All data on Specimen \# 2 ( 38 in. span)}

\begin{tabular}{|c|c|c|c|c|c|c|c|c|c|}
\hline Load & \multicolumn{3}{|c|}{$\begin{array}{c}\text { Strain on Wood } \\
(\mu \varepsilon)\end{array}$} & \multicolumn{2}{|c|}{$\begin{array}{c}\text { Strain on Fabric } \\
(\mu \varepsilon)\end{array}$} & \multicolumn{3}{|c|}{$\begin{array}{l}\text { Deflection } \\
\text { (in ) }\end{array}$} & \begin{tabular}{|l|} 
Load \\
\end{tabular} \\
\hline (kips) & $\begin{array}{l}\text { Non- } \\
\text { Wrap }\end{array}$ & Wrap & $\begin{array}{c}\text { Wrap } \\
+ \\
\text { Aging }\end{array}$ & Wrap & $\begin{array}{c}\text { Wrap } \\
+ \\
\text { Aging }\end{array}$ & $\begin{array}{l}\text { Non- } \\
\text { Wrap }\end{array}$ & Wrap & $\begin{array}{c}\text { Wrap } \\
+ \\
\text { Aging }\end{array}$ & (kips) \\
\hline 0 & 0 & 0 & 0 & 0 & 0 & 0 & 0.000 & 0.000 & 0 \\
\hline 0.25 & 166 & 155 & 115 & 207 & 153 & 0.024 & 0.020 & 0.015 & 0.25 \\
\hline 0.50 & 348 & 340 & 229 & 459 & 309 & 0.045 & 0.040 & 0.031 & 0.50 \\
\hline 0.75 & 537 & 524 & 306 & 709 & 416 & 0.066 & 0.060 & 0.045 & 0.75 \\
\hline 1.00 & 718 & 703 & 422 & 960 & 574 & 0.085 & 0.077 & 0.057 & 1.00 \\
\hline 1.25 & 911 & 886 & \begin{tabular}{|l|l|}
555 \\
\end{tabular} & 1217 & 761 & 0.103 & 0.095 & 0.072 & 1.25 \\
\hline 1.50 & 1099 & 1066 & 688 & 1475 & 950 & 0.122 & 0.113 & 0.085 & 1.50 \\
\hline 1.75 & 1294 & 1233 & 807 & 1713 & 1119 & 0.140 & 0.130 & 0.097 & 1.75 \\
\hline 2.00 & 1489 & 1408 & 955 & 1967 & 1329 & 0.159 & 0.146 & 0.111 & 2.00 \\
\hline 2.25 & 1676 & 1589 & 1082 & 2223 & 1510 & 0.177 & 0.163 & 0.125 & 2.25 \\
\hline 2.50 & 1864 & 1761 & 1218 & 2475 & 1699 & 0.195 & 0.180 & 0.138 & 2.50 \\
\hline 2.75 & 2070 & 1938 & 1361 & 2731 & 1911 & 0.215 & 0.196 & 0.152 & 2.75 \\
\hline 3.00 & 2279 & 2114 & 1503 & 2981 & 2111 & 0.235 & 0.213 & 0.167 & 3.00 \\
\hline 3.25 & 2480 & 2289 & 1647 & 3230 & 2313 & 0.255 & 0.230 & 0.180 & 3.25 \\
\hline 3.50 & 2697 & 2471 & 1799 & 3481 & 2527 & 0.275 & 0.246 & 0.205 & 3.50 \\
\hline 3.75 & 2902 & 2656 & 1956 & 3771 & 2749 & 0.295 & 0.264 & 0.211 & 3.75 \\
\hline 4.00 & 3123 & 2840 & 2116 & 4036 & 2974 & 0.315 & 0.270 & 0.227 & 4.00 \\
\hline 4.25 & 3360 & 3019 & 2281 & 4293 & 3209 & 0.337 & 0.296 & 0.242 & 4.25 \\
\hline 4.50 & 3558 & 3220 & 2460 & 4572 & 3461 & 0.356 & 0.315 & 0.259 & 4.50 \\
\hline 4.75 & 3789 & 3399 & 2642 & 4790 & 3713 & 0.379 & 0.332 & 0.277 & 4.75 \\
\hline 5.00 & 4014 & 3574 & 2830 & 5047 & 3976 & 0.399 & 0.348 & 0.296 & 5.00 \\
\hline 5.25 & & 3767 & 3003 & 5284 & 4216 & & 0.365 & 0.312 & 5.25 \\
\hline 5.50 & & 3954 & 3178 & 5586 & 4465 & & 0.383 & 0.329 & 5.50 \\
\hline 5.75 & & 4150 & 3373 & 5863 & 4734 & & 0.401 & 0.347 & 5.75 \\
\hline 6.00 & & 4347 & 3553 & 6135 & 4988 & & 0.420 & 0.365 & 6.00 \\
\hline 6.25 & & 4531 & 3738 & 6405 & 5271 & & 0.437 & 0.380 & 6.25 \\
\hline 6.50 & & 4730 & 3928 & 6690 & 5548 & & 0.448 & 0.399 & 6.50 \\
\hline 6.75 & & & 4107 & & 5811 & & & 0.416 & 6.75 \\
\hline 7.00 & & & $\begin{array}{l}4295 \\
\end{array}$ & & 6081 & & & 0.434 & 7.00 \\
\hline 7.25 & & & 4481 & & 6372 & & & 0.451 & 7.25 \\
\hline 7.50 & & & 4668 & & 6652 & & & 0.468 & 7.50 \\
\hline
\end{tabular}




\section{Table C.4.3}

All data on specimen \# 3 ( 38 in. span)

\begin{tabular}{|c|c|c|c|c|c|c|c|c|c|}
\hline Load & \multicolumn{3}{|c|}{$\begin{array}{l}\text { Strain on Wood } \\
(\mu \varepsilon)\end{array}$} & \multicolumn{2}{|c|}{$\begin{array}{c}\text { Strain on Fabric } \\
(\mu \varepsilon)\end{array}$} & \multicolumn{3}{|c|}{$\begin{array}{l}\text { Deflection } \\
\text { (in ) }\end{array}$} & \multirow{2}{*}{\begin{tabular}{|l} 
Load \\
(kips)
\end{tabular}} \\
\hline (kips) & $\begin{array}{l}\text { Non- } \\
\text { Wrap }\end{array}$ & Wrap & $\begin{array}{c}\text { Wrap } \\
+ \\
\text { Aging }\end{array}$ & Wrap & $\begin{array}{c}\text { Wrap } \\
+ \\
\text { Aging }\end{array}$ & $\begin{array}{l}\text { Non- } \\
\text { Wrap }\end{array}$ & Wrap & $\begin{array}{c}\text { Wrap } \\
+ \\
\text { Aging }\end{array}$ & \\
\hline 0 & 0 & 0 & 0 & 0 & 0 & 0 & 0 & 0 & 0 \\
\hline 0.25 & 146 & 144 & 220 & 160 & 220 & 0.024 & 0.025 & 0.028 & 0.25 \\
\hline 0.50 & 304 & 300 & 440 & 305 & 440 & 0.046 & 0.043 & 0.056 & 0.50 \\
\hline 0.75 & 467 & 452 & 643 & 460 & 644 & 0.065 & 0.059 & 0.075 & 0.75 \\
\hline 1.00 & 636 & 625 & 824 & 643 & 825 & 0.082 & 0.077 & 0.093 & 1.00 \\
\hline 1.25 & 811 & 820 & 1009 & 845 & 1012 & 0.099 & 0.096 & 0.111 & 1.25 \\
\hline 1.50 & 995 & 1030 & 1183 & 1060 & 1191 & 0.117 & 0.117 & 0.126 & 1.50 \\
\hline 1.75 & 1170 & 1214 & 1370 & 1250 & 1387 & 0.134 & 0.133 & 0.145 & 1.75 \\
\hline 2.00 & 1350 & 1421 & 1550 & 1465 & 1577 & 0.152 & 0.152 & 0.161 & 2.00 \\
\hline 2.25 & 1545 & 1630 & 1743 & 1681 & 1775 & 0.169 & 0.170 & 0.179 & 2.25 \\
\hline 2.50 & 1729 & 1822 & 1936 & 1881 & 1986 & 0.187 & 0.188 & 0.209 & 2.50 \\
\hline 2.75 & 1940 & 2020 & 2118 & 2088 & 2171 & 0.206 & 0.206 & 0.225 & 2.75 \\
\hline 3.00 & 2140 & 2237 & 2329 & 2313 & 2390 & 0.224 & 0.226 & 0.233 & 3.00 \\
\hline 3.25 & 2342 & 2423 & 2514 & 2510 & 2586 & 0.242 & 0.242 & 0.251 & 3.25 \\
\hline 3.50 & 2549 & 2630 & 2727 & 2729 & 2818 & 0.261 & 0.260 & 0.270 & 3.50 \\
\hline 3.75 & 2784 & 2832 & 2920 & 2944 & 3020 & 0.282 & 0.278 & 0.286 & 3.75 \\
\hline 4.00 & 2990 & 3030 & 3102 & 3151 & 3210 & 0.300 & 0.296 & 0.304 & 4.00 \\
\hline 4.25 & 3234 & 3240 & 3312 & 3372 & 3421 & 0.326 & 0.315 & 0.323 & 4.25 \\
\hline 4.50 & 3691 & 3499 & 3515 & 3614 & 3632 & 0.345 & 0.334 & 0.342 & 4.50 \\
\hline 4.75 & 3998 & 3754 & 3717 & 3868 & 3842 & 0.369 & 0.355 & 0.361 & 4.75 \\
\hline 5.00 & 4321 & 3987 & 3946 & 4103 & 4078 & 0.394 & 0.374 & 0.381 & 5.00 \\
\hline 5.25 & & 4194 & 4152 & 4318 & 4293 & - & 0.392 & 0.400 & 5.25 \\
\hline 5.50 & - & 4500 & 4372 & 4553 & 4515 & - & 0.410 & 0.420 & 5.50 \\
\hline 5.75 & & 4788 & 4582 & 4877 & 4724 & & 0.435 & 0.439 & 5.75 \\
\hline 6.00 & - & 5029 & 4827 & 5132 & 5029 & - & 0.457 & 0.461 & 6.00 \\
\hline 6.25 & & 5271 & 5109 & 5388 & 5286 & & 0.477 & 0.481 & 6.25 \\
\hline 6.50 & - & - & 5340 & - & 5520 & - & - & 0.499 & 6.50 \\
\hline 6.75 & 7 & - & 5605 & - & 5759 & - & - & 0.521 & 6.75 \\
\hline 7.00 & - & - & 5837 & - & 5980 & 二 & - & 0.541 & 7.00 \\
\hline 7.25 & - & - & 6100 & - & 6230 & & - & 0.563 & 7.25 \\
\hline 7.50 & - & - & 6386 & - & 6480 & 4 & - & 0.586 & 7.50 \\
\hline
\end{tabular}


$\underline{\text { Table C.4.4 }}$

$\underline{\text { Stress and Strain of Non-Wrap Half Scale Specimen \# } 1}$

\begin{tabular}{|c|c|c|}
\hline $\begin{array}{c}\text { Load } \\
\text { (kips) }\end{array}$ & $\begin{array}{c}\text { Strain on wood } \\
\text { (at midspan }) \\
(\mu \varepsilon)\end{array}$ & $\begin{array}{c}\text { Bending Stress From Calculation } \\
\text { (at midspan }) \\
(\mathrm{psi})\end{array}$ \\
\hline 0.00 & 0 & 0 \\
\hline 0.25 & 151 & 395 \\
\hline 0.50 & 290 & 790 \\
\hline 0.75 & 409 & 1,185 \\
\hline 1.00 & 564 & 1,580 \\
\hline 1.25 & 740 & 1,975 \\
\hline 1.50 & 871 & 2,370 \\
\hline 1.75 & 1030 & 2,765 \\
\hline 2.00 & 1180 & 3,160 \\
\hline 2.25 & 1357 & 3,555 \\
\hline 2.50 & 1500 & 3,950 \\
\hline 2.75 & 1661 & 4,345 \\
\hline 3.00 & 1818 & 4,740 \\
\hline 3.25 & 1973 & 5,135 \\
\hline 3.50 & 2133 & 5,530 \\
\hline 3.75 & 2291 & 5,925 \\
\hline 4.00 & 2455 & 6,320 \\
\hline 4.25 & 2603 & 6,715 \\
\hline 4.50 & 2761 & 7,110 \\
\hline 4.75 & 2945 & 7,505 \\
\hline 5.00 & 3098 & 7,900 \\
\hline & & \\
\hline
\end{tabular}

Note 1. Span length $(\mathrm{L})=38 \mathrm{in}$.

2. Data of strain on wood, refer to Table C.4.1

3. Calculation of Bending Stress ( For Three Points Bending Test )

$$
\begin{aligned}
& \text { Bending stress }=\frac{M C}{I}=1.58 \mathrm{P} \\
& M=\frac{P L}{4}=\frac{38 P}{4}=9.5 P \quad ; C=\frac{3}{2}=1.5 \text { in }, I=\frac{b h^{3}}{12}=\frac{4\left(3^{3}\right)}{12}=9 \mathrm{in}^{4}
\end{aligned}
$$




\section{$\underline{\text { Table C.4.5 }}$}

Deflection of Non-Wrap Half Scale Specimen\# 1

\begin{tabular}{|c|c|c|c|}
\hline $\begin{array}{c}\text { Load } \\
\text { ( kips })\end{array}$ & $\begin{array}{c}\text { Total Deflection } \\
\text { (in) }\end{array}$ & $\begin{array}{c}\text { Bending Deflection } \\
\text { From Calculation } \\
\text { (in ) }\end{array}$ & $\begin{array}{c}\text { Shear Deflection } \\
\text { From Calculation } \\
\text { (in ) }\end{array}$ \\
\hline 0 & 0 & 0 & 0 \\
\hline 0.25 & 0.025 & 0.013 & 0.013 \\
\hline 0.50 & 0.043 & 0.025 & 0.018 \\
\hline 0.75 & 0.057 & 0.038 & 0.020 \\
\hline 1.00 & 0.074 & 0.050 & 0.024 \\
\hline 1.25 & 0.093 & 0.063 & 0.031 \\
\hline 1.50 & 0.106 & 0.075 & 0.031 \\
\hline 1.75 & 0.123 & 0.088 & 0.036 \\
\hline 2.00 & 0.138 & 0.100 & 0.038 \\
\hline 2.25 & 0.157 & 0.113 & 0.045 \\
\hline 2.50 & 0.172 & 0.125 & 0.047 \\
\hline 2.75 & 0.189 & 0.138 & 0.052 \\
\hline 3.00 & 0.204 & 0.150 & 0.054 \\
\hline 3.25 & 0.219 & 0.163 & 0.057 \\
\hline 3.50 & 0.236 & 0.175 & 0.061 \\
\hline 3.75 & 0.251 & 0.188 & 0.064 \\
\hline 4.00 & 0.268 & 0.200 & 0.068 \\
\hline 4.25 & 0.284 & 0.213 & 0.072 \\
\hline 4.50 & 0.299 & 0.225 & 0.074 \\
\hline 4.75 & 0.318 & 0.238 & 0.081 \\
\hline 5.00 & 0.334 & 0.250 & 0.084 \\
\hline
\end{tabular}

Note 1.Total deflection data are referred to Table C.4.1.

2. Calculation of Bending Deflection (For Three Points Bending )

$$
\begin{aligned}
& \text { Bending Deflection }\left(\delta_{\mathrm{b}}\right)=\frac{P L^{3}}{48 E I}=5 \times 10^{-5} \mathrm{P} \text { in } \\
& \mathrm{E}_{\text {non-wrap }}=2.54 \times 10^{6} \text { psi. ( Refer to note from Figure } 4.1 \text { ) } \\
& \mathrm{L}=38 \text { in } \\
& \mathrm{I}_{\text {non-wrap }}=9 \text { in. }^{4}
\end{aligned}
$$

3. Calculation of Shear Deflection

Shear Deflection $\left(\delta_{\mathrm{s}}\right)=$ Total Deflection $\left(\delta_{\mathrm{t}}\right)-\operatorname{Bending} \operatorname{Deflection}\left(\delta_{\mathrm{b}}\right)$ 
$\underline{\text { Table C.4.6 }}$

Stress and Strain of Wrap Half Scale Specimen \# 1

\begin{tabular}{|c|c|c|c|}
\hline $\begin{array}{l}\text { Load } \\
\text { ( kips ) }\end{array}$ & $\begin{array}{c}\text { Strain on Wood } \\
\text { ( at midspan }) \\
(\mu \varepsilon)\end{array}$ & $\begin{array}{c}\text { Strain On Fabric } \\
(\text { at midspan }) \\
(\mu \varepsilon)\end{array}$ & $\begin{array}{l}\text { Bending Stress } \\
\text { From Calculation } \\
\text { (psi) }\end{array}$ \\
\hline 0 & 0 & 0 & 0 \\
\hline 0.25 & 88 & 106 & 297.13 \\
\hline 0.50 & 170 & 210 & 594.25 \\
\hline 0.75 & 266 & 331 & 891.38 \\
\hline 1.00 & 366 & 456 & 1188.50 \\
\hline 1.25 & 466 & 586 & 1485.63 \\
\hline 1.50 & 566 & 715 & 1782.75 \\
\hline 1.75 & 661 & 837 & 2079.88 \\
\hline 2.00 & 760 & 965 & 2377.00 \\
\hline 2.25 & 867 & 1101 & 2674.13 \\
\hline 2.50 & 970 & 1228 & 2971.25 \\
\hline 2.75 & 1077 & 1364 & 3268.38 \\
\hline 3.00 & 1197 & 1512 & 3565.50 \\
\hline 3.25 & 1301 & 1639 & 3862.63 \\
\hline 3.50 & 1416 & 1779 & 4159.75 \\
\hline 3.75 & 1530 & 1924 & 4456.88 \\
\hline 4.00 & 1656 & 2079 & 4754.00 \\
\hline 4.25 & 1768 & 2220 & 5051.13 \\
\hline 4.50 & 1896 & 2376 & 5348.25 \\
\hline 4.75 & 2022 & 2531 & 5645.38 \\
\hline 5.00 & 2170 & 2706 & 5942.50 \\
\hline
\end{tabular}

Note 1. Span length ( L ) $=38$ in.

2. Data of strain on wood and fabric, refer to Table C.4.1

3. Calculation of Bending Stress ( For Three Points Bending )

$$
\begin{aligned}
& \text { Bending stress }=\frac{M C}{I_{\text {transformed }}}=1.1885 \mathrm{P} \\
& M=\frac{P L}{4}=\frac{38 P}{4}=9.5 P
\end{aligned}
$$




$$
\begin{aligned}
& \mathrm{C}=1.5 \text { in } \\
& d=1.5+\frac{0.08}{2}=1.54 \text { in } \\
& n=\frac{E_{\text {composite }}}{E_{\text {non-wrap }}}=\frac{5 \times 10^{6}}{2.54 \times 10^{6}}=1.97, \mathrm{E}_{\text {non-wrap }} \text { refers to Figure } 4.1 \\
& A_{f}=(2)(4 x 0.08)=0.64 \mathrm{in}^{2} \\
& I_{\text {transformed }}=\frac{b h^{3}}{12}+n A_{f} d^{2}=\frac{4\left(3^{3}\right)}{12}+1.97(0.64)\left(1.54^{2}\right)=12 \mathrm{in}^{4}
\end{aligned}
$$


$\underline{\text { Table C.4.7 }}$

Deflection of Wrap Half Scale Specimen \# 1

\begin{tabular}{|c|c|c|c|}
\hline $\begin{array}{c}\text { Load } \\
\text { ( kips })\end{array}$ & $\begin{array}{c}\text { Total Deflection } \\
\text { (in) }\end{array}$ & $\begin{array}{c}\text { Bending Deflection } \\
\text { From Calculation } \\
\text { (in ) }\end{array}$ & $\begin{array}{c}\text { Shear Deflection } \\
\text { From Calculation } \\
\text { (in) }\end{array}$ \\
\hline 0 & 0 & 0 & 0 \\
\hline 0.25 & 0.007 & 0.009 & 0 \\
\hline 0.50 & 0.017 & 0.017 & 0 \\
\hline 0.75 & 0.029 & 0.026 & 0.003 \\
\hline 1.00 & 0.040 & 0.035 & 0.005 \\
\hline 1.25 & 0.052 & 0.043 & 0.009 \\
\hline 1.50 & 0.062 & 0.052 & 0.010 \\
\hline 1.75 & 0.073 & 0.061 & 0.012 \\
\hline 2.00 & 0.085 & 0.069 & 0.016 \\
\hline 2.25 & 0.096 & 0.078 & 0.018 \\
\hline 2.50 & 0.107 & 0.087 & 0.020 \\
\hline 2.75 & 0.118 & 0.095 & 0.023 \\
\hline 3.00 & 0.131 & 0.104 & 0.027 \\
\hline 3.25 & 0.142 & 0.113 & 0.029 \\
\hline 3.50 & 0.153 & 0.121 & 0.032 \\
\hline 3.75 & 0.165 & 0.130 & 0.035 \\
\hline 4.00 & 0.177 & 0.139 & 0.038 \\
\hline 4.25 & 0.190 & 0.147 & 0.043 \\
\hline 4.50 & 0.204 & 0.156 & 0.048 \\
\hline 4.75 & 0.216 & 0.165 & 0.051 \\
\hline 5.00 & 0.231 & 0.173 & 0.058 \\
\hline
\end{tabular}

Note 1 . Total deflection data are from Table 4.1

2. Bending Deflection $\left(\delta_{\mathrm{b}}\right)=\frac{P L^{3}}{48 E I_{\text {transformed }}}=3.47 \times 10^{-5} \mathrm{P} \quad$ in

$E_{\text {wrap }}=2.75 \times 10^{6}$ psi. ( Refer to Figure 4.3 )

$\mathrm{L}=38$ in.

$\mathrm{I}_{\text {transformed }}=12$ in. $^{4}$ (Refer to Note Item 3 of Table C.4.6)

3. Shear Deflection $\left(\delta_{\mathrm{s}}\right)=$ Total Deflection $\left(\delta_{\mathrm{t}}\right)-\operatorname{Bending} \operatorname{Deflection}\left(\delta_{\mathrm{b}}\right)$ 
$\underline{\text { Table C.4.8 }}$

Stress and Strain of Non-Wrap Half Scale Specimen \# 2

\begin{tabular}{|c|c|c|}
\hline $\begin{array}{c}\text { Load } \\
\text { (kips })\end{array}$ & $\begin{array}{c}\text { Strain on Wood } \\
(\text { at midspan }) \\
(\mu \varepsilon)\end{array}$ & $\begin{array}{c}\text { Bending Stress } \\
\text { (at midspan }) \\
(\mathrm{psi})\end{array}$ \\
\hline 0 & 0 & 0 \\
\hline 0.25 & 166 & 395 \\
\hline 0.50 & 348 & 790 \\
\hline 0.75 & 537 & 1,185 \\
\hline 1.00 & 718 & 1,580 \\
\hline 1.25 & 911 & 1,975 \\
\hline 1.50 & 1099 & 2,370 \\
\hline 1.75 & 1294 & 2,765 \\
\hline 2.00 & 1489 & 3,160 \\
\hline 2.25 & 1676 & 3,555 \\
\hline 2.50 & 1864 & 3,950 \\
\hline 2.75 & 2070 & 4,345 \\
\hline 3.00 & 2279 & 4,740 \\
\hline 3.25 & 2480 & 5,135 \\
\hline 3.50 & 2697 & 5,530 \\
\hline 3.75 & 2902 & 5,925 \\
\hline 4.00 & 3123 & 6,320 \\
\hline 4.25 & 3360 & 6,715 \\
\hline 4.50 & 3558 & 7,110 \\
\hline 4.75 & 3789 & 7,505 \\
\hline 5.00 & 4014 & 7,900 \\
\hline
\end{tabular}

Note 1. Span length ( L ) $=38$ in.

2. Data of strain on wood, refer to Table C.4.2

3. Calculation of Bending Stress (For Three Points Bending Test )

$$
\begin{aligned}
& \text { Bending stress }=\frac{M C}{I}=1.58 \mathrm{P} \\
& M=\frac{P L}{4}=\frac{38 P}{4}=9.5 P \\
& C=\frac{3}{2}=1.5 \text { in }, I=\frac{b h^{3}}{12}=\frac{4\left(3^{3}\right)}{12}=9 \mathrm{in}^{4}
\end{aligned}
$$




\section{$\underline{\text { Table C.4.9 }}$}

Deflection of Non-Wrap Half Scale Specimen\# 2

\begin{tabular}{|c|c|c|c|}
\hline $\begin{array}{c}\text { Load } \\
\text { kip })\end{array}$ & $\begin{array}{c}\text { Total Deflection } \\
\text { (in.) }\end{array}$ & $\begin{array}{c}\text { Bending Deflection } \\
\text { From Calculation } \\
\text { ( in. })\end{array}$ & $\begin{array}{c}\text { Shear Deflection } \\
\text { From Calculation } \\
\text { (in) }\end{array}$ \\
\hline 0 & 0 & 0 & 0 \\
\hline 0.25 & 0.024 & 0.016 & 0.008 \\
\hline 0.50 & 0.045 & 0.032 & 0.013 \\
\hline 0.75 & 0.066 & 0.048 & 0.018 \\
\hline 1.00 & 0.085 & 0.065 & 0.021 \\
\hline 1.25 & 0.103 & 0.081 & 0.022 \\
\hline 1.50 & 0.122 & 0.097 & 0.025 \\
\hline 1.75 & 0.140 & 0.113 & 0.027 \\
\hline 2.00 & 0.159 & 0.129 & 0.030 \\
\hline 2.25 & 0.177 & 0.145 & 0.032 \\
\hline 2.50 & 0.195 & 0.161 & 0.034 \\
\hline 2.75 & 0.215 & 0.177 & 0.038 \\
\hline 3.00 & 0.235 & 0.194 & 0.042 \\
\hline 3.25 & 0.255 & 0.210 & 0.045 \\
\hline 3.50 & 0.275 & 0.226 & 0.049 \\
\hline 3.75 & 0.295 & 0.242 & 0.053 \\
\hline 4.00 & 0.315 & 0.258 & 0.057 \\
\hline 4.25 & 0.337 & 0.274 & 0.063 \\
\hline 4.50 & 0.356 & 0.290 & 0.066 \\
\hline 4.75 & 0.379 & 0.306 & 0.073 \\
\hline 5.00 & 0.399 & 0.323 & 0.077 \\
\hline
\end{tabular}

Note 1. Total deflection data are referred to Table C.4.2.

2.Bending Deflection $\left(\delta_{\mathrm{b}}\right)=\frac{P L^{3}}{48 E I}=6.45 \times 10^{-5} \mathrm{P}$ in

$$
\begin{aligned}
& \mathrm{E}_{\text {non-wrap }}=1.97 \times 10^{6} \text { psi. ( Refer to note from Figure } 4.5 \text { ) } \\
& \mathrm{L}=38 \text { in } \\
& \mathrm{I}_{\text {non-wrap }}=9 \text { in. }{ }^{4}
\end{aligned}
$$

3.Shear Deflection $\left(\delta_{\mathrm{s}}\right)=$ Total Deflection $\left(\delta_{\mathrm{t}}\right)-$ Bending Deflection $\left(\delta_{\mathrm{b}}\right)$ 
$\underline{\text { Table C.4.10 }}$

Stress and Strain of Wrap Half Scale Specimen \# 2

\begin{tabular}{|c|c|c|r|}
\hline $\begin{array}{c}\text { Load } \\
(\text { kip })\end{array}$ & $\begin{array}{c}\text { Strain on Wood } \\
(\text { at center }) \\
(\mu \varepsilon)\end{array}$ & $\begin{array}{c}\text { Strain on Fabric } \\
(\text { at center }) \\
(\mu \varepsilon)\end{array}$ & $\begin{array}{c}\text { Bending Stress } \\
\text { From Calculation } \\
(\text { psi })\end{array}$ \\
\hline 0 & 0 & 0 & 0 \\
\hline 0.25 & 155 & 207 & 554.04 \\
\hline 0.50 & 340 & 459 & 831.07 \\
\hline 0.75 & 524 & 709 & 1108.09 \\
\hline 1.00 & 703 & 960 & 1385.11 \\
\hline 1.25 & 886 & 1217 & 1662.13 \\
\hline 1.50 & 1066 & 1475 & 2216.17 \\
\hline 1.75 & 1233 & 1713 & 2493.20 \\
\hline 2.00 & 1408 & 1967 & 2770.22 \\
\hline 2.25 & 1589 & 2223 & 3047.24 \\
\hline 2.50 & 1761 & 2475 & 3324.26 \\
\hline 2.75 & 1938 & 2731 & 3601.28 \\
\hline 3.00 & 2114 & 2981 & 3878.30 \\
\hline 3.25 & 2289 & 3230 & 4155.33 \\
\hline 3.50 & 2471 & 3481 & 4432.35 \\
\hline 3.75 & 2656 & 3771 & 4709.37 \\
\hline 4.00 & 2840 & 4036 & 4986.39 \\
\hline 4.25 & 3019 & 4293 & 5263.41 \\
\hline 4.50 & 3220 & 4572 & 5540.44 \\
\hline 4.75 & 3399 & 4790 & \\
\hline 5.00 & 3574 & 5047 & \\
\hline
\end{tabular}

Note 1. Span length ( L ) $=38$ in.

2. Data of strain on wood and fabric, refer to Table C.4.2

3. Calculation of Bending Stress ( For Three Points Bending Test )

$$
\begin{aligned}
& \text { Bending stress }=\frac{M C}{I_{\text {transformed }}}=1.10809 \mathrm{P} \\
& M=\frac{P L}{4}=\frac{38 P}{4}=9.5 P \\
& \mathrm{C}=1.5 \text { in }
\end{aligned}
$$




$$
\begin{aligned}
& d=1.5+\frac{0.08}{2}=1.54 \text { in } \\
& n=\frac{E_{\text {composite }}}{E_{\text {non-wrap }}}=\frac{5 \times 10^{6}}{1.97 \times 10^{6}}=2.54, \text { E }_{\text {non-wrap }} \text { refers to Figure } 4.5 \\
& A_{f}=(2)(4 x 0.08)=0.64 \mathrm{in}^{2} \\
& I_{\text {transformed }}=\frac{b h^{3}}{12}+n A_{f} d^{2}=\frac{4\left(3^{3}\right)}{12}+2.54(0.64)\left(1.54^{2}\right)=12.86 \mathrm{in}^{4}
\end{aligned}
$$


$\underline{\text { Table C.4.11 }}$

Deflection of Wrap Half Scale Specimen \# 2

\begin{tabular}{|c|c|c|c|}
\hline $\begin{array}{c}\text { Load } \\
\text { (kip })\end{array}$ & $\begin{array}{c}\text { Total Deflection } \\
\text { (in.) }\end{array}$ & $\begin{array}{c}\text { Bending Deflection } \\
\text { (in. ) }\end{array}$ & $\begin{array}{c}\text { Shear Deflection } \\
\text { (in) }\end{array}$ \\
\hline 0 & 0 & 0 & 0 \\
\hline 0.25 & 0.020 & 0.014 & 0.006 \\
\hline 0.50 & 0.040 & 0.029 & 0.011 \\
\hline 0.75 & 0.060 & 0.043 & 0.017 \\
\hline 1.00 & 0.077 & 0.057 & 0.020 \\
\hline 1.25 & 0.095 & 0.072 & 0.023 \\
\hline 1.50 & 0.113 & 0.086 & 0.027 \\
\hline 1.75 & 0.130 & 0.100 & 0.030 \\
\hline 2.00 & 0.146 & 0.115 & 0.031 \\
\hline 2.25 & 0.163 & 0.129 & 0.034 \\
\hline 2.50 & 0.180 & 0.143 & 0.037 \\
\hline 2.75 & 0.196 & 0.158 & 0.038 \\
\hline 3.00 & 0.213 & 0.172 & 0.041 \\
\hline 3.25 & 0.230 & 0.186 & 0.044 \\
\hline 3.50 & 0.246 & 0.201 & 0.045 \\
\hline 3.75 & 0.264 & 0.215 & 0.049 \\
\hline 4.00 & 0.280 & 0.229 & 0.051 \\
\hline 4.25 & 0.296 & 0.244 & 0.052 \\
\hline 4.50 & 0.315 & 0.258 & 0.057 \\
\hline 4.75 & 0.332 & 0.272 & 0.060 \\
\hline 5.00 & 0.348 & 0.287 & 0.061 \\
\hline & & & \\
\hline
\end{tabular}

Note 1. Total deflection data are referred to Table C.4.2.

2. Bending Deflection $\left(\delta_{\mathrm{b}}\right)=\frac{P L^{3}}{48 E I_{\text {transformed }}}=5.74 \times 10^{-5} \mathrm{P} \quad$ in $^{2}$

$\mathrm{E}_{\mathrm{wrap}}=1.55 \times 10^{6}$ psi. ( Refer to Figure 4.7)

$\mathrm{L}=38$ in.

$\mathrm{I}_{\text {transformed }}=12.86$ in. $^{4}$ (Refer to Table 4.6)

3. Shear Deflection $\left(\delta_{\mathrm{s}}\right)=$ Total Deflection $\left(\delta_{\mathrm{t}}\right)-$ Bending Deflection $\left(\delta_{\mathrm{b}}\right)$ 
$\underline{\text { Table C.4.12 }}$

$\underline{\text { Stress and Strain of Non-Wrap Half Scale Specimen \# } 3}$

\begin{tabular}{|c|c|c|}
\hline $\begin{array}{c}\text { Load } \\
\text { (kips) }\end{array}$ & $\begin{array}{c}\text { Strain on wood } \\
\text { (at midspan }) \\
(\mu \varepsilon)\end{array}$ & $\begin{array}{c}\text { Bending Stress From Calculation } \\
\text { (at midspan }) \\
(\mathrm{psi})\end{array}$ \\
\hline 0.00 & 0 & 0 \\
\hline 0.25 & 146 & 395 \\
\hline 0.50 & 304 & 790 \\
\hline 0.75 & 467 & 1,185 \\
\hline 1.00 & 636 & 1,580 \\
\hline 1.25 & 811 & 1,975 \\
\hline 1.50 & 995 & 2,370 \\
\hline 1.75 & 1170 & 2,765 \\
\hline 2.00 & 1350 & 3,160 \\
\hline 2.25 & 1545 & 3,555 \\
\hline 2.50 & 1729 & 3,950 \\
\hline 2.75 & 1940 & 4,345 \\
\hline 3.00 & 2140 & 4,740 \\
\hline 3.25 & 2342 & 5,135 \\
\hline 3.50 & 2549 & 5,530 \\
\hline 3.75 & 2784 & 5,925 \\
\hline 4.00 & 2990 & 6,320 \\
\hline 4.25 & 3234 & 6,715 \\
\hline 4.50 & 3691 & 7,110 \\
\hline 4.75 & 3998 & 7,505 \\
\hline 5.00 & 4321 & 7,900 \\
\hline & & \\
\hline
\end{tabular}

Note 1. Span length ( L ) $=38$ in.

2. Data of strain on wood, refer to Table C.4.1

3. Calculation of Bending Stress ( For Three Points Bending Test )

$$
\begin{aligned}
& \text { Bending stress }=\frac{M C}{I}=1.58 \mathrm{P} \\
& M=\frac{P L}{4}=\frac{38 P}{4}=9.5 P \quad ; C=\frac{3}{2}=1.5 \text { in }, I=\frac{b h^{3}}{12}=\frac{4\left(3^{3}\right)}{12}=9 \mathrm{in}^{4}
\end{aligned}
$$


$\underline{\text { Table C.4.13 }}$

Deflection of Non-Wrap Half Scale Specimen\# 3

\begin{tabular}{|r|c|c|c|}
\hline \multicolumn{1}{|c|}{$\begin{array}{c}\text { Load } \\
\text { (kips) }\end{array}$} & $\begin{array}{c}\text { Total Deflection } \\
\text { (in) }\end{array}$ & $\begin{array}{c}\text { Bending Deflection } \\
\text { From Calculation } \\
\text { (in ) }\end{array}$ & $\begin{array}{c}\text { Shear Deflection } \\
\text { From Calculation } \\
\text { ( in ) }\end{array}$ \\
\hline 0 & 0 & 0 & 0 \\
\hline 0.25 & 0.024 & 0.016 & 0.008 \\
\hline 0.50 & 0.046 & 0.031 & 0.015 \\
\hline 0.75 & 0.065 & 0.047 & 0.018 \\
\hline 1.00 & 0.082 & 0.062 & 0.020 \\
\hline 1.25 & 0.099 & 0.078 & 0.021 \\
\hline 1.50 & 0.117 & 0.093 & 0.024 \\
\hline 1.75 & 0.134 & 0.109 & 0.025 \\
\hline 2.00 & 0.152 & 0.124 & 0.028 \\
\hline 2.25 & 0.169 & 0.140 & 0.029 \\
\hline 2.50 & 0.187 & 0.156 & 0.032 \\
\hline 2.75 & 0.206 & 0.171 & 0.035 \\
\hline 3.00 & 0.224 & 0.187 & 0.037 \\
\hline 3.25 & 0.242 & 0.202 & 0.040 \\
\hline 3.50 & 0.261 & 0.218 & 0.043 \\
\hline 3.75 & 0.282 & 0.233 & 0.049 \\
\hline 4.00 & 0.300 & 0.249 & 0.051 \\
\hline 4.25 & 0.326 & 0.264 & 0.062 \\
\hline 4.50 & 0.345 & 0.280 & 0.065 \\
\hline 4.75 & 0.369 & 0.295 & 0.074 \\
\hline 5.00 & 0.394 & 0.311 & 0.083 \\
\hline & & & \\
\hline
\end{tabular}

Note 1.Total deflection data are referred to Table C.4.3.

2. Calculation of Bending Deflection ( For Three Points Bending )

$$
\begin{aligned}
& \text { Bending Deflection }\left(\delta_{\mathrm{b}}\right)=\frac{P L^{3}}{48 E I}=6.23 \times 10^{-5} \mathrm{P} \text { in } \\
& \mathrm{E}_{\text {non-wrap }}=2.04 \times 10^{6} \text { psi. ( Refer to note from Figure } 4.9 \text { ) } \\
& \mathrm{L}=38 \text { in } \\
& \mathrm{I}_{\text {non-wrap }}=9 \mathrm{in} .^{4}
\end{aligned}
$$

3. Calculation of Shear Deflection

Shear Deflection $\left(\delta_{\mathrm{s}}\right)=$ Total Deflection $\left(\delta_{\mathrm{t}}\right)-\operatorname{Bending} \operatorname{Deflection}\left(\delta_{\mathrm{b}}\right)$ 
$\underline{\text { Table C.4.14 }}$

$\underline{\text { Stress and Strain of Wrap Half Scale Specimen \# } 3}$

\begin{tabular}{|c|c|c|r|}
\hline $\begin{array}{c}\text { Load } \\
(\text { kips })\end{array}$ & $\begin{array}{c}\text { Strain on Wood } \\
(\text { at midspan }) \\
(\mu \varepsilon)\end{array}$ & $\begin{array}{c}\text { Strain On Fabric } \\
(\text { at midspan }) \\
(\mu \varepsilon)\end{array}$ & $\begin{array}{c}\text { Bending Stress } \\
\text { From Calculation } \\
(\mathrm{psi})\end{array}$ \\
\hline 0 & 0 & 0 & 280.00 \\
\hline 0.25 & 144 & 160 & 860.00 \\
\hline 0.50 & 300 & 305 & 1120.00 \\
\hline 0.75 & 452 & 460 & 1400.00 \\
\hline 1.00 & 625 & 643 & 1680.00 \\
\hline 1.25 & 820 & 845 & 1960.00 \\
\hline 1.50 & 1030 & 1060 & 2240.00 \\
\hline 1.75 & 1214 & 1250 & 2520.00 \\
\hline 2.00 & 1421 & 1465 & 3080.00 \\
\hline 2.25 & 1630 & 1681 & 3360.00 \\
\hline 2.50 & 1822 & 1881 & 3640.00 \\
\hline 2.75 & 2020 & 2088 & 3920.00 \\
\hline 3.00 & 2237 & 2313 & 4200.00 \\
\hline 3.25 & 2423 & 2510 & 4480.00 \\
\hline 3.50 & 2630 & 2729 & 4760.00 \\
\hline 3.75 & 2832 & 2944 & 5040.00 \\
\hline 4.00 & 3030 & 3151 & 5320.00 \\
\hline 4.25 & 3240 & 3372 & 5600.00 \\
\hline 4.50 & 3499 & 3614 & \\
\hline 4.75 & 3754 & 3868 & 4103 \\
\hline 5.00 & 3987 & & \\
\hline
\end{tabular}

Note 1. Span length ( L ) $=38$ in.

2. Data of strain on wood and fabric, refer to Table C.4.1

3. Calculation of Bending Stress ( For Three Points Bending )

$$
\begin{aligned}
& \text { Bending stress }=\frac{M C}{I_{\text {transformed }}}=1.12 \mathrm{P} \\
& M=\frac{P L}{4}=\frac{38 P}{4}=9.5 P
\end{aligned}
$$




$$
\begin{aligned}
& \mathrm{C}=1.5 \mathrm{in} \\
& d=1.5+\frac{0.08}{2}=1.54 \mathrm{in} \\
& n=\frac{E_{\text {composite }}}{E_{\text {non-wrap }}}=\frac{5 \times 10^{6}}{2.04 \times 10^{6}}=2.45, \mathrm{E}_{\text {non-wrap }} \text { refers to Figure } 4.9 \\
& A_{f}=(2)(4 x 0.08)=0.64 \mathrm{in}^{2} \\
& I_{\text {transformed }}=\frac{b h^{3}}{12}+n A_{f} d^{2}=\frac{4\left(3^{3}\right)}{12}+2.45(0.64)\left(1.54^{2}\right)=12.72 \mathrm{in}^{4}
\end{aligned}
$$


$\underline{\text { Table C.4.15 }}$

Deflection of Wrap Half Scale Specimen \# 3

\begin{tabular}{|c|c|c|c|}
\hline $\begin{array}{c}\text { Load } \\
\text { (kips) }\end{array}$ & $\begin{array}{c}\text { Total Deflection } \\
\text { (in) }\end{array}$ & $\begin{array}{c}\text { Bending Deflection } \\
\text { From Calculation } \\
\text { (in ) }\end{array}$ & $\begin{array}{c}\text { Shear Deflection } \\
\text { From Calculation } \\
\text { (in) }\end{array}$ \\
\hline 0 & 0 & 0 & 0 \\
\hline 0.25 & 0.025 & 0.013 & 0.012 \\
\hline 0.50 & 0.043 & 0.027 & 0.016 \\
\hline 0.75 & 0.059 & 0.040 & 0.019 \\
\hline 1.00 & 0.077 & 0.054 & 0.024 \\
\hline 1.25 & 0.096 & 0.067 & 0.029 \\
\hline 1.50 & 0.117 & 0.080 & 0.037 \\
\hline 1.75 & 0.133 & 0.094 & 0.039 \\
\hline 2.00 & 0.152 & 0.107 & 0.045 \\
\hline 2.25 & 0.170 & 0.120 & 0.050 \\
\hline 2.50 & 0.188 & 0.134 & 0.054 \\
\hline 2.75 & 0.206 & 0.147 & 0.059 \\
\hline 3.00 & 0.226 & 0.161 & 0.066 \\
\hline 3.25 & 0.242 & 0.174 & 0.068 \\
\hline 3.50 & 0.260 & 0.187 & 0.073 \\
\hline 3.75 & 0.278 & 0.201 & 0.077 \\
\hline 4.00 & 0.296 & 0.214 & 0.082 \\
\hline 4.25 & 0.315 & 0.227 & 0.088 \\
\hline 4.50 & 0.334 & 0.241 & 0.093 \\
\hline 4.75 & 0.355 & 0.254 & 0.101 \\
\hline 5.00 & 0.374 & 0.268 & 0.107 \\
\hline
\end{tabular}

Note 1. Total deflection data are from Table C.4.3

2. Bending Deflection $\left(\delta_{\mathrm{b}}\right)=\frac{P L^{3}}{48 E I_{\text {transformed }}}=5.35 \times 10^{-5} \mathrm{P} \quad$ in

$E_{\text {wrap }}=1.68 \times 10^{6}$ psi. ( Refer to Figure 4.3 )

$\mathrm{L}=38$ in.

$\mathrm{I}_{\text {transformed }}=12.72$ in. $^{4}$ (Refer to Note Item 3 of Table C.4.14)

3. Shear Deflection $\left(\delta_{\mathrm{s}}\right)=$ Total Deflection $\left(\delta_{\mathrm{t}}\right)-\operatorname{Bending} \operatorname{Deflection}\left(\delta_{\mathrm{b}}\right)$ 
$\underline{\text { Table C.4.16 }}$

Stress and Strain of Wrap and Wrap+Aging Half Scale Specimen \# 1

\begin{tabular}{|c||c|c|c|}
\hline \multicolumn{1}{|c||}{$\begin{array}{c}\text { Load } \\
\text { (kips.) }\end{array}$} & \multicolumn{2}{c|}{ Strain on Fabric $(\mu \varepsilon)$} & \multirow{2}{*}{$\begin{array}{c}\text { Bending Stress } \\
\text { (psi) }\end{array}$} \\
\hline 0 & Wrap & Wrap + Aging & 0 \\
\hline 0.25 & 0 & 0 & 297.13 \\
\hline 0.50 & 106 & 201 & 594.25 \\
\hline 0.75 & 210 & 385 & 891.38 \\
\hline 1.00 & 331 & 636 & 1188.50 \\
\hline 1.25 & 456 & 821 & 1485.63 \\
\hline 1.50 & 586 & 982 & 1782.75 \\
\hline 1.75 & 715 & 1139 & 2079.88 \\
\hline 2.00 & 837 & 1307 & 2377.00 \\
\hline 2.25 & 965 & 1455 & 2674.13 \\
\hline 2.50 & 1101 & 1615 & 2971.25 \\
\hline 2.75 & 1228 & 1780 & 3268.38 \\
\hline 3.00 & 1364 & 1933 & 3565.50 \\
\hline 3.25 & 1512 & 2086 & 3862.63 \\
\hline 3.50 & 1639 & 2241 & 4159.75 \\
\hline 3.75 & 1779 & 2398 & 4456.88 \\
\hline 4.00 & 1924 & 2543 & 4754.00 \\
\hline 4.25 & 2079 & 2704 & 5051.13 \\
\hline 4.50 & 2220 & 2849 & 5348.25 \\
\hline 4.75 & 2376 & 3006 & 5645.38 \\
\hline 5.00 & 2531 & 3155 & 5942.50 \\
\hline
\end{tabular}

Note 1. Strain data are referred to Table C.4.1

2. Bending Stress $=1.1885 \mathrm{P}$ psi $\quad$ (Refer to Note Item 3 of Table C.4.6) 
$\underline{\text { Table C.4.17 }}$

Stress and Strain of Wrap and Wrap+Aging Half Scale Specimen \# 2

\begin{tabular}{|c||c|c|c|}
\hline \multirow{2}{*}{$\begin{array}{c}\text { Load } \\
\text { (kips.) }\end{array}$} & \multicolumn{2}{c||}{ Strain on Fabric $(\mu \varepsilon)$} & \multirow{2}{*}{$\begin{array}{c}\text { Bending Stress } \\
(\mathrm{psi})\end{array}$} \\
\hline 0 & Wrap & Wrap + Aging & 0 \\
\hline 0.25 & 0 & 0 & 277.02 \\
\hline 0.50 & 207 & 153 & 554.04 \\
\hline 0.75 & 459 & 309 & 831.07 \\
\hline 1.00 & 709 & 416 & 1108.09 \\
\hline 1.25 & 960 & 574 & 1385.11 \\
\hline 1.50 & 1217 & 761 & 1662.13 \\
\hline 1.75 & 1475 & 950 & 1939.15 \\
\hline 2.00 & 1713 & 1119 & 2216.17 \\
\hline 2.25 & 1967 & 1329 & 2493.20 \\
\hline 2.50 & 2223 & 1510 & 2770.22 \\
\hline 2.75 & 2475 & 1699 & 3047.24 \\
\hline 3.00 & 2731 & 1911 & 3324.26 \\
\hline 3.25 & 2981 & 2111 & 3601.28 \\
\hline 3.50 & 3230 & 2313 & 3878.30 \\
\hline 3.75 & 3481 & 2527 & 4155.33 \\
\hline 4.00 & 3771 & 2749 & 4432.35 \\
\hline 4.25 & 4036 & 2974 & 4709.37 \\
\hline 4.50 & 4293 & 3209 & 4986.39 \\
\hline 4.75 & 4572 & 3461 & 5263.41 \\
\hline 5.00 & 4790 & 3713 & 5540.44 \\
\hline
\end{tabular}

Note 1. Strain data are referred to Table C.4.2

2. Bending Stress $=1.108097 \mathrm{P}$ psi $\quad($ Refer to Note Item 3 of Table C.4.10) 
$\underline{\text { Table C.4.18 }}$

Stress and Strain of Wrap and Wrap+Aging Half Scale Specimen \# 3

\begin{tabular}{|c||c|c|r|}
\hline \multirow{2}{*}{\multicolumn{1}{|c||}{$\begin{array}{c}\text { Load } \\
\text { (kips.) }\end{array}$}} & \multicolumn{2}{c|}{ Strain on Fabric $(\mu \varepsilon)$} & \multirow{2}{*}{$\begin{array}{c}\text { Bending Stress } \\
\text { (psi) }\end{array}$} \\
\hline 0 & Wrap & Wrap + Aging & 0 \\
\hline 0.25 & 0 & 0 & 560.00 \\
\hline 0.50 & 160 & 220 & 840.00 \\
\hline 0.75 & 305 & 440 & 1120.00 \\
\hline 1.00 & 460 & 644 & 1400.00 \\
\hline 1.25 & 643 & 825 & 1680.00 \\
\hline 1.50 & 845 & 1012 & 2240.00 \\
\hline 1.75 & 1060 & 1191 & 2520.00 \\
\hline 2.00 & 1250 & 1387 & 2800.00 \\
\hline 2.25 & 1465 & 1577 & 3080.00 \\
\hline 2.50 & 1681 & 1775 & 3360.00 \\
\hline 2.75 & 1881 & 1986 & 3640.00 \\
\hline 3.00 & 2088 & 2171 & 3920.00 \\
\hline 3.25 & 2313 & 2390 & 4200.00 \\
\hline 3.50 & 2510 & 2586 & 4760.00 \\
\hline 3.75 & 2729 & 2818 & 5040.00 \\
\hline 4.00 & 2944 & 3020 & 5320.00 \\
\hline 4.25 & 3151 & 3210 & 5600.00 \\
\hline 4.50 & 3372 & 3421 & \\
\hline 4.75 & 3614 & 3632 & \\
\hline 5.00 & 3868 & 3842 & \\
\hline
\end{tabular}

Note 1. Strain data are referred to Table C.4.3

2. Bending Stress $=1.12 \mathrm{P}$ psi $($ Refer to Note Item of Table C.4.14 $)$ 